$$
\begin{gathered}
\text { UNIVERSIDADE DE SÃO PAULO } \\
\text { ESCOLA DE COMUNICAÇÕES E ARTES } \\
\text { PROGRAMA DE PÓS-GRADUAÇÃO EM CIÊNCIA DA } \\
\text { INFORMAÇÂO }
\end{gathered}
$$

Fabiana Montanari Lapido

\title{
ÁREA DE BIODIVERSIDADE: adversidades na avaliação da produção científica
}




\section{UNIVERSIDADE DE SÃO PAULO \\ ESCOLA DE COMUNICAÇÕES E ARTES \\ PROGRAMA DE PÓS-GRADUAÇÃO EM CIÊNCIA DA \\ INFORMAÇÃO}

Fabiana Montanari Lapido

\section{ÁREA DE BIODIVERSIDADE: adversidades na avaliação da produção científica}

\begin{abstract}
Dissertação apresentada ao Programa de Pós-Graduação em Ciências da Informação, da Escola de Comunicação e Artes da Universidade de São Paulo, como exigência parcial para a obtenção do título de Mestre em Ciência da Informação.
\end{abstract}

Área de concentração: Cultura e Informação

Orientador: Prof. Dr. Rogério Mugnaini

VERSÃO CORRIGIDA

A versão original encontra-se disponível no PPGCl

São Paulo

2013 
Autorizo a reprodução e divulgação total ou parcial deste trabalho, por meio convencional ou eletrônico, para fins de estudo e pesquisa, desde que citada a fonte.

Lapido, Fabiana Montanari

Área de Biodiversidade: adversidades na avaliação da produção científica / Fabiana Montanari Lapido; orientação Prof. Dr. Rogério Mugnaini. São Paulo: s.n, 2013.

145 f.;il.

Dissertação (Mestrado) - Escola de Comunicações e Artes / Universidade de São Paulo.

1. Ciência da Informação 2. Periódicos científicos 3. Biodiversidade I. Título. II Mugnaini, Rogério, orient. 
LAPIDO, Fabiana Montanari

Área de Biodiversidade: adversidades na avaliação da produção científica

Dissertação apresentada ao Curso de Pós-Graduação em Ciência da Informação, da Escola de

Comunicações e Artes da

Universidade de São Paulo, como exigência parcial para a obtenção do título de Mestre em Ciência da Informação.

Aprovado em:

\section{Banca Examinadora}

Prof. Dr.:

Instituição:

Prof. Dr.:

Instituição:

Prof. Dr.:

Instituição:
Julgamento:

Assinatura:

Julgamento:

Assinatura:

Julgamento:

Assinatura: 


\section{DEDICATÓRIA}

Aos meus queridos e amados Milton, Beatrice, Theo e

Amanda, meus pais Loyr e Cida 


\section{AGRADECIMENTOS}

Ao meu orientador, Prof. Dr. Rogério Mugnaini, pelo apoio nos momentos de dificuldade e, sobretudo, pelas palavras de estímulo.

Ao Abel Packer, Rogério Meneghini e aos membros do Comitê Consultivo SciELO, por compartilharem comigo conhecimento e experiência que me levaram a encontrar, na comunicação científica, um espaço para realizações e projetos futuros.

À Dione Seripierre e Viviane Neves, do Museu de Zoologia da USP, pela participação na classificação dos títulos.

As minhas colegas do SciELO, Solange Santos, Adriana Luccisano e Denise Peres, pelo incentivo.

Em especial, aos meus queridos familiares pelo amor, carinho e compreensão diante da minha ausência e cansaço e pelo incentivo constante que me dedicaram: meu marido Milton, minha filha Beatrice, meus enteados Theo e Amanda e meus pais Loyr e Cida.

Agradeço a todos que me apoiaram, possibilitando que eu chegasse até o final. 


\section{RESUMO}

LAPIDO, Fabiana Montanari. Área de Biodiversidade: adversidades na avaliação da produção científica. 2013. 145 f. Dissertação (Mestrado em Ciência da Informação) - Escola de Comunicação e Artes, Universidade de São Paulo, São Paulo, 2013.

Conhecer as especificidades da comunicação científica em biodiversidade, por meio da avaliação dos periódicos que veiculam resultados de pesquisa na área. O estudo partiu dos periódicos científicos, nacionais e estrangeiros, classificados pelo Programa Qualis da Área de Biodiversidade, referente ao ano 2012, pertencentes às áreas de botânica, oceanografia, zoologia e ecologia. Para a avaliação dos periódicos, definiu-se um plano metodológico composto por duas etapas. A primeira incluiu a análise dos periódicos a partir dos indicadores bibliométricos, realizada a partir da porcentagem captada pela janela de citações de dois anos do Fator de Impacto e do próprio Fator de Impacto no período de 2007 a 2011, utilizando quartis para identificação dos periódicos de maior e menor posição no ranking da área, segundo cada um destes indicadores. A segunda etapa teve como objetivo realizar a análise dos aspectos formais dos periódicos, e considerou: tempo de existência ou duração, pontualidade, periodicidade, quantidade de artigos publicados por ano, porcentagem de artigos de pesquisa, datas de recebimento e aprovação, revisão por pares e idiomas de publicação. Dentre os principais resultados obtidos a partir da análise dos indicadores biblométricos, estão: os periódicos classificados pelo Qualis Biodiversidade apresentam uma baixa média, tanto da porcentagem da janela de citação, como do próprio Fator de Impacto; e $75 \%$ dos periódicos BOZE possuem índices abaixo de $20 \%$ para a janela de citação de dois anos. A análise dos aspetos formais não revelou diferenças significativas entre os periódicos, porém revelou a necessidade de uma revisão da qualidade dos periódicos classificados nos estratos B3 e B4. Constatou-se que as áreas BOZE apresentam diferenças significativas quanto à dinâmica de citações da produção científica, com destaque para as áreas de ecologia (maior obsolescência da literatura) e zoologia (menor obsolescência da literatura) que demonstraram desempenhos extremos.

Palavras-chave: Periódicos científicos; Periódicos de botânica, oceanografia, zoologia e ecologia; Indicadores bibliométricos; Comunicação científica; QUALIS 


\begin{abstract}
LAPIDO, Fabiana Montanari. Biodiversity Area: Difficulties in the evaluation of scientific production. 2013. $145 \mathrm{f}$. Dissertation (Masters in Information Science) - School of Communication and Arts, University of São Paulo, São Paulo, 2013.

Knowing the specifics of scientific communication in biodiversity, through the evaluation of journals that present research results in the area. The study was based on scientific journals, domestic and foreign, sorted by the 2012 Qualis Program for Biodiversity pertaining to the areas of botany, oceanography, zoology and ecology. A two steps method for the evaluation of journals was defined. The first included the analysis of the journals from the bibliometric indicators, carried out based on the citation percentage by quartile in a two year window of citations measuring the variation in impact factors over the years. The second aims to perform the analysis of the formal aspects of the journals, in particular: time of existence or duration, punctuality, frequency, number of articles published per year, percentage of research articles, dates of receipt and approval, review by peers and number of languages it is published in. Among the results of the study, it was found that the areas BOZE significant differences in the dynamics of scientific citations, highlighting the areas of ecology (greater obsolescence of literature) and zoology (lower obsolescence of literature) who demonstrated extreme performances.
\end{abstract}

Key-Words: Scientific journals; Scientific journals in of botany, oceanography, zoology and ecology; Bibliometric indicators; Scientific communication; QUALIS 


\section{LISTA DE FIGURAS}

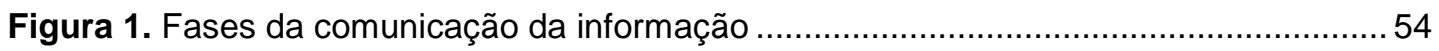

Figura 2. Paradigmas da evolução da comunicação científica: oral, escrita e on-line ..........55

Figura 3. Evolução do fluxo de comunicação científica: fluxo tradicional e eletrônico ..........56

Figura 4. Procedimentos Metodológicos ……............................................................. 97

Figura 5. Filtros aplicados para a seleção dos periódicos participantes do estudo............. 104

Figura 6. Exemplo ilustrativo da distribuição das citações recebidas no JCR em 2008, pelo

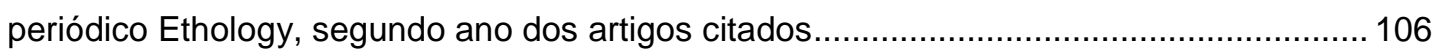




\section{LISTA DE GRÁFICOS}

Gráfico 1. Distribuição dos artigos por idioma de publicação e áreas do conhecimento ..... 77

Gráfico 2. Distribuição do número de periódicos por estrato Qualis ................................. 100

Gráfico 3. Distribuição de periódicos pelas áreas BOZE e estratos Qualis......................... 115

Gráfico 4. Distribuição dos títulos BOZE segundo valores mínimo, médio e máximo da porcentagem da janela de citação e ano do Journal Citation Reports

Gráfico 5. Distribuição dos títulos BOZE segundo valores mínimo, médio e máximo do Fator de Impacto e ano do Journal Citation Reports 118

Gráfico 6. Distribuição dos títulos BOZE segundo quartil 1 , mediana e quartil 3 da porcentagem da janela de citação e ano do Journal Citation Reports 119

Gráfico 7. Distribuição dos títulos BOZE segundo quartil 1, mediana e quartil 3 do Fator de Impacto e ano do Journal Citation Reports.

Gráfico 8. Distribuição percentual dos periódicos das áreas BOZE, anualmente, nos diferentes quartis da porcentagem da janela de citação entre o conjunto de periódicos do Grupo1 121

Gráfico 9. Distribuição percentual dos periódicos das áreas BOZE, anualmente, nos diferentes quartis do Fator de Impacto entre o conjunto de periódicos do Grupo1.....

Gráfico 10. Distribuição dos periódicos de ecologia quanto ao Fator de Impacto versus a porcentagem da janela de citações, ano 2012 124

Gráfico 11. Distribuição dos periódicos de botânica quanto ao Fator de Impacto versus a porcentagem da janela de citações, ano

Gráfico 12. Distribuição dos periódicos de oceanografia quanto ao Fator de Impacto versus a porcentagem da janela de citações, ano 2012

Gráfico 13. Distribuição dos periódicos de zoologia quanto ao Fator de Impacto versus a porcentagem da janela de citações, ano 2012

Gráfico 14. Distribuição do número de periódicos BOZE dos subgrupos 1, que reúnem os periódicos de maior Fator de Impacto e maior porcentagem de citações captadas pela janela de 2 anos, anos 2007-2011

Gráfico 15. Distribuição do número de periódicos BOZE dos subgrupos 4, que reúnem os periódicos de menor Fator de Impacto e menor porcentagem de citações captadas pela janela de 2 anos, anos 2007-2011

Gráfico 16. Distribuição dos periódicos por tempo de existência ..................................... 129

Gráfico 17. Distribuição dos periódicos por periodicidade............................................. 132 


\section{LISTA DE QUADROS}

Quadro 1. Principais eventos que marcaram o desenvolvimento da bibliometria ................ 27

Quadro 2. Comparação das aplicações dos distintos métodos quantitativos........................ 32

Quadro 3. Áreas do conhecimento do Qualis Periódicos ................................................... 42

Quadro 4. Composição da área de biodiversidade, conforme GBA ................................... 45

Quadro 5. Evolução dos modelos para a sistematização do fluxo de comunicação científica 59

Quadro 6. Diferenças entre dados, informação e conhecimento....................................... 79

Quadro 7. Diferenças entre canais formais, informais e eletrônicos .................................... 85 


\section{LISTA DE TABELAS}

Tabela 1. 20 países com maior número de periódicos com acesso aberto no mundo 68

Tabela 2. Mediana e mediana absoluta derivada do Índice $\mathrm{H}$ para os membros da Academia Brasileira de Ciências e da National Academy of Sciences of the USA ................................ 74

Tabela 3. Distribuição das citações concedidas pelos periódicos da Coleção ....................... 76

Tabela 4. Distribuição do número de periódicos por Estrato ………................................ 101

Tabela 5. Distribuição dos periódicos de BOZE por Estrato Qualis .................................... 103

Tabela 6. Distribuição dos periódicos classificados no Qualis Biodiversidade por grandes

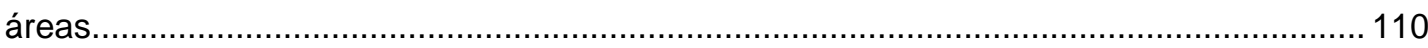

Tabela 7. Distribuição do número de periódicos por país de publicação e estratos Qualis Biodiversidade 112

Tabela 8. Distribuição dos periódicos por estratos Qualis e por bases de indexação .........114

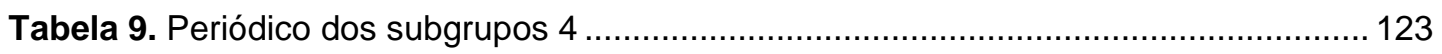

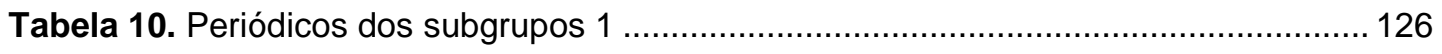

Tabela 11. Distribuição dos periódicos por áreas BOZE e tempo de existência .................. 130

Tabela 12. Média e mediana da quantidade de artigos publicados por ano ....................... 133

Tabela 13. Distribuição dos periódicos por porcentagem de artigos originais ..................... 133

Tabela 14. Distribuição dos periódicos por data de recebimento e aprovação .................... 134

Tabela 15. Distribuição dos periódicos por idioma aceito para publicação........................... 135

Tabela 16. Distribuição dos periódicos por idioma dos artigos ......................................... 136 


\section{LISTA DE ABREVIATURAS E SIGLAS}

BOAI - Budapest Open Access Initiative

BOZ - Botânica, Oceanografia e Zoologia

BOZE - Botânica, Oceanografia, Zoologia e Ecologia

CAPES - Coordenação de Aperfeiçoamento de Pessoal de Nível Superior

CCN - Catálogo Coletivo Nacional de Publicações Seriadas

CNPq - Conselho Nacional de Desenvolvimento Científico e Tecnológico

DOAJ - Directory of Open Access Journal

FAPESP - Fundação de Amparo à Pesquisa do Estado de São Paulo

IBICT - Instituto Brasileiro de Informação em Ciência e Tecnologia

ISI - Institute for Scientific Information

ISSN - International Serial Standard Number

OAI - Open Archives Iniciative

SciELO - Scientific Eletronic Library Online

WoS - Web of Science 


\section{SUMÁRIO}

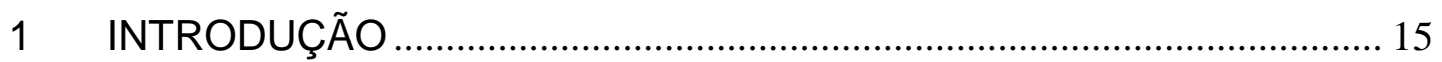

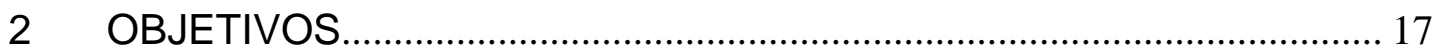

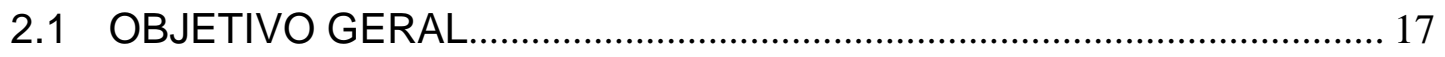

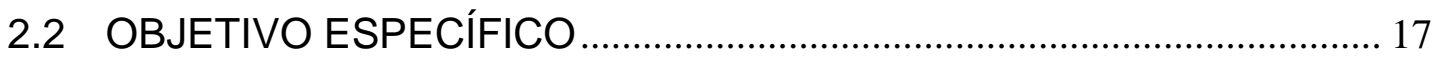

3 POLÍTICA CIENTÍFICA E AVALIAÇÃO DA CIÊNCIA ............................... 18

3.1 FORMAS DE MEDIÇÃO DA INFORMAÇÃO CIENTÍFICA ..................... 24

3.1.1 Principais Indicadores de Avaliação da Ciência ........................................................ 32

3.2 AVALIAÇÃO DOS PERIÓDICOS NACIONAIS PELO PROGRAMA QUALIS 38

3.2.1 Qualis Periódicos e a Avaliação da Área de Biodiversidade 43

4 A CIÊNCIA E A COMUNICAÇÃO DE SEUS RESULTADOS .................. 49

4.1 ACESSO ABERTO AO CONHECIMENTO CIENTÍFICO ............................. 60

4.2 ESPECIALIZAÇÃO DA CIÊNCIA E ESPECIFICIDADE DAS ÁREAS.. 69

4.3 TIPOS DE DOCUMENTOS E A COMUNICAÇÃO CIENTÍFICA ............78

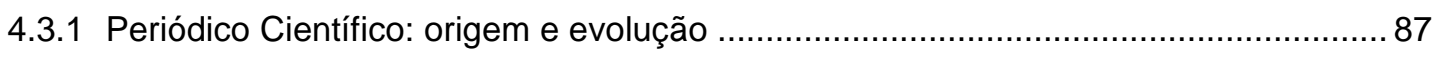

5 PROCEDIMENTOS METODOLÓGICOS ................................................... 94

5.1 CARACTERIZAÇÃO DAS FONTES DE DADOS ………………............ 98

5.2 DEFINIÇÃO DAS POPULAÇÕES ............................................................ 99

5.3 COLETA E TRATAMENTO DE DADOS .................................................... 104

5.3.1 Indicadores Bibliométricos: periódicos dos estratos A1, A2, B1 e B2 (Grupo 1) ....... 104

5.3.2 Aspectos Formais: periódicos dos estratos B3 e B4 (Grupo 2)............................... 106

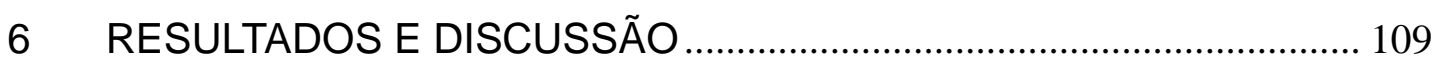

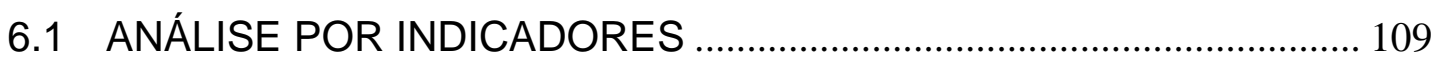

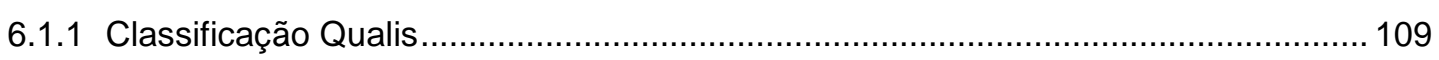

6.1.2 Indicadores Bibliométricos: periódicos dos estratos A1, A2, B1 e B2 (Grupo 1) ....... 116

6.2 ASPECTOS FORMAIS: PERIÓDICOS DOS ESTRATOS B3 E B4

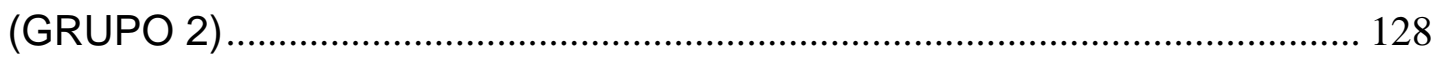

7 CONSIDERAÇÕES FINAIS ............................................................. 137

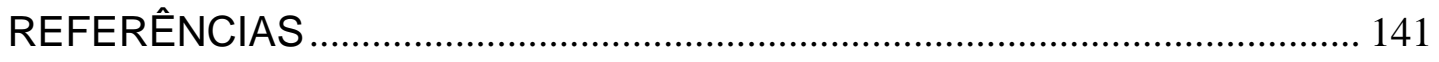




\section{INTRODUÇÃO}

A crise ambiental pela qual passamos levou os analistas a estabelecerem um consenso em torno da noção de que a preservação dos ecossistemas e da sua biodiversidade é de fundamental importância para o desenvolvimento sustentável e igualitário da humanidade. A conscientização ambiental da sociedade foi acompanhada por um aumento significativo da produção de informação científica na área de biodiversidade.

A informação científica é registrada e disseminada a partir de canais de diferentes formatos e suportes que se complementam e atendem às necessidades específicas de cada fase da pesquisa, constituindo, no conjunto, o que podemos chamar de literatura científica.

Os canais de comunicação são utilizados de formas distintas pelas comunidades científicas das várias áreas temáticas, que dão preferência a veículos mais adequados às suas necessidades e às características específicas da dinâmica de produção da informação científica estabelecida pelas diferentes áreas.

Considerado um dos principais canais utilizados para uso e comunicação da informação científica, o periódico constitui-se em objeto de diversos estudos e é, constantemente, submetido a processos que visam à avaliação de seus padrões de qualidade, realizados por distintas instâncias, como agências de fomento, bases de dados e pela própria comunidade científica.

O Qualis Periódicos (CAPES ${ }^{1}$, [19-?]) representa uma destas instâncias e é responsável por realizar, regularmente, a classificação em estratos de qualidade dos periódicos, nacionais e estrangeiros, de diversas áreas do conhecimento. Dentre elas, está a biodiversidade, criada em setembro de 2011, a partir da junção da ecologia e meio ambiente, com as ciências biológicas I (botânica, oceanografia biológica e zoologia).

\footnotetext{
${ }^{1}$ Documento não paginado da web. Disponível em: <http://www.capes.gov.br/avaliacao/qualis>. Acesso em: 19 mar. 2013
} 
As áreas que, atualmente, compõem o Qualis Biodiversidade guardam especificidades impostas por conjunturas históricas e econômicas da sociedade, que Ihes atribuem características distintas quanto aos padrões de produção, compartilhamento, recuperação, uso e preservação da informação científica. 


\section{OBJETIVOS}

\subsection{OBJETIVO GERAL}

- Conhecer as especificidades da comunicação científica em biodiversidade, por meio da avaliação dos periódicos que veiculam resultados de pesquisa na área, com vistas a oferecer subsídios para a adequação da avaliação da produção científica no Programa QUALIS da CAPES.

\subsection{OBJETIVO ESPECÍFICO}

- Avaliar os periódicos científicos, nacionais e estrangeiros, classificados pelo Programa Qualis da Área de Biodiversidade, em específico das áreas de Botânica, Oceanografia, Zoologia e Ecologia, a partir da análise dos indicadores bibliométricos e dos aspectos formais. 


\section{POLÍTICA CIENTíFICA E AVALIAÇÃO DA CIÊNCIA}

A história da constituição e organização da ciência moderna está atrelada às transformações comerciais, industriais e políticas ocorridas na Europa Ocidental entre os séculos XV a XVIII. A ciência concentrou suas descobertas nos campos da astronomia e da navegação nos séculos $X V$ e $X V I I$, enquanto a incorporação da ciência pela grande indústria ocorreu no século XVIII, sendo responsável por incrementar o modo de produção de mercadorias e subordinar o trabalho manual ao intelectual. A partir do século $\mathrm{XIX}$, a produção do conhecimento científico foi confiada a grupos técnicos específicos e ciência, técnica e tecnologia passaram a integrar um mesmo sistema (MOREL, 1979).

Segundo Schwartzman (2001, p. 1), até o século XIX a história da institucionalização da ciência europeia foi caracterizada pela "[...] conquista gradual, pela ciência experimental, de uma posição central na cultura e na cosmovisão do Ocidente". Nos países europeus, até então, a ciência experimental foi desenvolvida fora do ambiente universitário tradicional; somente no século XIX ocorreu a união entre a ciência experimental e a universidade, como conhecemos hoje.

Foi quando surgiram os primeiros laboratórios de pesquisa industrial na Alemanha e o sistema universitário do país passou a formar indivíduos em profissões demandadas pela indústria. Aos alemães seguiram-se os Estados Unidos que, em 1940, contavam com mais de 2.200 laboratórios montados em empresas (MOREL, 1979).

Dessa forma, as sociedades industrializadas assistiram à institucionalização da profissão de "[...] produtor de conhecimentos científicos [...]", que operavam segundo normas e regras estabelecidas pelos próprios pesquisadores de uma área ou campo científico, segundo:

critérios internos de legitimação - exames, temas, técnicas, áreas, publicações, teses - que condicionam um sistema de recompensas, como a eponímia (prática de vincular o nome do cientista ao descobrimento), o Prêmio Nobel, medalhas, títulos acadêmicos, filiação a sociedades, academias, etc., configurandose um sistema altamente competitivo (MOREL, 1979, p. 17). 
As transformações ocorridas no modo de produção do conhecimento científico resultaram em extraordinária expansão do setor de pesquisa, que, a partir do início do século XIX, passou a apresentar um crescimento exponencial no número de publicações, patentes, pesquisadores. Até então trabalhando de forma isolada, esses pesquisadores passaram a desempenhar suas funções em contanto constante com seus pares (MOREL, 1979).

Durante a Segunda Guerra (1939-1945), os estudos sobre a bomba atômica (Projeto Manhattan ${ }^{2}$ ) consolidaram a expansão do setor de pesquisa e incorporaram à produção científica o parcelamento das tarefas e a divisão de trabalho, típicos da indústria. Ele também foi responsável por promover o estabelecimento de "[...] uma nova era nas relações entre cientistas e o Estado" (MOREL, 1979, p. 19).

Para Gibbons e Wittrock (apud SCHWARTZMAN, 2001, p. 24) o Projeto Manhattan promoveu o estabelecimento de uma ciência maior, com aporte amplo de recursos, desenvolvimento de atividades de pesquisas complexas e participação de um grande número de pessoas. Tais custos e complexidade provocaram a diluição das fronteiras que, até então, separavam as ciências da tecnologia. No pós-guerra, ficaram evidentes as vantagens que a aplicação da ciência poderia trazer para as nações. E, então, o desenvolvimento e o controle científicos passaram a ser realizados pelo Estado, por meio de políticas públicas que passaram a incorporar a política científica à política global, nos países industrializados (MOREL, 1979).

No Brasil, a política científica foi institucionalizada em 1950. Porém, para o melhor entendimento desse processo, é necessário descrever, mesmo que de forma breve, os aspectos econômicos e sociais que a condicionaram historicamente.

2 Projeto de pesquisa e desenvolvimento responsável pela produção das primeiras bombas atômicas durante a Segunda Guerra Mundial, liderado por Estados Unidos, com o apoio do Reino Unido e Canadá. Disponível em: <http://projetomanhattan.blogspot.com.br/2007/04/um-breve-resumoda-histria-da-bomba-e.html >. Acesso em: 29 ago. 2013. 
Schwartzman (2001) divide o desenvolvimento da política científica brasileira nas seguintes fases:

- Primeira fase: corresponde aos anos que antecederam a Segunda Guerra Mundial e foi marcada pelas tentativas de criação de novas instituições universitárias.

- Segunda fase: período pós-guerra caracterizado por tentativas de modificar a estrutura universitária tradicional por inteiro; momento em que a pesquisa científica e tecnológica adquire um papel central no planejamento socioeconômico.

- Terceira fase: compreende os anos de 1960 a 1970 e se caracteriza por "[...] tentativas de criar nichos isolados e protegidos para a pesquisa científica, com apoio em uma crença renovada no valor de redenção da moderna ciência e tecnologia" (p. 22).

- Quarta fase: iniciada em 1990, apresenta como características a "[...] crescente sensibilidade às particularidades do trabalho científico e às suas complexas interações com a educação superior, a tecnologia e as profissões" (p. 22).

Por sua vez, Morel (1979) assinala três fases de desenvolvimento da política científica brasileira, resumidas a seguir.

\section{Primeira Fase - Do Brasil Colonial a 1950: ausência de uma política científica nacional}

Fase que vai do período colonial - em que qualquer tentativa de desenvolvimento científico era inibida pelo governo português - até 1950, caracterizada pela ausência de uma política científica. Até a Primeira República $^{3}$, as atividades científicas dependiam de homens isolados e o

\footnotetext{
3 Também chamada de República Velha, compreende o período da história brasileira entre a proclamação da República, em 15 de novembro de 1889, até a Revolução de 1930, que depôs o presidente Washington Luís. Disponível em: <http://historiandonanet07.wordpress.com/2011/01/31/primeira-republica/>. Acesso em: 23 ago. 2013.
} 
sistema educacional e científico do país refletia os interesses do setor agrário exportador.

A partir de 1930, com a industrialização, expandiram-se as instituições de ensino superior, que assumiram então a função de formar recursos humanos para o novo sistema produtivo. Nesse contexto foram criados os institutos de pesquisa tecnológica. As mudanças no sistema produtivo nacional, vinculadas às promessas de aplicação prática da ciência evidenciada pela Segunda Guerra, impulsionaram o desenvolvimento científico-tecnológico nacional.

Além da criação de instituições de ensino superior - Universidade do Rio de Janeiro, Universidade de Minas Gerais, Universidade de São Paulo e institutos de pesquisa, esse período foi marcado pela criação de instituições ligadas ao desenvolvimento científico nacional, como o Centro Brasileiro de Pesquisas Físicas (CBPF), a Sociedade Brasileira para o Progresso da Ciência (SBPC) e a Fundação de Amparo à Pesquisa do Estado de São Paulo (FAPESP).

\section{Segunda Fase - De 1950 a 1967: a institucionalização da política científica nacional}

Em um período marcado pela consolidação do capitalismo industrial no Brasil, a política científica foi institucionalizada por meio da criação do Conselho Nacional de Pesquisa (CNPq) e da Comissão de Aperfeiçoamento de Pessoal de Ensino Superior (CAPES) em 1951.

Também foram criados a Comissão Supervisora do Plano dos Institutos (COSUPI), o Programa de Expansão do Ensino Tecnológico (PROTEC), a Universidade de Brasília e o Fundo de Desenvolvimento Técnico-Científico (FUNTEC). Na mesma época, a FAPESP iniciou suas atividades.

A política científica do período esteve voltada para a formação de recursos humanos qualificados. Porém, devido à expansão das empresas 
estrangeiras no Brasil, o sistema científico permaneceu desvinculado do setor produtivo.

\section{Terceira Fase - Política científica recente: a ciência e o Estado}

Após 1967, intensificaram-se as iniciativas de política científica, que passou a compor o planejamento global do Estado. Incorporada ao discurso governamental, a política científica nacional visava duas metas: a primeira, promover o aprimoramento tecnológico no país, possibilitando dessa forma 0 desenvolvimento econômico; a segunda, promover a projeção internacional do Brasil como grande potência.

A política científica estava voltada para um conjunto de medidas financeiras e institucionais "[...] segundo a qual o desempenho das instituições depende tão somente de sua organização interna, da qualidade do pessoal e da adequação entre meios e fins" (MOREL, 1979, p. 56). Na década de 1960, ocorreu a intensificação das iniciativas de política científica, em decorrência de um Estado fortalecido. Nesse período, informa o autor, importantes medidas do governo Costa e Silva foram implantadas visando tornar mais eficiente o sistema científico: "[...] a Reforma Universitária, o Tempo Integral, o Fundo Nacional de Desenvolvimento Científico e Tecnológico" (p. 56).

Segundo Morel (apud MUGNAINI, 2013, no prelo):

é na década de 1970 que os esforços direcionados a conceber um sistema de ciência e tecnologia começam a gerar frutos efetivamente, como a infraestrutura educacional e principalmente a pós-graduação; a criação de planos e concepção de um sistema de desenvolvimento científico e tecnológico.

A partir da década de 1970, uma série de medidas foi adotada e criados diversos planos e programas visando o desenvolvimento científico e tecnológico no país. Entre os quais o Plano Nacional de Desenvolvimento (PND), o Plano Básico de Desenvolvimento Científico e Tecnológico (PBDCT), o Plano Nacional de Pós-graduação (PNPG) e Programa de Apoio ao Desenvolvimento Científico e Tecnológico (PADCT). Pela primeira vez, 
também, falou-se em um sistema de informações em ciência e tecnologia (C\&T).

Dentre os planos e programas desenvolvidos pelo governo federal, destaca-se o Programa de Apoio ao Desenvolvimento Científico e Tecnológico (PADCT), criado em 1984, como um instrumento complementar à política de fomento à $\mathrm{C} \& \mathrm{~T}$, com o objetivo específico de:

ampliar, melhorar e consolidar a competência técnico-científica nacional no âmbito de universidades, centros de pesquisa e empresas, através do financiamento de projetos de pesquisa integrados que produzam impactos no desenvolvimento científico e tecnológico do País (CNPq apud MUGNAINI, 2003, p. 35).

O PADCT resultou de acordos de empréstimo entre o governo brasileiro e o Banco Mundial, tendo sido aplicado em três fases distintas, que perduraram até 2004 (MUGNAINI, 2003; CNPq, [19-?]):

a) PADCT I - 9 de julho de 1985: concebido para fortalecer a pesquisa \& desenvolvimento $(P \& D)$ no país e para prover a melhoria na capacidade de decisão do governo.

b) PADCT II - 5 de fevereiro de 1991: incluiu questões levantadas no contexto das reformas iniciadas em 1990, em particular à política industrial e de comércio exterior e à política de informática, dentre elas as questões relacionadas à inovação tecnológica.

c) PADCT III - 17 de março de 1998 e prorrogado até 31 de julho de 2004: com atuação em nível nacional e internacional, essa fase do programa esteve voltada à captação de recursos internacionais para aplicação em suporte às atividades de C\&T, incluindo a revisão dos indicadores nacionais, possibilitando a comparação do Brasil com outros países, bem como a caracterização do desenvolvimento da infraestrutura de ciência e tecnologia.

Esforços para o desenvolvimento de indicadores nacionais de ciência e tecnologia foram realizados nas últimas décadas, resultando na disponibilização de um conjunto de dados a partir da Plataforma Lattes e dos 
indicadores de pesquisa do CNPq; Programa Qualis da CAPES e SciELO da FAPESP. Tais fontes compõem o conjunto de indicadores nacionais, com publicação regular, que contribuem para a geração de dados bibliométricos, com maior consistência e confiabilidade, para utilização no desenvolvimento de políticas em C\&T.

\subsection{FORMAS DE MEDIÇÃO DA INFORMAÇÃO CIENTÍFICA}

A avaliação da produção científica de países, instituições, grupos de pesquisa ou pesquisadores individuais é realizada a partir da utilização de técnicas específicas, com aplicação de métodos quantitativos, qualitativos ou, ainda, quali-quantitativos. As técnicas quantitativas utilizadas na avaliação da produtividade científica são desenvolvidas no contexto da bibliometria, cienciometria, informetria e webometria, disciplinas semelhantes que trabalham diferentes enfoques para a medição da difusão do conhecimento e do fluxo de informação científica (VANTI, 2002).

$O$ surgimento das bases de dados computadorizadas incrementou a realização de estudos de medição da produtividade de países, instituições, grupos de pesquisa ou pesquisadores individuais, promovendo o desenvolvimento do campo da bibliometria, bem como o surgimento da cienciometria, informetria e webometria. Os resultados desses estudos subsidiam a definição de políticas em ciência e tecnologia e a tomada de decisão quanto à alocação de recursos advindos de órgãos governamentais e de instituições de fomento à pesquisa.

A bibliometria tem sua origem no início do século $X X$, a partir da aplicação de métodos matemáticos e estatísticos para a realização de análises da produção científica. Seu objetivo é subsidiar as ações de bibliotecas e centros de informação quanto ao desenvolvimento de coleções e controle bibliográfico, além de outros serviços de informação. Desde então foram propostas leis bibliométricas, teorias e princípios que norteiam 0 desenvolvimento do campo e se proliferam os estudos que visam sua 
aplicação na avaliação de diferentes áreas científicas (BECERRA; FLEITAS, 2002; MUGNAINI, 2013).

O termo bibliometria foi cunhado por Paul Otlet, em 1934, tendo se popularizado com Alan Pritchard, em 1969, a partir de seu estudo denominado "Statistical bibliography or bibliometrics?", que a definiu como a disciplina que tem por objetivo a aplicação de métodos matemáticos e estatísticos a livros e outros documentos. Outros dois termos utilizados para denominar a disciplina e que antecederam ao termo bibliometria foram, respectivamente, statistical bibliography, empregado por Edward Wyndham Hulme, em 1923, no livro "Statistical bibliography in relation to the growth of modern civilization"; e librametry, em 1948, utilizado por Siyali Ramamrita Ranganathan em conferência da The Association for Information Management (ASLIB) (BECERRA; FLEITAS, 2002; MUGNAINI, 2013).

Porém, há controversas quanto à origem da bibliometria e das métricas de avaliação. Urbizagástegui Alvarado (2007) afirma que tais técnicas estavam em uso muito antes de 1969, nas diferentes áreas científicas, a citar: biologia (biometria), ciências sociais (sociometria), antropologia (antropometria), psicologia (psicometria), economia (econometria). Corroborando essa ideia, Shapiro (1992) destaca que no campo jurídico a contagem de publicações já existia em 1817 e que em 1894 e 1895 já havia duas análises de citações de decisões jurídicas.

Segundo Tague-Sutckiffe (apud VANTI, 2002), a bibliometria pode ser definida como o estudo da produção, disseminação e uso da informação registrada em diversos canais de comunicação, a partir de indicadores quantitativos. A bibliometria é encarregada de definir padrões e modelos matemáticos para medir esses processos, produzindo resultados que subsidiem a tomada de decisão em políticas científicas. Para Guedes e Borschiver (2005, p. 2), a bibliometria constitui-se um "[...] conjunto de leis e princípios empíricos que contribuem para estabelecer os fundamentos teóricos da Ciência da Informação".

De acordo com Araújo (2006, p. 12), originalmente a bibliometria estava voltada para o estudo de livros - "[...] quantidade de edições e 
exemplares, quantidade de palavras contidas nos livros, espaço ocupado pelos livros nas bibliotecas, estatísticas relativas à indústria do livro". Com o passar dos anos, começou a ser aplicada aos estudos de outros veículos, como os periódicos científicos, para, posteriormente, ocupar-se também das citações e da produtividade de autores.

Mugnaini (2013) reuniu os principais eventos que marcaram o desenvolvimento da bibliometria no mundo, que vão desde a realização dos primeiros exercícios quantitativos para a análise da produção científica, realizados por Francis J. Coli e Nellie B. Eakes, em 1917, até as últimas décadas, caracterizadas pela intensa aplicação dos indicadores bibliométricos na avaliação das diferentes áreas científicas e pelo desenvolvimento de um conjunto de indicadores nacionais, conforme resumo apresentado no Quadro 1. 
Quadro 1. Principais eventos que marcaram o desenvolvimento da bibliometria

\begin{tabular}{|c|c|}
\hline Ano & Eventos \\
\hline 1917 & $\begin{array}{l}\text { Francis J. Cole e Nellie B. realizaram um dos primeiros exercícios quantitativos para análise da produção } \\
\text { científica, visando mensurar o crescimento da literatura em determinada área temática utilizando } \\
\text { "estatística bibliográfica". }\end{array}$ \\
\hline 1927 & $\begin{array}{l}\text { Alfred } J \text {. Lotka propôs uma das primeiras leis matemáticas para análise da produtividade científica de } \\
\text { autores, defendendo que as frentes de pesquisa são compostas por poucos autores muito produtivos, cujo } \\
\text { número é inversamente proporcional ao número de autores com apenas uma publicação. }\end{array}$ \\
\hline 1928 & $\begin{array}{l}\text { P. L. K. Gross e E. M. Gross realizaram estudo inovador que avaliou as citações a periódicos de química, } \\
\text { a partir do uso das referências bibliográficas, no intuito de selecionar os mais relevantes para uma pequena } \\
\text { biblioteca de determinada área. }\end{array}$ \\
\hline 1934 & $\begin{array}{l}\text { Samuel C. Bradford propôs uma lei (Lei de Bradford) de dispersão das publicações de artigos em } \\
\text { periódicos, o que possibilitou identificar os mais relevantes em uma determinada área. A Lei de Bradford } \\
\text { possui vasta aplicação, considerando os diversos estudos de periódicos e a importância deles para a } \\
\text { comunicação científica. }\end{array}$ \\
\hline 1949 & $\begin{array}{l}\text { George K. Zipf formulou uma lei (Lei de George K. Zipf), com ampla aplicação na área de linguística, que } \\
\text { considerava o ranking de frequências das palavras ocorridas em um documento. }\end{array}$ \\
\hline 1955 & $\begin{array}{l}\text { Eugene Garfield publicou artigo sobre um índice de citação com motivação inicial de facilitar o acesso à } \\
\text { bibliografia citada nos documentos. Nesse mesmo artigo, mencionou a ideia de um fator de impacto de } \\
\text { periódicos. }\end{array}$ \\
\hline 1963 & $\begin{array}{l}\text { Criado o Science Citation Index (SCl) por Eugene Garfield, fundador do Institute for Scientific Information } \\
\text { (ISI) - atual Thomson Scientific da Thomson Reuters. }\end{array}$ \\
\hline 1969 & $\begin{array}{l}\text { Derek J. de Solla Price deu origem à especialidade da cienciometria com a realização de estudos } \\
\text { quantitativos de diversos aspectos da ciência, considerando o sistema de pesquisa como um todo e não } \\
\text { apenas a análise de produção científica. }\end{array}$ \\
\hline 1975 & $\begin{array}{l}\text { Tem início a segunda geração de estudos de análise da produção científica, com a utilização das bases de } \\
\text { dados, conceitos e métodos desenvolvidos pela primeira geração, provendo a produção de informações } \\
\text { úteis à política científica. O Journal Citation Reports (JCR) começa a ser publicado exatamente nesse } \\
\text { ano, constituindo-se o "divisor de águas" entre as duas fases. }\end{array}$ \\
\hline 1980 & $\begin{array}{l}\text { A bibliometria passou a ocupar novas posições, possibilitando o mapeamento da literatura, a aplicação } \\
\text { crescente no aprimoramento das técnicas de recuperação da informação e, com maior destaque, sua } \\
\text { contribuição, em nível internacional, confirmando a relevância de indicadores bibliométricos em política } \\
\text { científica. }\end{array}$ \\
\hline $\begin{array}{l}\text { Últimas } \\
\text { décadas }\end{array}$ & $\begin{array}{l}\text { Aplicações mais recentes, que datam das últimas duas décadas, têm dinamizado a compreensão de } \\
\text { aspectos dinâmicos da comunicação científica, identificados a partir da análise da literatura, revelando: } \\
\text { áreas de excelência, associações temáticas, interdisciplinaridade, disciplinas emergentes e redes de } \\
\text { colaboração temática. Destaca-se também a incorporação a conjuntos de indicadores nacionais } \\
\text { publicados periodicamente, garantindo a continuidade na geração de dados bibliométricos e, } \\
\text { consequentemente, maior confiabilidade para o uso dessas fontes de informação para definição de } \\
\text { políticas. }\end{array}$ \\
\hline
\end{tabular}

Fonte: elaborado a partir de MUGNAINI, 2013, no prelo

Araújo (2006) observa que o crescimento da bibliometria na agenda de pesquisa está relacionado com o surgimento da cienciometria, informetria e webometria. São brevemente apresentados a seguir, em ordem cronológica, os conceitos que definem esses termos, bem como alguns aspectos ligados às suas respectivas origens. 
A cientometria ou cienciometria teve origem na extinta União Soviética e na Europa Oriental, sendo o termo empregado especialmente na Hungria. Entre os primeiros autores da cientometria destacam-se: Derek John de Solla Price, em 1963, com a publicação de Calculus in science - a obra analisa a ciência a partir de indicadores quantitativos, tendo como objeto de estudo o vínculo científico, o crescimento da informação, sua estrutura e fluxo (BECERRA; FLEITAS, 2002); e Dobrov e Karennoi, em uma publicação do All-Union Institut for Scientific and Technical Information (VINITI), de 1969, sobre a aplicação de métodos quantitativos para o estudo da história da ciência e do progresso tecnológico. Porém, o termo cientometria se popularizou com a publicação do periódico húngaro Scientometrics, fundado em 1978 por Tibor Braun (VANTI, 2002; ARAÚJO, 2006).

A cientometria foi definida por Nalimov e Mulcsenko, em 1969, na obra denominada de Naokometrija. Izucente rezvitja naukikak informacionogo processa - ( $A$ aplicação de métodos quantitativos à pesquisa sobre o desenvolvimento da ciência como um processo informativo) [tradução nossa] (BECERRA; FLEITAS, 2002, p. 4). O termo recebeu outra definição de Haitun, em 1983, complementada posteriormente por Morales-Morejón, ficando como segue: cientometria é a disciplina que se encarrega da medição e avaliação do efeito da ciência sobre a sociedade (BECERRA; FLEITAS, 2002).

Para Tague-Sutckiffe (apud VANTI, 2002, p. 155) a cienciometria: estuda, por meio de indicadores quantitativos, uma determinada
disciplina da ciência. Estes indicadores quantitativos são utilizados
dentro de uma área do conhecimento, por exemplo, mediante a
análise de publicações, com aplicação no desenvolvimento de
políticas científicas. Tenta medir os incrementos de produção e
produtividade de uma disciplina, de um grupo de pesquisadores de
uma área, a fim de delinear o crescimento de determinado ramo
do conhecimento.

Van Raan (apud VANTI, 2002, p. 155) define a cienciometria como a disciplina dedicada aos "[...] estudos quantitativos em ciência e tecnologia e a descobrir os laços existentes entre ambas, visando ao avanço do 
conhecimento e buscando relacionar este com questões sociais e de políticas públicas". O autor ainda destaca o caráter multidisciplinar da cienciometria, devido à procedência dos métodos utilizados para a avaliação da ciência e da tecnologia, advindos das ciências naturais, sociais e comportamentais (estatística e outros métodos matemáticos, modelos sociológicos, pesquisas e métodos psicológicos de entrevista, informática, filosofia da ciência, linguística etc.).

Segundo Macias-Chapula (1998, p. 134), a cienciometria consiste no estudo da ciência enquanto disciplina ou atividade econômica, cujos resultados são aplicados no desenvolvimento de políticas científicas. Constitui-se em um segmento da sociologia da ciência e abarca "[...] estudos quantitativos das atividades científicas, incluindo a publicação e, portanto, sobrepondo-se à bibliometria".

Por sua vez, o termo informetria foi introduzido, em 1979, pelo professor alemão Otto Nacke, diretor do Institut für Informetrie, em Bielferd, Alemanha, com o trabalho intitulado Informetría: un nuevo nombre para una nueva disciplina: definición, estado de la ciencia y principios de desarrollo, que resultou da utilização de métodos e modelos matemáticos para solucionar problemas relacionados à informação. A aceitação definitiva do termo ocorreu em 1989, quando o Encontro Internacional de Bibliometria passou a ser chamado de Conferência Internacional de Bibliometria, Cienciometria e Informetria (VANTI, 2002; ARAÚJO, 2006; BECERRA; FLEITAS, 2002).

Tague-Sutckiffe (apud MACIAS-CHAPULA, 1998, p. 134) define a informetria como:

o estudo dos aspectos quantitativos da informação em qualquer formato, e não apenas registros catalográficos ou bibliografias, referente a qualquer grupo social, e não apenas aos cientistas. A informetria pode incorporar, utilizar e ampliar os muitos estudos de avaliação da informação que estão fora dos limites da bibliometria e cienciometria.

Dentre os aspectos que diferenciam claramente a informetria da bibliometria e cienciometria, Vanti (2002) destaca que a informetria não se 
limita apenas ao estudo da informação registrada, incluindo também o processo de comunicação informal e pesquisas sobre uso e necessidade de informação de elites intelectuais, bem como de grupos sociais desfavorecidos.

Para Vanti (2002) os estudos de medição da informação científica desenvolvidos a partir da aplicação de técnicas bibliométricas, cienciométricas e informétricas são responsáveis por fornecer respostas a questões específicas do fluxo de informação, nas várias áreas temáticas, possibilitando: a) identificar as tendências e o crescimento do conhecimento em determinada área científica; b) identificar os periódicos que constituem o núcleo forte de uma disciplina; c) medir a abrangência dos periódicos secundários; d) identificar os usuários de uma área temática ou disciplina; e) prever tendência na publicação de informação científica; f) medir a dispersão e a obsolescência da literatura científica; g) medir a produtividade de autores individuais, grupos de pesquisa, instituições e países; h) analisar o grau e padrões de colaboração entre autores; i) medir as citações e cocitações; j) analisar o desempenho dos sistemas de recuperação da informação científica; k) analisar a linguagem, as palavras e as frases de forma estatística; e I) avaliar a circulação e o uso da literatura científica em bibliotecas e unidades de informação.

Mais recente, a webometria consiste na aplicação de métodos informétricos para avaliar o fluxo de informação na world wide web (www). A autoria do termo webometria (webometrics) é atribuída a Almind e Ingwersen. Surgiu na década de $1990 \mathrm{com}$ a popularização da internet, recebendo também outros termos menos populares, porém semelhantes, como web mining, cyber geography e web intelligence. Na literatura da área é encontrado, ainda, o termo cybermetrics, que trata da avaliação da web sem o enfoque da avaliação científica, correspondendo ao nome de um periódico apresentado durante a VI Conferência Internacional de Cienciometria e Informetria, em Jerusalém, em 1997 (VANTI, 2002; BETTONI, 2011). 
Bjorneborn (apud BETTONI, 2011, p. 48) define a webometria como o estudo da elaboração e uso dos recursos de informação, estruturas e tecnologias na web, a partir de quatro áreas principais: "[...] análise do conteúdo de uma página; (b) analise da estrutura de ligações (links); (c) análise de uso (por meio de logs); e (d) análise da tecnologia empregada (performance)".

Diversos autores se ocupam de distinguir as disciplinas de bibliometria, cienciometria, informetria e webometria. Conforme destacado por Araújo (2006), McGrath, em 1989, propôs a caracterização consistente das disciplinas, considerando seus respectivos objetos de estudo, variáveis, métodos específicos e objetivos. O Quadro 2 apresenta dados de comparação das aplicações da bibliometria, cienciometria, informetria e webometria, com base na caracterização proposta por McGrath e adaptada por Vanti (2002). 
Quadro 2. Comparação das aplicações dos distintos métodos quantitativos

\begin{tabular}{|c|c|c|c|c|}
\hline Subcampo & Bibliometria & Cienciometria & Informetria & Webometria \\
\hline $\begin{array}{l}\text { Objeto de } \\
\text { estudo }\end{array}$ & $\begin{array}{l}\text { Livros, documentos, } \\
\text { revistas, artigos, } \\
\text { autores, usuários }\end{array}$ & $\begin{array}{l}\text { Disciplinas, assuntos, } \\
\text { áreas e campos } \\
\text { científicos e } \\
\text { tecnológicos; patentes, } \\
\text { dissertação e teses }\end{array}$ & $\begin{array}{l}\text { Palavras, documentos, } \\
\text { bases de dados, } \\
\text { comunicações } \\
\text { informais (inclusive em } \\
\text { âmbitos não } \\
\text { científicos), home } \\
\text { pages na WWW }\end{array}$ & $\begin{array}{l}\text { Sítios WWW (URL, } \\
\text { título, tipo, domínio, } \\
\text { tamanho e links), } \\
\text { motores de busca }\end{array}$ \\
\hline Variáveis & $\begin{array}{l}\text { Número de } \\
\text { empréstimos } \\
\text { (circulação) e de } \\
\text { citações, frequência de } \\
\text { extensão de frases }\end{array}$ & $\begin{array}{l}\text { Fatores que diferenciam } \\
\text { as subdisciplinas; } \\
\text { como os cientistas se } \\
\text { comunicam }\end{array}$ & $\begin{array}{l}\text { Difere da cienciometria } \\
\text { no propósito das } \\
\text { variáveis: por exemplo, } \\
\text { medir a recuperação, a } \\
\text { relevância, a revocação }\end{array}$ & $\begin{array}{l}\text { Número de páginas por } \\
\text { sítio, número de links } \\
\text { por sítio, número de } \\
\text { links que remetem a } \\
\text { um mesmo sítio, } \\
\text { número de sítios } \\
\text { recuperados }\end{array}$ \\
\hline Métodos & $\begin{array}{l}\text { Ranking, frequência, } \\
\text { distribuição }\end{array}$ & $\begin{array}{l}\text { Análise de conjunto e } \\
\text { de correspondência, } \\
\text { coocorrência de } \\
\text { termos, expressões, } \\
\text { palavras-chave etc. }\end{array}$ & $\begin{array}{l}\text { Modelo vetor-espaço, } \\
\text { modelos booleanos de } \\
\text { recuparação, modelos } \\
\text { probabilísticos; } \\
\text { linguagem de } \\
\text { processamento, } \\
\text { abordagens baseadas } \\
\text { nos conhecimentos, } \\
\text { tesauros }\end{array}$ & $\begin{array}{l}\text { Fator de Impacto da } \\
\text { Web (FIW), densidade } \\
\text { dos links, "sitações", } \\
\text { estratégias de busca }\end{array}$ \\
\hline Objetivos & $\begin{array}{l}\text { Alocar recursos: } \\
\text { pessoas, tempo, } \\
\text { dinheiro, etc. }\end{array}$ & $\begin{array}{l}\text { ldentificar domínios de } \\
\text { interesse. Onde os } \\
\text { assuntos estão } \\
\text { concentrados. } \\
\text { Compreender como e } \\
\text { quanto os cientistas se } \\
\text { comunicam. }\end{array}$ & $\begin{array}{l}\text { Melhorar a eficiência da } \\
\text { recuperação da } \\
\text { informação, identificar } \\
\text { estruturas e relações } \\
\text { dentro dos diversos } \\
\text { sistemas de informação }\end{array}$ & $\begin{array}{l}\text { Avaliar o sucesso de } \\
\text { determinados sítios, } \\
\text { detectar a presença de } \\
\text { países, instituições e } \\
\text { pesquisadores na rede } \\
\text { e melhorar a eficiência } \\
\text { dos motores de busca } \\
\text { na recuperação das } \\
\text { informações }\end{array}$ \\
\hline
\end{tabular}

Fonte: VANTI, 2002, p. 160

De maneira geral, apresentou-se neste tópico conceitos sobre as

disciplinas de bibliometria, cienciometria, informetria e a webometria, bem como aspectos ligados às suas respectivas origens, de forma a criar condições para apresentação do próximo tópico, que trata dos indicadores bibliométricos utilizados na avaliação da ciência.

\subsubsection{Principais Indicadores de Avaliação da Ciência}

A avaliação da ciência ganha destaque no período do pós-guerra, devido ao aumento significativo da geração de informação científica. A bibliometria, que até então se restringia aos estudos de livros e periódicos para a tomada de decisão de bibliotecas e unidades de informação, 
desenvolveu-se intensamente e passou contar com um conjunto de indicadores para a avaliação da produção científica de indivíduos, grupos, nações ou veículos de comunicação científica (periódicos, livros, teses).

Dentre os principais marcos de seu desenvolvimento, destacam-se as três leis clássicas que orientam o campo da bibliometria, elaboradas entre as décadas de 1920 e 1940. A primeira a ser formulada foi a Lei de Lotka ou Lei do Quadrado Inverso, em 1926, a partir de estudo referente à produtividade de pesquisadores, com a utilização dos dados de autores contidos no Chemical Abstracts, no período de 1909 a 1916. Nesse estudo, Alfred James Lotka observou que um pequeno número de autores é responsável pela publicação de uma larga proporção da literatura científica, enquanto um grande número de pesquisadores se iguala, em produção, ao reduzido número daqueles mais produtivos. A partir daí, Lotka formulou a lei dos quadrados inversos: $y x=6 / p 2 x a$, onde $y x$ é a frequência de autores publicando número $x$ de trabalhos e a é um valor constante, específico para cada campo científico (VANTI, 2002; ARAÚJO, 2006; SANTOS, 2010).

A segunda a surgir foi a Lei de Bradford ou Lei da Dispersão (1934), que resultou de uma série de estudos sobre um conjunto de periódicos da área de geofísica, cujo objetivo era identificar o núcleo de títulos relevantes para o tema. Samuel C. Bradford constatou a existência de um grupo menor de periódicos que se relacionam de forma mais próxima ao tema e um grupo maior que, por sua vez, se relacionam de maneira estreita com o tema. Para cada grupo, à medida que o número de periódicos aumenta, a produtividade diminui (VANTI, 2002; ARAÚJO, 2006; SANTOS, 2010). Quando o grupo de periódicos foi ordenado por produtividade decrescente relevante a um determinado assunto, verificou-se a constituição de três zonas, cada uma com 1/3 dos artigos relevantes: "[...] a primeira zona contém um pequeno número de periódicos altamente produtivos, a segunda contém um número maior de periódicos menos produtivos, e a terceira inclui mais periódicos ainda, mas cada um com menos produtividade" (ARAÚJO, 2006, p. 14).

A Lei de Zipf ou Lei do Mínimo Esforço constitui-se na terceira lei da bibliometria, elaborada em 1949 por George Kingsley Zipf, linguista da 
Universidade de Harvard. Tal lei descreve a relação entre as palavras em determinado texto e a ordem de série das mesmas, tendo sido formulada a partir de um estudo da obra Ulysses, de James Joyce, que possibilitou constatar uma regularidade na seleção e uso das palavras, bem como a existência de um pequeno número de palavras utilizado muito mais frequentemente e que representa o assunto do documento. Zipf verificou que "[...] a palavra mais utilizada aparecia 2653 vezes, a centésima palavra mais utilizada ocorria 256 vezes e a ducentésima palavra ocorria 133 vezes" (ARAÚJO, 2006, p. 16). Ele então concluiu que a posição de uma palavra, quando multiplicada pela sua frequência, resultava em uma constante de aproximadamente 26.500 (VANTI, 2002; ARAÚJO, 2006; SANTOS, 2010).

Além das três leis clássicas, o campo da bibliometria é sustentado por um conjunto de teorias, princípios e indicadores que, nas últimas duas décadas, têm se desenvolvido e sido aplicados em diversos estudos acerca da dinâmica da comunicação científica nas diferentes áreas temáticas. A seguir, são destacados alguns indicadores de avaliação da ciência.

- Teoria epidêmica de Goffman - A partir da análise de citações, faz uma analogia da difusão da comunicação escrita com a transmissão de doenças infecciosas. Com a análise matemática de Goffman, é possível estimar os níveis de importância e o prognóstico de comportamento de linhas de pesquisa em determinada área do conhecimento (SANTOS, 2010).

- Frente de pesquisa e colégios invisíveis - A partir da análise das citações de um conjunto de autores da recente literatura, é possível identificar a frente de pesquisa, bem como as relações múltiplas na literatura sobre determinado assunto. Possibilita também identificar, a partir dos artigos entrelaçados, o trabalho de pesquisadores que formam os colégios invisíveis. Nos estudos de frente de pesquisa pode-se observar a existência de um pequeno grupo de autores e de publicações que apresentam maior impacto em uma determinada área (PRICE apud SANTOS, 2010). 
- Obsolescência e vida média - A obsolescência tem como objetivo analisar a diminuição do uso de um determinado documento ao longo dos anos. A vida média, por sua vez, possibilita identificar a metade da vida útil de uma pesquisa e representa um indicador de influência dos periódicos. A obsolescência e a vida média utilizam-se da analise de citações e estão diretamente relacionadas à dinâmica de geração de conhecimento científico em uma determinada área do conhecimento (SANTOS, 2010).

- Acoplamento bibliográfico e cocitação - Entende-se por acoplamento bibliográfico o agrupamento de artigos que citam o(s) mesmo(s) documento(s), possibilitando medir o grau de ligação entre eles, a partir da quantidade de documentos citados pelos mesmos. Já a cocitação refere-se ao agrupamento de artigos que foram citados pelos mesmos documentos, possibilitando medir o grau de ligação entre eles, a partir da quantidade de documentos que os citam simultaneamente (MARSHAKOVA apud SANTOS, 2010).

- Lei de Pareto ou princípio dos 80/20 - Surgiu a partir da observação de um fenômeno que ocorria no contexto do comércio e da indústria e que, posteriormente, foi aplicado em bibliotecas e sistemas de informação para a tomada de decisão quanto à formação e desenvolvimento de coleções. Segundo o Princípio do 80/20, 80\% da demanda por informação é atendida por $20 \%$ do conjunto das fontes de informação (TRUESWELL apud SANTOS, 2010).

- Índice H - Criado pelo físico Jorge E. Hirsch, em 2005, é um indicador para medir a produtividade e a qualidade científica dos pesquisadores, apresentando simplicidade metodológica semelhante à do fator de impacto. Recentemente, foi adaptado para análise de periódicos e incorporado ao módulo de bibliometria das bases de dados WoS e Scopus, o que corroborou sua rápida aceitação pela comunidade científica. 
- Fator de Impacto - O Fator de Impacto é o indicador mais utilizado pela comunidade científica; em seu calculo é considerada a quantidade de citações que um determinado periódico recebeu no ano corrente, divididas pela quantidade de artigos publicados nos dois ou três últimos anos. Estudos confirmam a existência de correlação entre o $\mathrm{Fl} \mathrm{e}$ indicadores como as taxas de leitura e de assinatura, avaliação de qualidade de periódicos científicos (SAHA; SAINT; CHRISTAKIS apud MUGNAINI, 2013; SANTOS, 2010). Apesar da intensa utilização e disseminação do $\mathrm{FI}$, sua aplicação na análise de periódicos científicos tem resultado em muitas críticas por parte da comunidade científica. Isso pode ser constatado a partir do crescente número de artigos que apresentam críticas ao Fator de Impacto, bem como a seu uso, conforme verificado pelo estudo de Archambault e Larivière (apud MUGNAINI, 2013), que registrou um aumento de 23 para 146, no período de 1995 a 2005.

- Y-Factor, Eigenfactor e Scimago Journal Rank - O Fator Y e o Eigenfactor foram criados com o objetivo de avaliar a reputação dos periódicos científicos, com base nas redes de citação. O Fator-Y constitui-se em indicador híbrido que considera a popularidade e 0 prestigio dos periódicos. Já o Eigenfactor utiliza um conceito de citação qualificada (ou "balanceada"), com base no prestígio do periódico citante. Dessa forma, se for um periódico com muitas citações, o autor do artigo citado apresentará melhor desempenho. $O$ Scimago Journal \& Country Rank, de autoria de um grupo espanhol, considera a base de dados da Scopus e possibilita o recorte por áreas de pesquisa, disciplinas e países, com definição variável da janela de citação (BETTONI, 2011).

Esses diferentes indicadores, que representam uma fração do conjunto de indicadores que compõem o campo da bibliometria, utilizam-se da contagem das citações recebidas ou concedidas para avaliar o 
desempenho de indivíduos, grupos de pesquisa, nações e veículos de comunicação científica (periódicos, livros, teses).

As citações são definidas por Foresti (1989) como um conjunto de referencias que, quando incluídas em uma determinada publicação, possibilitam evidenciar a relações existentes entre autores, instituições e áreas científicas, bem como entre as próprias publicações. Ainda segundo a autora (p. 2), as citações:

contribuem para o desenvolvimento da ciência, provêem 0 necessário reconhecimento de um cientista por seus colegas, estabelecem os direitos de propriedade e prioridade da contribuição científica de um autor, constituem importantes fontes de informação, ajudam a julgar os hábitos de uso da informação e mostram a literatura que é indispensável para o trabalho dos cientistas.

A análise de citações é considerada a mais relevante no contexto dos estudos bibliométricos, possibilitando identificar as especificidades nos processos de produção e comunicação da informação científica nas diferentes áreas temáticas. A utilização da análise de citações nesses estudos possibilita identificar:

autores mais citados, autores mais produtivos, elite de pesquisa,
frente de pesquisa, fator de impacto dos periódicos, procedência
geográfica e/ou institucional dos autores mais influentes em um
determinado campo de pesquisa, tipo de documento mais
utilizado, idade média da literatura utilizada, obsolescência da
literatura, procedência geográfica e/ou institucional da bibliografia
utilizada; periódicos mais citados, core de periódicos que
compõem um campo, entre outras finalidades (ARAUJO apud
SANTOS, 2010, p. 61).

Porém, estudiosos da área de bibliometria advertem sobre a inadequação da aplicação da análise de citações em estudos que visam à comparação entre grandes áreas temáticas, em razão das especificidades da comunicação científica (GARFIELD, 1999; BETONI, 2011; CHINCHILLARODRÍGUES; MIGUEL; MOYA-ARAGÓN, 2012).

Os vários indicadores bibliométricos são instrumentos quantitativos, imbuídos de vantagens e desvantagens, que desempenham importante papel nos processos de avaliação da produção científica, atribuindo mais 
objetividade aos resultados. Porém, sua aplicação exige análise atenta quanto à adequação ao tipo de estudo.

\subsection{AVALIAÇÃO DOS PERIÓDICOS NACIONAIS PELO PROGRAMA QUALIS}

A Coordenação de Aperfeiçoamento de Pessoal de Nível Superior (CAPES) desenvolveu um sistema de avaliação da produção intelectual gerada no âmbito dos programas de pós-graduação do Brasil que inclui um conjunto de procedimentos, visando, de forma indireta, à avaliação da qualidade dos artigos e de outros tipos de produção científica, a partir de seus respectivos veículos de comunicação (CAPES ${ }^{1}$, [19-?]).

Esse sistema, denominado Qualis, realiza a classificação dos veículos que difundem a produção científica dos docentes e discentes dos programas de pós-graduação, a partir de informações ingressadas pelos próprios programas no aplicativo "Coleta de Dados". Como produto do Sistema Qualis, tem-se uma lista de periódicos e outros veículos apresentada de forma estratificada e dividida em áreas temáticas, podendo ser consultada a partir do portal da CAPES. Em específico para o Qualis Periódicos, o acesso à classificação dos periódicos, bem como aos critérios utilizados, é garantido pelo aplicativo WebQualis (CAPES ${ }^{1}$, [19-?]).

O Qualis Periódicos é parte integrante do Sistema de Avaliação da Pós-Graduação da CAPES e desde sua implantação, em 1998, classifica regularmente os periódicos, operando com base nos seguintes fundamentos: a) avaliação dos periódicos por áreas temáticas; b) participação de pesquisadores representando a comunidade científica das diferentes áreas; e c) utilização da produção intelectual de docentes e discentes como um indicador de qualidade dos cursos de pós-graduação (SOUZA apud SANTOS, 2001).

Segundo Campos (2010), o Qualis é formado por três componentes: 
- Qualis Critérios: inclui os critérios e procedimentos utilizados para a estratificação da produção científica, por meio de periódicos, anais de eventos e livros, podendo variar conforme a área do conhecimento.

- Qualis Dados: este componente constitui-se a base de dados de um tipo de veículo de publicação - periódicos, anais de eventos ou livros - de uma determinada área.

- Qualis Lista: refere-se à lista de periódicos estratificada e, em específico, constitui-se no produto do Qualis Periódicos.

Para a classificação dos periódicos são constituídas comissões permanentes de avaliação, em cada área do Qualis Periódicos, integradas por revisores ad hoc e representantes de área da CAPES. Essas comissões se dividem da seguinte forma: coordenador de área, um grupo de avaliação e outro de consultores, cabendo ao primeiro revisar, anualmente, a classificação dos periódicos e ao segundo, conduzir a avaliação e classificação dos títulos (SANTOS, 2010; JACON, 2007).

Desde sua implementação o Qualis Periódicos vem passando por modificações. Em sua primeira aplicação, no triênio 1998-2000, se utilizava de duas dimensões para a classificação dos periódicos: a abrangência internacional, nacional e local - e a qualidade - A, B ou C. Para cada dimensão, os periódicos eram divididos em três estratos e poderiam receber as seguintes classificações: Internacional A, Internacional B, Internacional C, Nacional A, Nacional B, Nacional C, Local A, Local B e Local C (CAMPOS, 2010).

Segundo Souza (apud SANTOS, 2010), o modelo implementado em 1998 reuniu as seguintes características: a) avaliação trienal dos veículos; b) utilização do standard internacional de qualidade para cada área do conhecimento; c) processos de avaliação e coleta de dados sendo realizados com utilização de recursos das tecnologias de informação; e d) adoção da avaliação continuada dos veículos. 
Problemas detectados na classificação no triênio 2005-2007 levaram a CAPES a reformular o Qualis Periódicos, resultando na implementação de um novo modelo em 2008, que passou a ser composto por oito estratos: $A 1$, o mais elevado; A2; B1; B2; B3; B4; B5; e C, com peso zero (CAMPOS, 2010). Para garantir a não concentração de títulos nos estratos superiores ficou estabelecido que: A1 e A2 devem incluir menos de $25 \%$ do total de periódicos e o número de $A 2$ deve ser superior ao de $A 1$; o número de periódicos classificados em A1, A2 e B1 deve ser menor que $51 \%$ do total de títulos considerados pela área (CAMPOS, 2010).

Com o novo Qualis Periódicos a classificação dos títulos deve observar os seguintes aspectos (CAMPOS, 2010, p. 487):

1. Cada área deve definir o que considera periódico;

2. Para enfatizar o caráter classificatório do Qualis, as áreas devem povoar significativamente pelo menos cinco dos sete estratos;

3. Recomenda-se que haja uma diferença expressiva entre os pesos atribuídos aos vários estratos;

4. Cada área deverá apresentar em seu documento os critérios pelos quais define cada estrato (fator de impacto, índice $\mathrm{H}$ ou outros modos de mensurar sua qualidade). Destaca-se a necessidade povoar os dois estratos superiores (A1 e A2) de maneira particularmente criteriosa;

5. Nas grandes áreas em que for possível e, em especial, naquelas em que já é tradição, como as Engenharias e a Saúde, que se mantenha a política de um Qualis único ou de um Qualis com regras únicas; $\mathrm{e}$

6. Recomenda-se que, pelo menos no interior de cada grande área, procure-se formular regras de Qualis próximas entre si, mas sem depreciação das áreas que têm maior tradição de publicação em periódicos ou sobrevalorização daquelas que ainda têm pouco volume nesse campo; portanto, um periódico pode obter notas diferentes em distintas áreas.

Tal mudança no modelo Qualis suscitou reações da comunidade científica brasileira, constituindo-se em tema de editoriais, artigos, reuniões de editores científicos, bem como objeto de teses e dissertações que sinalizam a desvalorização dos periódicos científicos nacionais e reivindicam o aprimoramento do Programa Qualis. Com a aplicação do novo modelo, os periódicos nacionais foram drasticamente excluídos do estrato $A 1 \mathrm{e}$, para algumas áreas, também do estrato A2. 
Exemplo a citar foi o editorial intitulado "Classificação dos Periódicos pelo Sistema Qualis da CAPES: a mudança dos critérios é urgente", que resultou de uma série de encontros entre editores científicos de revistas médicas brasileiras com representantes da CAPES. Publicado simultaneamente em diversos periódicos nacionais em 2010, o editorial apresenta recomendações dos editores da área médica para a melhoria do Qualis Periódicos. Dentre elas, pode-se citar a não utilização do Fator de Impacto como único indicador de qualidade das publicações. Ademais, reivindica apoio à internacionalização dos periódicos científicos brasileiros (ANDRIOLO, 2010).

Cabral Filho (2009) indica três desafios aos editores brasileiros impostos pelo novo Qualis: a) provável redução do número de submissões de artigos aos periódicos nacionais, resultando no empobrecimento da qualidade dos títulos, bem como a possível extinção dos classificados nos estratos mais baixos; b) classificação dos programas de pós-graduação em conceitos mais baixos; e c) incremento no número de estudos no campo da bibliometria que visem o esclarecimento da utilização do Fator de Impacto como indicador de qualidade dos periódicos científicos, o que já se pode constatar na literatura científica da área de bibliometria.

Para Santos (2010) também se constituiu em tema para debates e polêmicas o fato de que o Sistema Qualis possibilita que as diferentes áreas temáticas utilizem critérios distintos de avaliação, o que faz com que um mesmo veículo seja classificado em estratos distintos, dependendo da comissão que realizou a avaliação.

Nesse ponto, faz-se necessário apresentar as áreas que, atualmente, são contempladas no Qualis Periódicos, conforme exposto no Quadro 3 e distribuídas pelas grandes áreas do CNPq: 
Quadro 3. Áreas do conhecimento do Qualis Periódicos

\begin{tabular}{|c|c|c|}
\hline \multicolumn{3}{|c|}{ Áreas temáticas Qualis - 49 áreas } \\
\hline Ciências agrárias & Ciência biológicas & Ciências exatas e da terra \\
\hline $\begin{array}{ll}\text { 1. } & \text { Ciência de alimentos } \\
\text { 2. } & \text { Ciências agrárias I } \\
\text { 3. } & \text { Medicina veterinária } \\
\text { 4. } & \text { Zootecnia/recursos pesqueiros }\end{array}$ & $\begin{array}{ll}\text { 1. } & \text { Biodiversidade } \\
\text { 2. } & \text { Biotecnologia } \\
\text { 3. } & \text { Ciências ambientais } \\
\text { 4. } & \text { Ciências biológicas I } \\
\text { 5. } & \text { Ciências biológicas II } \\
\text { 6. } & \text { Ciências biológicas III }\end{array}$ & $\begin{array}{ll}\text { 1. } & \text { Astronomia/física } \\
\text { 2. } & \text { Ciência da computação } \\
\text { 3. } & \text { Geociências } \\
\text { 4. } & \text { Matemática/probabilidade e } \\
\text { 5. } & \text { Materiaística } \\
\text { 6. } & \text { Química } \\
\end{array}$ \\
\hline Ciências humanas & Ciências da saúde & Ciências sociais aplicadas \\
\hline $\begin{array}{ll}\text { 1. } & \text { Antropologia/arqueologia } \\
\text { 2. } & \text { Ciência política e relações } \\
\text { internacionais } \\
\text { 3. } \\
\text { Educação } \\
\text { 5. }\end{array}$ & $\begin{array}{ll}\text { 1. } & \text { Educação física } \\
\text { 2. } & \text { Enfermagem } \\
\text { 3. } & \text { Farmácia } \\
\text { 4. } & \text { Medicina I } \\
\text { 5. } & \text { Medicina II } \\
\text { 6. } & \text { Medicina III } \\
\text { 7. } & \text { Nutrição } \\
\text { 8. } & \text { Odontologia } \\
\text { 9. } & \text { Saúde coletiva }\end{array}$ & $\begin{array}{ll}\text { 1. } & \text { Administração, ciências } \\
\text { contábeis e turismo } \\
\text { 2. Arquitetura e urbanismo } \\
\text { 3. Ciências sociais aplicadas I } \\
\text { 4. Direito } \\
\text { 5. Economia } \\
\text { 6. Planejamento urbano e } \\
\text { regional/demografia } \\
\text { 7. Serviço social }\end{array}$ \\
\hline Engenharias & Linguística, letras e artes & Multidisciplinar \\
\hline $\begin{array}{ll}\text { 1. } & \text { Engenharias I } \\
\text { 2. } & \text { Engenharias II } \\
\text { 3. } & \text { Engenharias III } \\
\text { 4. } & \text { Engenharias IV } \\
\end{array}$ & $\begin{array}{ll}\text { 1. } & \text { Artes/música } \\
\text { 2. } & \text { Letras/linguística }\end{array}$ & 1. Interdisciplinar \\
\hline
\end{tabular}

Fonte: Webqualis, 2012

Segundo Jacon (2007), cada uma das 49 áreas do Qualis Periódicos define os instrumentos que utilizará para a classificação dos veículos, desde que respeitada a metodologia proposta pela CAPES (avaliação por pares). A área de saúde, por exemplo, utiliza-se do Journal of Citation Reports (JCR); outras estabelecem critérios editoriais específicos; já a psicologia utiliza-se de aspectos intrínsecos (conteúdo) e extrínsecos (forma) para a avaliação dos veículos.

Machado e Zaher (2010) apontam para o papel indutor que o Qualis Periódicos tem desempenhado, à medida que redireciona a produção científica brasileira para publicações com FI mais elevados, desencorajando, por outro lado, os pesquisadores brasileiros a publicarem em periódicos com FI baixos. Além disso, o sistema deixa de considerar as características específicas das áreas de pesquisa, promovendo uma concorrência indevida entre distintas áreas e disciplinas de um mesmo campo do conhecimento. 
Camargo Jr. (2013, s.n.) ressalta que a utilização, pelo Qualis, do Fator de Impacto como um indicador para classificar periódicos:

\begin{abstract}
tende indiretamente a privilegiar as publicações fechadas. Por serem mais antigas, têm sua posição mais consolidada e serão provavelmente contempladas com melhores indicadores. A disputa pela publicação nas revistas com melhores indicadores tende a criar um círculo vicioso, uma importante barreira de entrada para novas publicações - e dada a introdução historicamente recente da internet, as revistas abertas são novas publicações. Modificação no Qualis que levasse à valorização das revistas abertas seria um importante passo na superação do atual modelo oligopolista, especialmente se acompanhada de medidas que viabilizassem o financiamento da publicação.
\end{abstract}

Diante de tantas polêmicas e reclamações da comunidade científica em relação ao Qualis Periódicos, faz-se necessário colocar as contribuições do programa para a promoção da qualidade dos periódicos científicos nacionais: a) serviu de estímulo aos editores nacionais para buscarem indexação em bases de dados, como SciELO, Scopus e WoS; e b) promoveu a organização dos editores em áreas temáticas, que passaram a realizar reuniões que tinham como tema central o debate da qualidade de periódicos científicos nacionais.

Em seus 15 anos de operação, o Qualis Periódicos alterou o comportamento da comunidade científica nas diferentes áreas do conhecimento e, a partir da análise de seus resultados - positivos e negativos -, é possível evidenciar o caminho que ainda terá de trilhar para atingir uma avaliação mais adequada da produção científica nacional, especificamente dos periódicos científicos nacionais.

\title{
3.2.1 Qualis Periódicos e a Avaliação da Área de Biodiversidade
}

Podemos definir informação científica em biodiversidade como aquela gerada por meio de pesquisa científica que tenha como objetivo o estudo dos "[...] seres vivos, seu material genético e os complexos ecológicos e também os fluxos, os nexos, as articulações e as ações por meio dos quais esses seres se mantêm relacionados" (IANNI, 2005, p. 79). 
O termo em inglês biological diversity (diversidade biológica) foi introduzido por Thomas Lovejoy no ano de 1980, enquanto o termo biodiversity (biodiversidade) foi utilizado pela primeira vez por W.G. Rosen em 1985. Na década de 1990, o termo biodiversidade popularizou-se por ocasião da assinatura da convenção sobre a diversidade biológica, na época da Conferência do Rio de Janeiro (LÉVÊQUE, 1999). Desde então, o termo passou a ser intensamente utilizado por biólogos, ecologistas, ambientalista, jornalistas e outros segmentos da sociedade ligados às questões ambientais.

A UNESCO ${ }^{4}$ (2011) conceitua o termo biodiversidade, conforme segue:

\begin{abstract}
Biodiversidade é a variação de formas de vida dentro de um ecossistema, bioma, ou considerando toda a Terra. Biodiversidade é muitas vezes usado como uma medida da saúde dos sistemas biológicos. A biodiversidade encontrada na Terra, hoje, é composta de muitos milhões de espécies biológicas distintas, que é o produto de cerca de 3,5 bilhões de anos de evolução (tradução nossa).
\end{abstract}

Segundo Albagli (1996), o termo biodiversidade inclui a vida biológica no planeta, em seus diferentes níveis, bem como sua capacidade de reprodução. Corresponde à "variabilidade viva", abrangendo a diversidade entre e no âmbito das espécies e de seus habitats. Ianni (2005, p. 79) coloca que a biodiversidade "[...] expressa as bases sobre as quais as diferentes formas de vida se apoiam e dependem mutuamente. Do desenvolvimento e do equilíbrio da biodiversidade depende a manutenção dos processos de evolução de todo o mundo vivo".

A biodiversidade, ainda, pode ser definida como (ThesBio $\left.{ }^{5}, 2012\right)$ :

Um conjunto amplo da variedade de comunidades de solo, vegetação e animais (biomas) em escala mundial, continental, nacional e regional, ou da diversidade de ecossistemas dentro

\footnotetext{
${ }^{4}$ Documento não paginado na web. Disponível em: http://www.ecounesco.ie/eco-biodiversity-ireland. Acessado em: novembro de 2012.

"Biodiversity is the variation of life forms within a given ecosystem, biome, or for the entire Earth. Biodiversity is often used as a measure of the health of biological systems. The biodiversity found on Earth today consists of many millions of distinct biological species, which is the product of nearly 3.5 billion years of evolution".

${ }^{5}$ Documento não paginado na web. Disponível em: http://thesaurus.bhlscielo.org. Acessado em: janeiro de 2013.
} 
desses biomas, ou do número de espécies existente em cada ecossistema. A biodiversidade é objeto de uma política nacional dada a sua importância no equilíbrio dos sistemas vivos, para a sobrevivência da Terra; também foi chamada de diversidade biológica, de acordo com a Convenção das Nações Unidas, assinada por ocasião da Eco-92, no Rio de Janeiro.

A partir das definições do termo biodiversidade verifica-se que não se trata de um tema que pode ser classificado em uma única área temática, mas sim em diversas áreas temáticas, como: biologia, zoologia, botânica, ecologia, oceanografia e ciências ambientais, dentre outras. Para Rios, Silva e Sá (1996, p. 1) "[...] o tema Biodiversidade não possui uma área ou classificação específica, sendo, portanto, multidisciplinar, podendo ser encontrados aspectos relacionados ao assunto nas diversas classificações de áreas do conhecimento existentes".

De acordo com Heywood (1995), a definição de biodiversidade é um assunto que demanda discussões consideráveis. Segundo uma visão ampla do Global Biodiversity Assessment (GBA), a biodiversidade envolve quatro componentes principais: o ecológico, o genético, de organismos e o cultural, conforme apresentado no Quadro 4.

Quadro 4. Composição da área de biodiversidade, conforme GBA

\begin{tabular}{|c|c|c|}
\hline $\begin{array}{l}\text { Diversidade } \\
\text { ecológica } \\
\text { biomas } \\
\text { biorregiões } \\
\text { paisagens } \\
\text { ecossistemas } \\
\text { habitats } \\
\text { população }\end{array}$ & $\begin{array}{l}\text { Diversidade } \\
\text { genética } \\
\text { população } \\
\text { indivíduos } \\
\text { cromossomos } \\
\text { genes } \\
\text { nucleotídeos }\end{array}$ & $\begin{array}{l}\text { Diversidade de } \\
\text { organismos } \\
\text { reinos } \\
\text { filos } \\
\text { famílias } \\
\text { gêneros } \\
\text { espécies } \\
\text { subespécies } \\
\text { população }\end{array}$ \\
\hline \multicolumn{3}{|c|}{ Diversidade cultural e as interações humanas em todos os níveis } \\
\hline
\end{tabular}

Nas últimas décadas a produção de informação científica em biodiversidade vem ganhando destaque devido à crise ambiental, que tem mobilizado vários segmentos da sociedade em prol da conscientização de 
que a preservação dos ecossistemas e da sua biodiversidade é de fundamental importância para o desenvolvimento sustentável e igualitário da humanidade, bem como garantia de sua própria sobrevivência.

Foi nesse contexto e em reconhecimento à importância desse campo para o país que a CAPES criou no Qualis Periódicos, em setembro de 2011, a área de biodiversidade, a partir da ampliação da área de ecologia e meio ambiente, com a inclusão de Ciências Biológicas I (botânica, oceanografia biológica e zoologia - $\mathrm{BOZ}^{6}$ ) e Interdisciplinar (CAPES $\left.{ }^{7}, 2011\right)$.

Estão entre os problemas que motivaram a criação da área de biodiversidade no Qualis: a) parte considerável da biodiversidade do Brasil ainda encontra-se não descrita ou inacessível em coleções; b) pouco entendimento sobre a organização da diversidade biológica, bem como sobre suas respostas às ações antrópicas; c) carência de modelos conceituais e inovações tecnológicas que viabilizem a exploração sustentável e economicamente competitiva dos recursos da biodiversidade; d) comunicação ineficiente entre a ciência e a tomada de decisão, tanto no âmbito da administração pública como da privada; e e) carência de profissionais nas áreas de gestão da biodiversidade e biologia de conservação (CAPES $\left.{ }^{7}, 2011\right)$.

Conforme os documentos disponíveis no portal da CAPES, para a junção das áreas de ecologia e meio ambiente com a BOZ fez-se necessário o aprimoramento dos instrumentos de avaliação, processo que foi facilitado pela semelhança detectada entre os dois conjuntos, com relação aos seguintes aspectos $\left(\right.$ CAPES $\left.^{8}, 2013\right)$ :

a) mediana do Fator de Impacto no triênio 2007-2009, tendo atingido

\footnotetext{
${ }^{6}$ Sigla utilizada no estudo para referir-se ao conjunto de periódicos das áreas de botânica, oceanografia, zoologia e ecologia. Foi adaptada da sigla BOZ que é utilizada pelo QUALIS para denominar os programas de pós-graduação das áreas de biologia, oceanografia biológica e zoologia. 7 Documento não paginado da web. Disponível em: http://www.capes.gov.br/images/07 biod comunicado 01-2011.pdf. Acessado em: 17 de junho de 2013.

8 Documento não paginado da web. Disponível em: http://www.capes.gov.br/images/Comunicado 012013 Qualis Biodiversidade.pdf. Acessado em: 17 de junho de 2013.
} 
1.5 em ecologia e 1.16 em BOZ;

b) distribuição semelhante dos periódicos dos dois conjuntos nos diferentes estratos, referente ao triênio 2007-2009;

c) distribuição do número médio de produtos Qualis no triênio 20072009, por docente permanente para cada estrato de conceito dos cursos.

A estratificação da produção científica da área de biodiversidade foi baseada $\left(\right.$ CAPES $\left.^{8}, 2013\right)$ :

\begin{abstract}
em cálculos de mediana dos fatores de impacto, indexação dos periódicos e uso dos mesmos após expansão da base de periódicos indexados somando aos indexados pelo ISI (JCR) aqueles com fator de impacto Scopus (SJR), seguindo o mesmo modelo apresentado no Comunicado anterior. No entanto, a agregação de um importante volume de novos periódicos (mais de 550 ) aos 1817 periódico já classificados como B5 ou superior no WebQualis determinou pequenos reajustes no fatores de impacto para definir o estrato $A$, que agora compreende os periódicos com Fl>2.88 e o estrato A2, que agora compreende os periódicos com $\mathrm{Fl}>1.92$. Os critérios de definição de outros estratos foram mantidos, a saber, B1 que compreende os periódicos com $\mathrm{Fl}>0.624$, B2 que compreende os periódicos indexados em 2010 nas bases ISI ou Scopus, B3 estando constituídos pelos periódicos indexados na base SciELO somados aos periódicos que tiveram na base de dados analisada uso, entre 2007 e 2010, igual ou superior a 10, B4 que é definido pelos periódicos com uso superior a 4 e o estrato B5 constituídos pelos periódicos considerados impróprios pela área.
\end{abstract}

A constituição da área de biodiversidade, a partir da junção da ecologia e meio ambiente com a BOZ, foi alvo de críticas da comunidade científica das áreas de botânica e zoologia, resultando na elaboração de uma carta da Sociedade Brasileira de Zoologia. Assinada por 130 zoólogos, botânicos, editores e coordenadores de programas de pós-graduação, o documento questionou os critérios utilizados para a estratificação da produção científica das áreas, em específico o uso do Fator de Impacto como critério único de avaliação. Ademais, tanto os pesquisadores de zoologia como os de botânica apontaram para a heterogeneidade das áreas que compõem o Qualis Biodiversidade, no que se refere à dinâmica de geração e citação da informação científica (MACHADO; ZAHER, 2010). 
Vale citar o exemplo da zoologia, em específico da taxonomia, em que o Fator de Impacto não é reconhecido pelos pesquisadores que atuam na área como um indicador de mérito acadêmico, pois os trabalhos taxonômicos tendem a não serem citados dentro da janela de dois anos, utilizada para o cálculo dessa métrica (MACHADO; ZAHER, 2010).

Segundo pesquisadores da área de botânica, o modelo de implantação do Qualis Biodiversidade "[...] incorreu em um erro ao utilizar os mesmos parâmetros da antiga área, levando à supervalorização das revistas com cunho ecológico em relação às demais linhas de pesquisa agora integradas a essa nova área" (HARLEY, 2011, s.n.).

Um dos objetivos desse trabalho é avaliar os periódicos científicos nacionais e estrangeiros classificados pelo Programa QUALIS da CAPES na área de biodiversidade, identificando suas características específicas, bem como seu desempenho a partir dos indicadores quantitativos e qualitativos. 


\title{
4 A CIÊNCIA E A COMUNICAÇÃO DE SEUS RESULTADOS
}

\begin{abstract}
O conhecimento científico que possuímos é o resultado de um esforço social, que ao longo dos séculos se desenvolveu com a abordagem adequada aos seus objetivos e onde 0 trabalho de cada indivíduo é informado e controlado por um de seus colegas nessa empreitada que envolve o passado, o presente e o futuro (RAVETZ, 1971).
\end{abstract}

A evolução da ciência se apoia no processo de construção e reconstrução do conhecimento científico, que ocorre a partir da geração e validação de novos conhecimentos ou da revisão, complementação e substituição dos já estabelecidos. Tal fato denota o dinamismo da ciência e o caráter provisório de seus resultados. Isto é, os resultados gerados a partir de pesquisa científica não possuem caráter permanente, mas "[...] inseremse num processo ininterrupto de investigação, o que faz da ciência uma instituição social, dinâmica, contínua, cumulativa" (TARGINO, 2000, p. 2).

O conhecimento produzido em um determinado campo científico é disseminado aos membros de sua comunidade por meio da comunicação científica, que pode ser entendida como o processo que inclui a produção de informação científica, sua validação por pares, seu acondicionamento e disseminação a partir de distintos canais e posterior utilização pela comunidade científica. Dessa forma, contribui para a geração de novas informações e conhecimentos e, consequentemente, para o avanço mesmo da ciência.

Não é possível situar na história o início da comunicação científica, pois para isso seria necessária uma definição quanto ao que seja pesquisa (MEADOWS, 1999). Apesar das dificuldades em afirmar quando se iniciou, é consenso entre os pesquisadores que o processo de comunicação científica, na forma como o conhecemos hoje, teve origem no final do século XVII, "[...] com a proliferação das revistas científicas advindas das correspondências dentro e entre as sociedades científicas" (HURD apud GOMES, 2012, p. 48).

A criação do termo comunicação científica é atribuída ao físico e historiador da ciência John Bernal, que em 1940 a definiu como "[...] um 
amplo processo de geração e transferência de informação científica" (apud SOUZA, 2003, p. 136). Para Meadows e Ziman (apud MARCONDES et al., 2008, p. 24) a comunicação científica constitui-se mecanismo que possibilita a incorporação de novos conhecimentos em uma área científica, a partir de um longo processo que envolve leitura, avaliação, crítica, citação do artigo pela comunidade científica e incorporação do novo conhecimento "[...] ao acervo de 'conhecimento público' da humanidade".

Weitzel (2006, p. 88) define comunicação científica como "[...] um processo que envolve a construção, comunicação e uso do conhecimento científico para possibilitar a promoção de sua evolução". Segundo Lievrouw (apud MUELLER, 1994, p. 314), ela constitui-se um ciclo composto por três etapas - "[...] a concepção, a documentação e a popularização [...]" baseando-se em dois conceitos:

a) Do processo de comunicação: "[...] atividade ou comportamento que facilita a construção e o compartilhamento de significado entre indivíduos".

b) Da estrutura da comunicação: "[...] relações entre indivíduos que estão ligados pelos significados que construíram e compartilham".

Gomes (2012, p. 48) destaca a pluralidade das definições e conceitos que alicerçam a pesquisa no âmbito da comunicação científica, constituídos ao longo da história a partir de diferentes perspectivas, linhas de pesquisa e estudiosos. Em específico, o autor analisa as distintas formas pelas quais 0 termo "comunicação científica" vem sendo interpretado por pesquisadores que, por vezes, relacionam-na ao tripé "[...] pesquisa, sistema e sociedade [...]", em que a investigação aparece ou não incorporada ao processo; ou simplesmente a definem como um processo de comunicação dos resultados de pesquisa aos pares, situando-a em oposição ao processo de divulgação científica circunscrito à disseminação dos resultados de pesquisa ao público leigo. 
No que se refere à importância da comunicação científica para a evolução da ciência, Meadows (1999, p. vii) afirma que ela é tão vital para a ciência quanto a própria pesquisa científica, "[...] pois a esta não cabe reivindicar com legitimidade este nome enquanto não houver sido analisada e aceita pelos pares". Complementando essa ideia, Oliveira (2005, p. 34) coloca que a "[...] comunicação científica é um processo inerente ao fazer científico, e sua relevância sempre foi reconhecida pelos cientistas que, ao longo dos tempos, instituíram diferentes canais de intercâmbio". Ainda segundo a autora (2005, p. 35):

\begin{abstract}
A divulgação do andamento e dos resultados das pesquisas é de vital importância para que o ciclo da comunicação científica se complete (pesquisa - divulgação - leitura - validação e aceitação pelos pares - pesquisa), proporcionando o progresso da ciência com a geração de novos conhecimentos ou utilização de conhecimentos já produzidos.
\end{abstract}

Dada a importância da comunicação científica para o compartilhamento do conhecimento e avanço da ciência, faz-se necessário mencionar algumas das funções que Ihes são atribuídas (MENZEL apud TARGINO, 2000, p. 46):

a) responder questões específicas;

b) fornecer conteúdo para a atualização dos pesquisadores de um determinado campo científico;

c) promover o estudo de novos campos científicos;

d) indicar áreas emergentes;

e) redirecionar ou ampliar o rol de interesse dos pesquisadores;

f) validar novos conhecimentos científicos; e

g) aperfeiçoar a produção científica dos pesquisadores (feedback).

A comunidade científica vem utilizando diferentes canais para realizar a disseminação de informação científica entre seus pares, caracterizando as várias fases de sua evolução. Ao longo da história, os canais utilizados pelos cientistas vêm se modificando e reinventando, motivados pelas 
necessidades dos membros de sua comunidade e apoiados pelo desenvolvimento tecnológico. Segundo Meadows (1999, p. 1), a forma como os pesquisadores disseminam informação científica "[...] depende do veículo empregado, da natureza das informações e do público alvo. Da mesma forma que, com o passar do tempo, isso sofre mudanças, também sofrem alterações a formulação e o acondicionamento das informações".

No início, prevalecia a comunicação oral, de que são exemplos os debates filosóficos que tomavam a periferia de Atenas, nos séculos V e IV a.C. Os gregos também se utilizavam da comunicação escrita para transmitir o conhecimento, de que são testemunhas os vários manuscritos com os debates de Aristóteles, que influenciaram a cultura árabe e a europeia. Porém, a disseminação do conhecimento a partir da escrita somente obteve relevância com o advento da imprensa de Gutenberg, na Europa Ocidental do século XV. Os avanços dos métodos de impressão possibilitaram que as publicações se multiplicassem pelo continente europeu, constituindo-se em importante marco para a história da comunicação do conhecimento (MEADOWS, 1999).

Aliadas ao desenvolvimento da tipografia, a evolução dos sistemas postais e a publicação regular de "folhas noticiosas" que relatavam acontecimentos locais - consideradas precursoras do jornal moderno reuniram as condições que culminaram no incremento da comunicação entre os pesquisadores dos séculos XVI e XVII e no surgimento, na segunda metade do século XVII, do principal veículo utilizado para a comunicação do conhecimento: o periódico científico (MEADOWS, 1999).

O contexto da Segunda Guerra Mundial, por sua vez, agregou as condições para o surgimento da primeira geração de computadores, em 1945, propiciado por descobertas feitas ao longo dos séculos anteriores, como a invenção da calculadora, em 1623, e da máquina de escrever, em 1874, e, em 1936, o desenvolvimento do conceito de algoritmo (GOMES, 2012).

Em meados do século $X X$, o crescimento da produção científica e o acúmulo de artigos científicos, somados à dificuldade em utilizar e relacionar 
as informações disponíveis nas diversas áreas do conhecimento, apontaram os indícios de que o paradigma até então vigente - o da comunicação em meio impresso - necessitava de um novo formato para apoiar todo o processo de comunicação. Nesse contexto, surgiu a comunicação eletrônica, na metade do século XX, com o desenvolvimento de tecnologias que resultaram na criação da web $^{9}$ (CÔRTES, 2006).

Tanto o surgimento do computador como o advento da internet influenciaram fortemente a comunicação científica, que para Vickery (apud GOMES, 2012, p. 44) possui sua história composta por sete grandes períodos:

as civilizações antigas (cerca de 600 a.C.), a cultura clássica (600 a.C. até 500 d.C.), medieval (500-1450), a etapa da 'revolução científica' (1450-1700), os séculos XVIII, XIX e XX. E, a partir de cada fase é possível identificar as principais atividades científicas e técnicas, os papéis sociais que assumem um caráter de 'relevância' para a ciência em tal e qual período e os mecanismos decorrentes do avanço nas tecnologias da comunicação, dentre diversas outras correlações.

$\mathrm{Na}$ Figura 1, são apresentadas as fases da comunicação da informação de Barreto (1998), que servem para pontuar os paradigmas vigentes. Para cada fase, o autor relaciona as modificações na estrutura da comunicação da informação.

\footnotetext{
${ }^{9}$ Nome pelo qual a rede mundial de computadores internet se tornou conhecida, a partir de 1991, com a criação de uma interface gráfica que facilitou o acesso e estendeu seu alcance ao público em geral. Forma reduzida do termo em inglês "world wide web", literalmente "rede mundial da web". Disponível em: <http://houaiss.uol.com.br/busca?palavra=web>. Acesso em: 19 ago. 2013.
} 
Figura 1. Fases da comunicação da informação

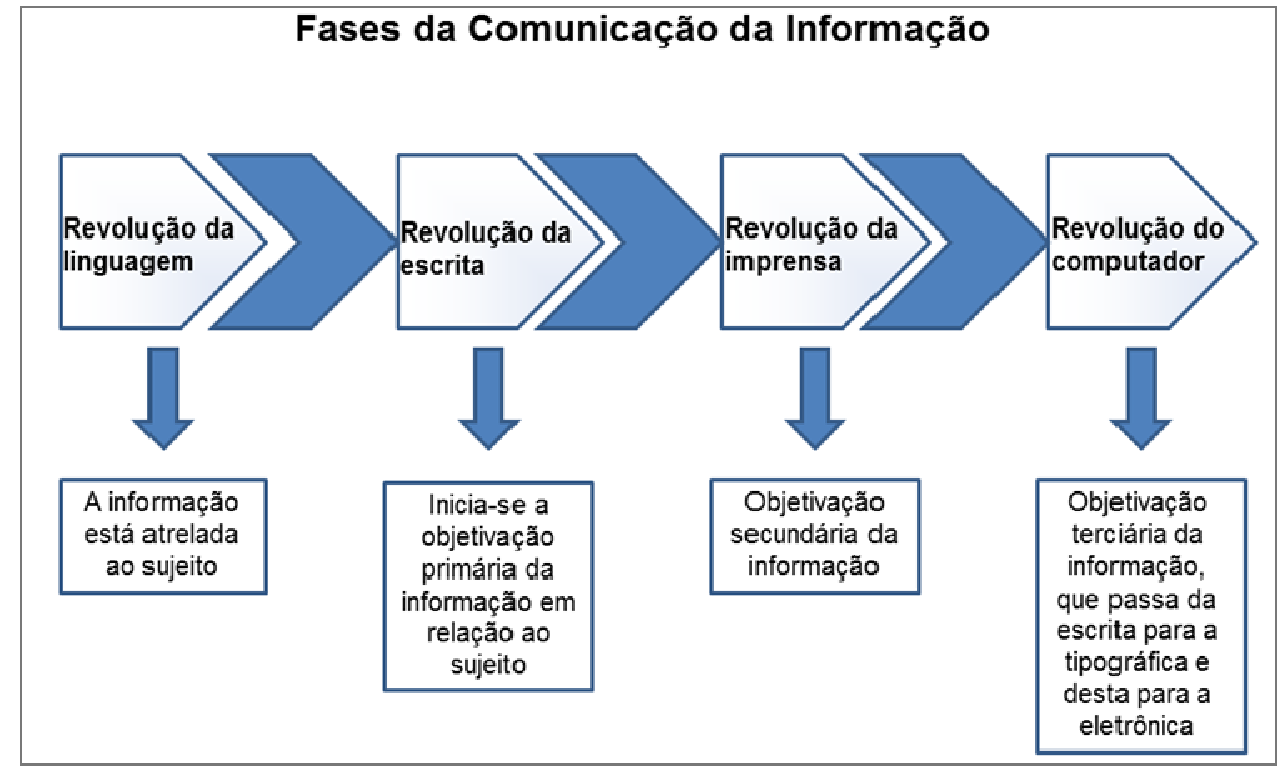

Fonte: baseado em Barreto (1998)

Côrtes (2006) faz uma analogia entre o conceito de paradigmas de Kuhn e a evolução da comunicação científica, com a apresentação dos principais canais utilizados para a transmissão da informação em cada fase - comunicação oral, comunicação escrita e comunicação online - conforme linha do tempo apresentada na Figura 2. 
Figura 2. Paradigmas da evolução da comunicação científica: oral, escrita e on-line

\begin{tabular}{|c|c|c|c|c|c|}
\hline \multicolumn{6}{|c|}{ Evolução da Comunicação Científica } \\
\hline \multirow[t]{2}{*}{$\begin{array}{l}\text { Idade Antiga } \\
\text { - Invençäão do } \\
\text { papel na China } \\
\text { - Utilizaçâo de } \\
\text { livros em papiro e } \\
\text { pergaminho para } \\
\text { o registro do } \\
\text { conhecimento } \\
\text { - Comunicação do } \\
\text { conhecimento } \\
\text { realizada } \\
\text { predominantemen } \\
\text { te de forma oral }\end{array}$} & $\begin{array}{l}\text { Idade Média } \\
\text { - Difusão do } \\
\text { papel no } \\
\text { Ocidente } \\
\text { - Cópias das } \\
\text { obras feittas } \\
\text { pelos monges } \\
\text { - Papel } \\
\text { substitui-se o } \\
\text { pergaminho }\end{array}$ & \multicolumn{2}{|c|}{$\begin{array}{l}\text { Idade Moderna } \\
\text {-Avanços nos métodos de } \\
\text { impressão (Gutenberg) } \\
\text { - Aumento das Universidades } \\
\text { - Aumento da difusão do } \\
\text { conhecimento } \\
\text { - Surgimento das Sociedades } \\
\text { Cientíicas e dos periódicos } \\
\text { cientificos } \\
\text { - Papel feito de trapos de linho e } \\
\text { algodão (duráveis) }\end{array}$} & \multicolumn{2}{|c|}{$\begin{array}{l}\text { Idade Contemporânea } \\
\text { - Procura por novos materiais } \\
\text { para fabricaçăo do papel, } \\
\text { abundantes e baratos } \\
\text { - 1850: madeira é utilizada para a } \\
\text { fabricaçäo do papel (pouco } \\
\text { resistente) } \\
\text { - Web: possibilidade e desa fios } \\
\text { ainda não explorados } \\
\text { - Democratizaçäo do acesso à } \\
\text { informação cientifica }\end{array}$} \\
\hline & $\begin{array}{r}\text { Satu } \\
\text { devido } \\
\text { confia }\end{array}$ & $\begin{array}{l}\text { ação } \\
\text { pouca } \\
\text { lildade }\end{array}$ & $\begin{array}{c}\text { Comunicação } \\
\text { Predominantemente } \\
\text { Escrita }\end{array}$ & $\begin{array}{c}\uparrow \\
\begin{array}{r}\text { Quebra de } \\
\text { paradigma }\end{array} \\
\uparrow \\
\text { uraçäo pelo aca } \\
\text { artigos e dificul } \\
\text { utilizar e relacio } \\
\text { informaçóes }\end{array}$ & $\begin{array}{l}\text { Comunicação } \\
\text { Predominantemente } \\
\text { Online }\end{array}$ \\
\hline
\end{tabular}

Fonte: elaborado a partir de Côrtes (2006)

O surgimento da comunicação eletrônica, na metade do século $X X$, alterou significativamente o processo de comunicação científica, desde a concepção de uma nova informação até sua manipulação, disseminação à comunidade científica e utilização para a geração de novos conhecimentos, tornando-o mais dinâmico e promovendo maior acesso aos resultados de pesquisa.

Segundo Oliveira e Noronha (2005, p. 82):

O impacto das novas tecnologias de informação na comunicação científica tem sido marcante. O uso de recursos eletrônicos na comunicação entre pesquisadores é predominante nos dias atuais, o que tem modificado o processo de comunicação científica, com - estabelecimento de uma nova categoria - comunicação científica eletrônica.

Segundo Castro (2006, p. 59), a internet modificou o modo de se produzir ciência, "[...] com a integração da comunidade científica com outros setores da sociedade, atuando em redes transdisciplinares e heterogêneas 
de colaboração entre instituições de natureza variada". Ainda segundo a autora (p. 58), no fluxo da comunicação científica tradicional as etapas ocorrem de maneira sequencial e se constituem reflexo do "[...] modelo de publicação impressa e pode ser descrito esquematicamente em cinco etapas: redação, revisão, publicação, indexação e disseminação". Com o meio eletrônico "o processo de produção do conhecimento científico passou a ser não-linear (Figura 3), com participação de todos os interessados, desde o momento da concepção das pesquisas até a aplicação de seus resultados" (CASTRO, 2006, p. 59).

Figura 3. Evolução do fluxo de comunicação científica: fluxo tradicional e eletrônico

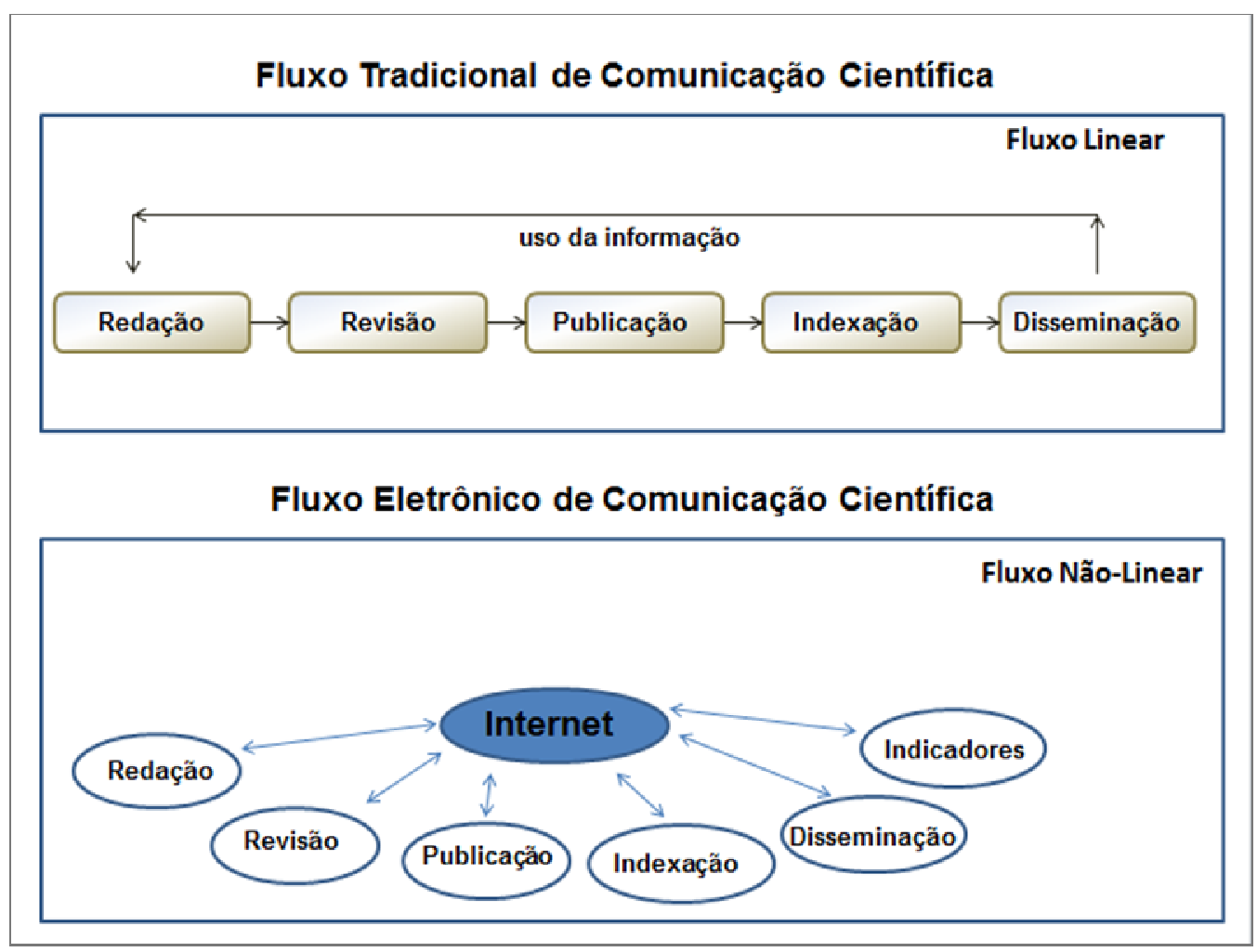

Fonte: baseado em Castro (2009)

Dentre as vantagens proporcionadas à comunicação científica pelos meios eletrônicos, Schweitzer, Rodrigues e Rados (2011) colocam em destaque o menor tempo de execução das atividades do processo de 
comunicação, a maior visibilidade e atualidade dos artigos publicados e a dissolução de barreiras geográficas impostas pela publicação impressa.

Oliveira e Noronha (2005) colocam que a utilização do meio eletrônico propicia o compartilhamento de informação e a interatividade entre os pesquisadores de diferentes disciplinas e regiões geográficas, possibilitando o desenvolvimento de pesquisas cooperativas e de trabalhos com autoria múltipla, bem como o desenvolvimento de relações interdisciplinares.

Além de abrir novas possibilidades de interação e compartilhamento da informação científica, a publicação eletrônica trouxe avanços notórios à produção de indicadores para a avaliação da produção científica. Para Lima e Velho (2008, p. 3) os avanços das tecnologias de informação e comunicação (TIC) e, consequentemente, a proliferação das bases de dados, possibilitaram "[...] o acesso e a manipulação de grandes volumes de dados [...]" e a utilização da bibliometria como um recurso para a mensuração científica.

Para Baptista et al. (2007, p. 3) as discussões relacionadas ao uso de tecnologia no processo de comunicação científica estão consolidadas na literatura científica e podem ser resumidas a partir de três aspectos:

\begin{abstract}
O primeiro, o processo de comunicação científica baseado no meio eletrônico, resultado do uso de tecnologias de informação e comunicação para disseminação da pesquisa. O segundo, os impactos que esse uso provoca na própria comunicação científica e nas comunidades científicas, resultado de mudanças observadas nas práticas dos pesquisadores. E, por último, mas não somente, as reações dos pesquisadores aos modelos de negócios para a publicação científica, que não exploram as potencialidades das tecnologias disponíveis, não permitindo, por conseguinte, os benefícios delas advindos.
\end{abstract}

Barreto (1998) aponta as principais mudanças ocorridas na estrutura do fluxo de informação com o advento do meio eletrônico: a) interação do receptor com a informação, sem intermediação; b) interação com o fluxo informativo em tempo real; c) possibilidade de elaborar informação combinando texto, imagem e som; e d) espaço de comunicação ampliado por uma conexão em rede. 
O fluxo tradicional de comunicação científica apresenta limitações que restringem $o$ acesso aos documentos publicados, atingindo especialmente os países em desenvolvimento. Por exemplo, no modelo tradicional, o processo de publicação de um artigo científico - que inclui a preparação dos manuscritos, aprovação, edição, impressão e distribuição - poder levar de meses a anos, dependo da forma como é realizada a gestão editorial do periódico. No fluxo tradicional, o acesso ao documento impresso é dificultado tanto pelas barreiras impostas pelo formato como pelos custos elevados de assinaturas e distribuição. Além disso, a publicação em formato impresso exige contínua ampliação dos espaços para alocação das coleções (CASTRO, 2006).

O fluxo da comunicação científica em ambiente eletrônico propicia a interação entre produtores (autores, revisores e editores), intermediários (bibliotecas e centros de informação) e usuários de informação (leitores e pesquisadores), além de estimular a troca de dados e experiências, deixando de se constituírem em barreiras as distâncias físicas entre os vários atores (CASTRO, 2006).

Gomes, em estudo realizado em 2012, retratou a evolução do conhecimento produzido na área de comunicação científica, apontando os principais modelos desenvolvidos por diferentes autores que contribuíram para o entendimento e a sistematização do fluxo de comunicação científica em contextos históricos diversos, desde a comunicação impressa até a eletrônica, conforme resumo contido no Quadro 5. 
Quadro 5. Evolução dos modelos para a sistematização do fluxo de comunicação científica

\begin{tabular}{|c|c|c|}
\hline Autor & Data & Modelo \\
\hline $\begin{array}{l}\text { UNESCO, } \\
\text { ICSU }\end{array}$ & 1971 & $\begin{array}{l}\text { UNISIST: o modelo inclui os canais informais, semiformais e formais e a } \\
\text { comunicação perpassa pelas "unidades organizacionais (editores, bibliotecas, } \\
\text { centros de informação, dentre outras) e documentais (livros, periódicos, teses, } \\
\text { relatórios, bibliografias específicas etc.)" (SONDERGARD et al., 2003); questiona a } \\
\text { necessidade de elementos básicos utilizados na comunicação, como as resenhas, e } \\
\text { a ausência de dicionários, glossários, manuais e enciclopédias. }\end{array}$ \\
\hline $\begin{array}{l}\text { Garvey e } \\
\text { Griffith }\end{array}$ & 1979 & $\begin{array}{l}\text { Sistema de comunicação científica: mapeamento do sistema de comunicação } \\
\text { científica na área de psicologia, desde a elaboração de um projeto de pesquisa até a } \\
\text { divulgação de seus resultados. O modelo foi desenvolvido tendo como base a } \\
\text { comunicação em meio impresso, sendo aplicado para o entendimento do processo } \\
\text { de comunicação científica em distintas áreas do conhecimento. Inclui os canais e a } \\
\text { produção de diferentes documentos nos vários estágios da pesquisa. }\end{array}$ \\
\hline \multirow{5}{*}{ Hurd } & \multirow{5}{*}{1996} & $\begin{array}{l}\text { Releitura do tradicional modelo de Garvey/Griffith: faz uma reavaliação do modelo } \\
\text { de Garvey e Griffith, considerando o advento da internet. }\end{array}$ \\
\hline & & $\begin{array}{l}\text { Modernized Garvey/Griffith: destaca o impacto das tecnologias de informação nos } \\
\text { elementos tradicionais contidos no modelo de Garvey e Griffith, contextualizando o } \\
\text { processo de comunicação científica com a introdução de elementos eletrônicos. }\end{array}$ \\
\hline & & $\begin{array}{l}\text { Modelo "no journal": elimina o periódico como unidade de distribuição e coloca o } \\
\text { artigo e o relatório de pesquisa como unidade principal. Descreve como a rede de } \\
\text { comunicação pode apoiar a distribuição de artigos eletrônicos. Inclui a manutenção } \\
\text { do processo de avaliação por pares para a validação do conhecimento científico. }\end{array}$ \\
\hline & & $\begin{array}{l}\text { Modelo "unvetted": exclui o processo de avaliação por pares e faz uma análise do } \\
\text { "primeiro repositório de documentos eletrônicos com o princípio dos arquivos } \\
\text { abertos, o ArXiv, criado em } 1991 \text { pelo físico Paul Ginsparg." }\end{array}$ \\
\hline & & $\begin{array}{l}\text { Modelo "collaboratory": inclui um ambiente colaborativo, com a rede mundial de } \\
\text { computadores interligando uma comunidade global de pesquisa. Nesse contexto, os } \\
\text { pesquisadores fariam o intercâmbio de dados e utilizariam os recursos de uma } \\
\text { biblioteca virtual, eliminando assim as barreiras geográficas. Os dados passam a ser } \\
\text { a unidade de troca de informação. }\end{array}$ \\
\hline Hurd & 2000 & $\begin{array}{l}\text { Modelo para } 2020 \text { : o manuscrito passa a ser a unidade básica da comunicação } \\
\text { científica e sua publicação no periódico constitui-se mais um dos resultados da } \\
\text { pesquisa, ao término da comunicação formal e informal entre indivíduos e grupos. }\end{array}$ \\
\hline $\begin{array}{l}\text { Shearer; } \\
\text { Birsall }\end{array}$ & 2002 & $\begin{array}{l}\text { Sistema de CC canadense : os atores sociais sofrem o impacto de forças externas } \\
\text { (tecnologia, globalização, economia, alterações dos padrões de pesquisa e políticas } \\
\text { públicas) que provocam alterações no sistema de comunicação científica. }\end{array}$ \\
\hline \multirow{5}{*}{$\begin{array}{l}\text { Sondergaard } \\
\text { et al. }\end{array}$} & \multirow{5}{*}{2003} & $\begin{array}{l}\text { Modificação do mdelo de Garvey/Griffith: revisa o modelo tradicional de Garvey e } \\
\text { Griffith, incluindo uma análise dos impactos da internet na comunicação científica e } \\
\text { as diferenças existentes entre as disciplinas. }\end{array}$ \\
\hline & & $\begin{array}{l}\text { Modelo "the communication of internet-based scholary information": representa } \\
\text { uma atualização do modelo UNISIST no que se refere aos documentos eletrônicos, } \\
\text { sendo, segundo os autores, mais abrangente que outros modelos desenvolvidos } \\
\text { com enfoque nesse suporte. }\end{array}$ \\
\hline & & $\begin{array}{l}\text { Modelo "the communication of scholary information": realiza a integração do } \\
\text { modelo UNISIST com a internet, incluindo os canais tradicionais e os "mediados por } \\
\text { computador". }\end{array}$ \\
\hline & & $\begin{array}{l}\text { Releitura do modelo UNISIST- "domain analytic approach": representa a base } \\
\text { científica de uma área, considerando o universo transdisciplinar. Nesse modelo, } \\
\text { produtores, usuários e intermediários de conhecimento são os membros da } \\
\text { comunidade. }\end{array}$ \\
\hline & & $\begin{array}{l}\text { Outputs para a produção do conhecimento: inclui o contexto disciplinar e inputs e } \\
\text { outputs para a geração do conhecimento científico. }\end{array}$ \\
\hline $\begin{array}{l}\text { Relatório } \\
\text { LiquidPub }\end{array}$ & 2007 & $\begin{array}{l}\text { Ciclo de publicação científica: este modelo considera os editores como } \\
\text { intermediários entre autores e seus leitores-alvo, em um contexto de demanda em } \\
\text { que as bibliotecas possibilitam o acesso à literatura publicada. }\end{array}$ \\
\hline Costa & 2008 & $\begin{array}{l}\text { Adaptação do modelo de Garvey/Griffith: adapta o modelo tradicional, que reflete a } \\
\text { coexis tência dos meios impresso e eletrônico, estabelecendo uma relação de } \\
\text { complementaridade crescente do meio eletrônico em relação ao meio impresso. }\end{array}$ \\
\hline
\end{tabular}

Fonte: elaborado com base em Gomes (2012) 
Os vários modelos desenvolvidos para sistematizar o fluxo de comunicação científica refletem seu desenvolvimento ao longo da história, bem como imprimem às questões surgidas no âmbito da comunicação científica novas perspectivas, como: o advento da internet, que introduziu o artigo como unidade principal de acesso à informação científica; a reestruturação ou exclusão do processo de peer review; os colégios invisíveis virtuais; a inclusão de agentes externos no processo de comunicação científica; ênfase nas diferenças disciplinares; consideração dos conceitos de inputs e outputs na geração do conhecimento científico; e inclusão do documento impresso e eletrônico em um mesmo momento histórico, o que reflete a atualidade. Enfim, esses modelos expressam o caminho trilhado pela comunicação científica e os esforços de pesquisadores para entender as mudanças de paradigma e projetar suas consequências, como ocorrido com o advento da comunicação eletrônica.

A era eletrônica influenciou fortemente o processo de comunicação científica, produzindo efeitos que vão além das vantagens advindas da publicação eletrônica: incluiu mudanças significativas na cultura científica; dinamizou os processos de publicação, disseminação e acesso à literatura científica; incrementou as formas de avaliação dos resultados de pesquisa; e criou condições férteis para o surgimento do movimento de acesso aberto à informação científica.

\subsection{ACESSO ABERTO AO CONHECIMENTO CIENTÍFICO}

O acesso aberto ao conhecimento científico constitui-se uma das vantagens proporcionadas pelas tecnologias de informação e da comunicação, representando um dos mais expressivos acontecimentos dos últimos tempos, no que se refere à comunicação científica. Dentre os seus benefícios, pode-se citar a promoção do compartilhamento de informação científica, que é responsável por subsidiar a geração de novos conhecimentos, inovação e, consequentemente, pelo desenvolvimento da ciência e das nações. 
Para Suber (apud BAPTISTA et al., 2007, p. 5) o acesso livre ao conhecimento científico "[...] diz respeito à acessibilidade ampla e irrestrita a conteúdos disponíveis em formato digital, no sentido em que remove barreiras de preço e de permissão, tornando a literatura científica disponível com o mínimo de restrições de uso". Para que se caracterize como acesso aberto pleno é necessário o atendimento de três condições essenciais: "[...] fácil acesso online; disponível para qualquer pessoa sem custo; disponível para usos adicionais sem restrições" (CAMARGO JR., 2013, s.n.).

O acesso aberto tem como princípio "[...] a disseminação ampla e irrestrita dos resultados de pesquisas financiadas com recursos públicos" (BAPTISTA et al., 2007, p. 2). Para Rodrigues e Oliveira (2012, p. 80), “[...] o movimento a favor do Acesso Aberto se baseia no pressuposto de que todas as publicações financiadas com recursos públicos já estão pagas e devem estar disponíveis para todos, sem custo adicional".

$\mathrm{Na}$ Declaração de Budapest (Budapest Open Access Initiative $\mathrm{BOAI}$ ) o acesso aberto pode ser definido como a disponibilidade gratuita do conhecimento científico na internet (BOAI apud GUANAES; GUIMARAES, 2012, p. 62):

\begin{abstract}
permitindo a qualquer usuário ler, baixar arquivo, copiar, distribuir, imprimir, buscar ou fazer um link para os textos completos desses artigos, rastreá-los para indexação, passá-los como dados para software ou usá-los para qualquer outro propósito legal, sem barreiras financeiras, legais ou técnicas, a não ser aquelas inseparáveis do acesso à própria internet.
\end{abstract}

Segundo Chinchilla-Rodrígues, Miguel e Moya-Aragón (2012), o movimento de acesso aberto à literatura científica é uma alternativa ao modelo tradicional de disseminação e acesso ao conhecimento científico por meio de pagamento de assinaturas, que vigorou por mais de 300 anos.

O movimento de acesso aberto surgiu na década de 90 do século $X X$, especialmente nos Estados Unidos e Europa Ocidental, em um momento de acentuado crescimento da produção científica e de intensa comercialização do conhecimento científico. Sua origem está associada a uma reação dos pesquisadores aos elevados preços das assinaturas, bem como ao modelo 
de negócio praticado pelas editoras comerciais de periódicos científicos (BAPTISTA et al., 2007).

A disseminação dos resultados de pesquisa se concentrava nas editoras comerciais que dominavam o mercado dos periódicos científicos. Os elevados preços das assinaturas levaram à chamada "crise dos periódicos" (serial crisis), obrigando as bibliotecas e unidades de informação a cancelarem suas assinaturas. Conforme dados da Association of Research Libraries, dos Estados Unidos, no período de 1986 a 2004 os gastos com assinaturas de periódicos sofreram um acréscimo de 273\% (CAMARGO JR, 2013, s.n.). Para King e Tenopir (apud GOULART; CARVALHO, 2008, p. 843):

O efeito sobre o preço das assinaturas foi considerável. Estimativas indicam que, num período de 20 anos, os preços das revistas norte-americanas (a grande maioria dos títulos indexados no $\mathrm{SCl}$ e também nas de maiores índices de impacto) aumentaram de U\$ 39 em média, em 1975, para U\$284, em 1995.

Porém, a reação dos pesquisadores não se deu somente devido aos elevados preços das assinaturas, mas também ao modelo de negócios da publicação científica. De acordo com Camargo Jr. (2013, s.n.):

os insumos básicos necessários à publicação (artigos e serviços editoriais) são providos às editoras (publishers) a custo zero (ou, no máximo, simbólico; alguns editores recebem pequena remuneração) e os compradores do produto ainda subsidiam a produção, uma vez que pagam salários de autores e editores. Adicionalmente, produziu-se um mercado concentrado, do qual se estima que três gigantes (Reed Elsevier, Springer and Wiley) respondam por mais de $40 \%$ dos periódicos existentes. [...] Agreguem-se a isso práticas comerciais abusivas, como o "empacotamento" (bundling) da assinatura de diversas revistas, forçando bibliotecas universitárias a adquirir periódicos nos quais não teriam interesse para terem acesso aos que de fato querem. Essas práticas só são viáveis num mercado fortemente oligopolizado, como é o caso da publicação comercial, e controlado por pequeno número de editoras de grande porte e alcance global.

Outro fator que corroborou o desenvolvimento do acesso aberto foi a constatação, pela comunidade científica, de que a disponibilização dos documentos científicos sem restrições de acesso, à medida que promovia acessibilidade ampla e irrestrita aos resultados de pesquisa, possibilitava 0 
aumento das citações e do impacto desses resultados (BAPTISTA et al., 2007). Segundo Guanaes e Guimarães (2012, p. 58), a incorporação das tecnologias de informação e o movimento de acesso aberto ao processo de comunicação científica são apontados como "[...] uma alternativa ímpar para maximizar a acessibilidade e o impacto da informação".

O acesso aberto encontrou na Convenção de Santa Fé, no Novo México (EUA), em 1999, a base tecnológica para o empreendimento de suas ações. Com o desenvolvimento do repositório arXiv outras iniciativas de repositório começaram a surgir e, com isso, a necessidade de integrá-los. Nesse contexto foi realizada, então, a convenção, dedicada à discussão de um modelo de interoperabilidade para integrar as iniciativas de repositórios de e-prints. Teve como resultado o estabelecimento do modelo OAI (open archives initiatives), viabilizando, assim, as ações do acesso aberto no mundo (IBICT, 20-?).

O modelo OAl teve como meta principal contribuir para a transformação da comunicação científica, a partir da "[...] definição de aspectos técnicos e de suporte organizacional de uma estrutura de publicação científica aberta, na qual ambas, a camada comercial e livre, possam se estabelecer [...]" (BAPTISTA et al., 2007, p. 9). Desde então, as discussões em torno do acesso aberto ao conhecimento científico tem movimentado o ambiente acadêmico, constituindo-se tema de diversos eventos científicos em todo o mundo.

O encontro em Budapeste, promovido pelo Open Society Institute (OSI), em 2001, foi o ponto de partida do movimento de acesso aberto. Teve como resultado a formalização, em 2002, da Declaração de BOAI, que o define e recomenda duas estratégias complementares de apoio ao movimento: a) o auto-arquivamento dos artigos pelos autores em repositórios temáticos ou institucionais; e b) a publicação de artigos em periódicos científicos de acesso aberto, que não cobram assinaturas ou taxas de acesso. A primeira estratégia é conhecida como via verde e a segunda, via dourada (GUMIEIRO; COSTA, 2012; GOULART; CARVALHO, 2008; SANTOS, 2010; BAPTISTA et al., 2007; IBICT, 20-?). 
Chan, Kirsop e Arunachalam (apud GUMIEIRO; COSTA, 2012, p. 103) definem a via verde como:

\begin{abstract}
repositórios eletrônicos que incluem não só artigos submetidos ao processo tradicional de revisão dos pares (postprints), como, também, versões eletrônicas preliminares de documentos científicos (pré-prints), teses, manuais, materiais de ensino ou qualquer outro tipo de material que os autores ou sua instituição desejem que se tornem disponíveis para o público.
\end{abstract}

Por sua vez, a via dourada é definida por Chan, Kirsop, Arunachalam (apud GUMIEIRO; COSTA, 2012, p. 103) como:

um modelo em que taxas de assinatura e de acesso não são cobradas dos leitores, além do que os direitos autorais permanecem com os autores. Como dito anteriormente, 0 periódico científico é considerado em muitas disciplinas como o principal meio de comunicação entre os cientistas. Disponibilizar o amplo acesso a esse veículo é uma conquista para a comunidade científica, principalmente para aqueles pesquisadores que não têm condições financeiras para pagar as taxas de acesso impostas pelo sistema tradicional de publicação.

Para Goulart e Carvalho (2008, p. 843), a Declaração de Budapeste possibilitou a realização de um serviço público sem precedentes, que resultou da "[...] convergência de uma velha tradição e uma nova tecnologia. A velha tradição: a vontade dos cientistas e pesquisadores em dar a conhecer os resultados de seus trabalhos. A nova tecnologia: a Rede Mundial de Computadores".

Ela foi seguida pela Declaração de Bethesda, que é resultado de um encontro realizado em Maryland, Estados Unidos, em 2003, pelo Howard Hughes Medical Institute. O encontro teve como objetivo promover discussões entre os pesquisadores da área biomédica sobre as condições de concessão do acesso aberto à literatura científica (GUMIEIRO; COSTA, 2012; GOULART; CARVALHO, 2008; SANTOS, 2010; BAPTISTA et al., 2007; IBICT, 20-?).

A Declaração de Bethesda indica as condições que uma publicação deve reunir para que seja considerada em acesso livre (IBICT, 20-?):

a) concessão de direito de acesso gratuito, irrevogável, mundial e perpétuo; licença para copiar, utilizar, distribuir, transmitir e exibir o trabalho publicamente assim como realizar e distribuir obras 
derivadas, em qualquer suporte digital e com qualquer propósito responsável, sujeito à correta atribuição da autoria;

b) versão completa da obra e todos os materiais suplementares, depositada imediatamente após a publicação inicial, em pelo menos um repositório em linha que seja mantido por uma instituição acadêmica, sociedade científica, agência governamental, ou outra organização reconhecida que pretenda promover o acesso livre, a distribuição irrestrita, a interoperabilidade, e o arquivamento em longo prazo.

A Declaração de Berlim, elaborada também em 2003, a partir de uma reunião promovida pelo Max Planck Institute, complementou o processo, formando as Declarações BBB (Budapeste, Bethesda e Berlim), que se constituem os principais documentos de apoio ao movimento de acesso aberto ao conhecimento científico.

A reunião de Berlim, além de ratificar as recomendações de Budapeste e Bethesda, teve como objetivo discutir formas de promover os princípios do acesso aberto entre os pesquisadores e bolsistas, bem como desenvolver meios de avaliação e reconhecimento das contribuições disponibilizadas em canais de acesso aberto (IBICT, 20-?; SANTOS, 2010).

Após as Declarações BBB, outras manifestações de apoio ao movimento surgiram, ratificando conceitos e recomendações e debatendo políticas que visam à sua promoção em várias regiões do mundo. Conforme registros apresentados no Open Access Directory $\left(O A D^{10}\right)$, no período de 1991 a 2011 foram elaboradas mais de 70 declarações relacionadas ao movimento de acesso aberto em todo o mundo. Os dados apresentados pelo OAD mostram também que as declarações Campinas Statement on Open Access e Declaration from Buenos Aires on information, documentation and libraries, elaboradas em 2004, marcaram o início dos debates sobre o acesso aberto ao conhecimento científico na América Latina.

Norteadas pelas Declarações BBB, as instituições a seguir estabeleceram políticas e ações que visam à promoção do acesso aberto (COSTA, 2008, p. 228):

\footnotetext{
${ }^{10}$ Disponível em: $<$ http://oad.simmons.edu/oadwiki/Declarations in support of $\mathrm{OA}>$. Acesso em: 21 mar. 2013.
} 
- National Institutes of Health (NIH), Estados Unidos - maior agência governamental de fomento da pesquisa na área de saúde dos Estados Unidos, o NIH elaborou e operacionalizou, desde 2005, uma política de acesso aberto. Esta, por sua vez, a partir de abril de 2008, passou a ser obrigatória no sentido em que requer 0 depósito compulsório, em seu repositório institucional, o PubMedCentral, de todo resultado de pesquisa financiada pela agência, publicado em periódico científico. $O$ modelo foi reproduzido no Reino Unido e em alguns outros países, para a área das Ciências da Saúde;

- Wellcome Trust, Reino Unido - uma das maiores agências privadas de fomento do Reino Unido, decidiu, à mesma época que o $\mathrm{NIH}$, política semelhante para as pesquisas por ela financiadas, isto é, a obrigatoriedade do depósito no PubMEd Central UK;

- Research Councils, Reino Unido - são sete os conselhos de pesquisa do Reino Unido, distribuídos por áreas do conhecimento. Tais conselhos adotaram, gradual e crescentemente (nem todos ao mesmo tempo), políticas de depósito compulsório para as publicações de pesquisas por eles financiadas. São, tal como o CNPq no Brasil, as agências governamentais de fomento à pesquisa naquele país;

- Harvard University, Estados Unidos - as Faculdades de Ciências e Artes e de Direito, da Universidade de Harvard adotaram, recentemente, políticas de depósito compulsório. Isso, como não poderia deixar de ser, significa que, seja qual for o editor das publicações em que seus pesquisadores publicarem seus trabalhos, há que ser realizado o depósito de uma cópia deles no repositório da instituição;

- University of Southampton, Inglaterra - pioneira nessas questões no Reino Unido, a Universidade de Southampton não se limitou a definir políticas de depósito compulsório. Na verdade, foram criadas estratégias para que os trabalhos cujos depósitos não permitem o acesso (acesso embargado) possam, mesmo assim, ser lidos. Trata-se da ação de requerer uma cópia diretamente do autor.

- Stanford University, Estados Unidos - a Faculdade de Educação da Universidade de Stanford decidiu, tal como colegas de Harvard e Southampton, prover acesso aberto a artigos científicos publicados por seus pesquisadores.

- Capes, Brasil - a agência definiu, desde 2006, política que requer o depósito compulsório de teses e dissertações defendidas no Brasil na Biblioteca Digital e Teses e Dissertações, a qual está disponível em ambiente interoperável e de acesso aberto.

Tanto a via verde como a via dourada tem apresentado progressos, e diversos estudos e fontes de informação sobre o tema comprovam essa assertiva. No Brasil, o Instituto Brasileiro de Informação em Ciência e Tecnologia vem promovendo a criação de repositórios digitais de acesso aberto. Como exemplos pode-se citar: Diálogo Científico (DiCi), MTD-Br, 
Sistema TEDE, Portal Oasis.br, Sistema Dspace, Biblioteca Digital Brasileira de Teses e Dissertações (BDTD) e Biblioteca Digital Brasileira.

As primeiras iniciativas de repositórios tiveram origem na década de 1980 e início dos anos 1990, cujos exemplos conhecidos são o arXiv, RePec e PubMed, ainda hoje destinados a disciplinas acadêmicas. No início de 2000 proliferaram os repositórios institucionais, que rapidamente superaram os temáticos ou disciplinares (XIA, 2012). A partir de dados disponíveis no Registry of Open Access Repositories $\left(R_{0 A R}{ }^{11}\right)$ é possível verificar a existência de mais de 2.800 repositórios de diferentes países. Além do ROAR, outros sites disponibilizam dados sobre repositórios temáticos e institucionais, como o OpenDOAR ${ }^{12}$.

Quanto aos avanços da via dourada, os dados apresentados pelo Directory of Open Access Journals $\left(D O A J^{13}\right)$ indicam que, em maio de 2013, existiam 9.369 periódicos com acesso aberto registrados no diretório, originários de 119 países. A Tabela 1 mostra dados de ingresso de periódicos no DOAJ, no período de 2002 a 2013, referentes aos 20 países com o maior número de periódicos com acesso aberto no mundo, bem como a posição ocupada pelo Brasil, abaixo apenas dos Estados Unidos.

\footnotetext{
${ }^{11}$ Documento não paginado da web. Disponível em: <http://roar.eprints.org/view/geoname/>. Acesso em: 19 mar. 2013.

${ }_{12}$ Documento não paginado da web. Disponível em: <www.opendoar.org>. Acesso em: 17 mar. 2013.

${ }^{13}$ Documento não paginado da web. Disponível em:

<http://www.doaj.org/doaj?func=byCountry\&uiLanguage=en>. Acesso em: 10 abr. 2013.
} 
Tabela 1. 20 países com maior número de periódicos com acesso aberto no mundo

\begin{tabular}{|l|l|r|r|r|r|r|r|r|r|r|r|r|r|r|}
\hline \multirow{2}{*}{ Country } & \multicolumn{9}{|c|}{ Number of journals added into DOAJ } & \multirow{2}{*}{ Total } \\
\cline { 2 - 16 } & & 2002 & 2003 & 2004 & 2005 & 2006 & 2007 & 2008 & 2009 & 2010 & 2011 & 2012 & 2013 & \\
\hline 1 & United States & 16 & 196 & 83 & 86 & 51 & 85 & 177 & 105 & 158 & 217 & 89 & 69 & 1332 \\
\hline 2 & Brazil & 0 & 8 & 117 & 47 & 51 & 55 & 72 & 44 & 135 & 131 & 141 & 77 & 878 \\
\hline 3 & United Kingdom & 5 & 106 & 41 & 38 & 37 & 31 & 32 & 56 & 117 & 45 & 65 & 30 & 603 \\
\hline 4 & India & 0 & 14 & 16 & 14 & 15 & 17 & 22 & 47 & 126 & 92 & 95 & 92 & 550 \\
\hline 5 & Spain & 0 & 5 & 16 & 59 & 49 & 27 & 62 & 27 & 77 & 71 & 49 & 38 & 480 \\
\hline 6 & Egypt & 3 & 0 & 1 & 4 & 8 & 17 & 28 & 66 & 31 & 126 & 66 & 36 & 386 \\
\hline 7 & Germany & 4 & 12 & 20 & 34 & 26 & 32 & 27 & 23 & 36 & 28 & 17 & 31 & 290 \\
\hline 8 & Romania & 0 & 4 & 1 & 0 & 7 & 5 & 12 & 36 & 79 & 71 & 33 & 34 & 282 \\
\hline 9 & Canada & 0 & 24 & 11 & 10 & 15 & 15 & 26 & 30 & 46 & 44 & 34 & 15 & 270 \\
\hline 10 & Italy & 0 & 4 & 9 & 18 & 16 & 12 & 12 & 28 & 45 & 48 & 37 & 37 & 266 \\
\hline 11 & Turkey & 0 & 4 & 7 & 21 & 10 & 11 & 22 & 24 & 36 & 44 & 30 & 29 & 238 \\
\hline 12 & Colombia & 0 & 2 & 2 & 6 & 19 & 19 & 18 & 26 & 19 & 33 & 59 & 22 & 225 \\
\hline 13 & Iran & 0 & 0 & 0 & 5 & 6 & 12 & 11 & 10 & 31 & 45 & 47 & 44 & 211 \\
\hline 14 & France & 0 & 10 & 6 & 21 & 9 & 10 & 17 & 9 & 36 & 18 & 39 & 13 & 188 \\
\hline 15 & Poland & 0 & 9 & 4 & 8 & 9 & 7 & 19 & 6 & 16 & 48 & 16 & 14 & 156 \\
\hline 16 & Chile & 0 & 3 & 41 & 19 & 13 & 7 & 14 & 10 & 14 & 6 & 14 & 9 & 150 \\
\hline 17 & Mexico & 0 & 1 & 4 & 26 & 16 & 12 & 14 & 8 & 10 & 18 & 20 & 16 & 145 \\
\hline 18 & Switzerland & 2 & 7 & 4 & 8 & 4 & 1 & 18 & 14 & 23 & 24 & 31 & 8 & 144 \\
\hline 19 & Argentina & 0 & 0 & 1 & 8 & 11 & 14 & 14 & 8 & 28 & 26 & 24 & 9 & 143 \\
\hline 20 & Australia & 0 & 15 & 13 & 11 & 7 & 10 & 8 & 13 & 19 & 21 & 5 & 7 & 129 \\
\hline & Total & 30 & 424 & 397 & 443 & 379 & 399 & 625 & 590 & 1082 & 1156 & 911 & 630 & 7066 \\
\hline
\end{tabular}

Fonte: portal DOAJ (http://www.doaj.org/doaj?func=byCountry\&uiLanguage=en)

A partir da Tabela 1 também é possível verificar que a difusão do conceito e das práticas do acesso aberto se deu de formas distintas nos vários países e regiões do mundo, considerando tanto a via verde como a dourada. Conforme cronograma da expansão do acesso aberto, elaborado por Peter Suber, antes dos anos 1990 o movimento predominava nos Estados Unidos. No início da mesma década surgiram os primeiros esforços na Europa Ocidental e, após a virada do milênio, começou a se espalhar por outras regiões. Porém, ainda hoje, alguns países em desenvolvimento, em particular os da África, estão lutando pela difusão do conceito e das práticas do acesso aberto, bem como pela construção de um sistema efetivamente aberto (XIA, 2012).

Estudos recentes sobre o acesso aberto na América Latina atribuem o avanço do movimento na região a motivações que diferem das que o 
impulsionaram na Europa, nos Estados Unidos e no Canadá. Para Figari (apud RODRIGUE; OLIVEIRA, 2012, p. 78) "[...] o conceito de Acesso Aberto na América Latina tem uma abordagem própria, uma vez que a questão principal é atender à falta de periódicos e não apenas reagir ao custo elevado das publicações".

Desde sua origem o acesso aberto tem motivado a realização de diversas reuniões, a elaboração de vários documentos de apoio ao movimento e se constituído em tema de diversos estudos que consideram seus diferentes aspectos, como o impacto e a qualidade dos periódicos de acesso aberto e dos conteúdos dos repositórios; o contexto em que o movimento difundiu-se nos diferentes países e regiões do mundo; as estratégias e práticas que possibilitaram seu desenvolvimento; e as motivações de autores para disponibilizarem seus artigos em acesso aberto, dentre outros aspectos. Mais que corroborar o entendimento do movimento, tais iniciativas têm como consequências a compreensão e o aprimoramento do processo de comunicação científica como um todo.

\subsection{ESPECIALIZAÇÃO DA CIÊNCIA E ESPECIFICIDADE DAS ÁREAS}

[...] a comunidade científica desenvolveu seu
próprio mecanismo de defesa contra o insumo de
informações em excesso. (...) Á medida que a
ciência se expandiu, os pesquisadores restringiram
sua atenção a partes selecionadas, de tal modo
que a informação que precisam absorver continua
a situar-se dentro dos limites aceitáveis
(MEADOWS, 1999).

A especialização da ciência tem sua origem no século XVII, como consequência da expansão do saber, ocasião em que as áreas temáticas e estudos acerca do mundo constituíam-se uma modalidade de investigação filosófica. Nesse contexto, as ciências físicas eram denominadas filosofia natural, as ciências sociais modernas recebiam a denominação de filosofia moral e as ciências biológicas, por sua vez, de história natural (MEADOWS, 1999). 
Ainda no século XVII a classificação de disciplinas começou a sofrer transformações, sendo admitida a geração da informação científica a partir de métodos analíticos (comprovações matemáticas) ou empíricos (observações e experimentos). Isso resultou na ampliação da definição do significado atribuído à palavra científico, que, já no século XIX, incluía matérias como história e economia (MEADOWS, 1999).

Ao final do século XVIII e início do XIX ocorreu a emancipação das disciplinas científicas mais gerais, até se configurem como autônomas. Os filósofos naturais, por exemplo, se voltaram a uma especialidade científica e não mais aos aspectos diferenciados do mundo natural (PANZA; PRESAS apud CARIBÉ, 2011).

Com o passar dos anos a ciência e a própria comunicação científica foram se organizando e adquirindo a configuração atual. Combinada com outros fatores locais, essa organização promoveu a constituição e solidificação de várias disciplinas (GOMES, 2012).

Como consequência, os pesquisadores tornam-se mais especializados em suas respectivas áreas de atuação. Os títulos de periódicos refletem essa tendência de especialização da ciência, que se acentuou após a Segunda Guerra Mundial. As academias e sociedades científicas se especializaram a partir do século XVIII e, de forma intensa, no século XIX, continuando sua ampliação no século XX, com o surgimento de novas áreas de pesquisa (MEADOWS, 1999).

Apesar da tendência à especialização, é importante destacar a existência de periódicos que, ao contrário, não são especializados e possuem como missão a disseminação do conhecimento científico produzido em várias áreas temáticas. Eles cumprem, porém, função análoga à dos periódicos especializados. Exemplos bem-sucedidos são Nature e Science, conforme colocado por Ezponda (2008, p. 544):

Ahora bien, la tecnociencia contemporánea está profundamente marcada por la existencia de algunas revistas que destacan claramente como distribuidoras de conocimiento, por ejemplo Nature y Science. La singularidad de dichas publicaciones consiste en que no son disciplinarias, sino interdisciplinarias. Son leídas por científicos de muchas disciplinas y especialidades, y 


\begin{abstract}
desempeñan bien una función básica para la transferencia: distribuir los avances más importantes en el conocimiento que cada disciplina genera a los cultivadores de las demás disciplinas. Las Philosophical Transactions de la Royal Academy llevaron a cabo históricamente una función similar: informar al público científico culto de los resultados de las principales investigaciones en las diversas ciencias (física, matemática, biología, química, geología, astronomía, meteorología, etc.). Hoy en día la ciencia está mucho más especializada, pero esos grandes "medios de distribución del conocimiento", que no de divulgación, cumplen una función similar.
\end{abstract}

Além da especialização da ciência, outras consequências advêm da expansão do saber: a) maior tempo e dedicação do pesquisador neófito para alcançar a frente de pesquisa à medida que o tempo passa; b) com o passar dos anos, a formação de pesquisadores tornou-se mais complexa; c) cursos de graduação sofreram mudanças no que se refere à quantidade e estrutura de informação com a qual se tem de lidar; d) estrutura teórica mais complexa do conhecimento científico; e e) surgimento e aprimoramento da atividade de orientação. A profissionalização da pesquisa ocorreu nas décadas próximas a 1800 (MEADOWS, 1999).

O surgimento de matérias e especialidades pode ocorrer a partir da subdivisão de matérias gerais, processo denominado de brotamento, ou pela união de dois ramos que resultam na formação de uma nova especialidade, o que é conhecido como fusão (MEADOWS, 1999). Gomes (2012, p. 46) coloca que algumas disciplinas surgiram:

\begin{abstract}
no espectro de uma especialização dentro de uma grande área, outras em decorrência de conjunturas históricas e econômicas das sociedades e algumas continuam "nascendo" da fusão e/ou interdisciplinaridade temática - quase que num processo inverso ao anterior. Cada uma, no entanto, acabou por desenvolver alguns princípios básicos sobre o que é ou como se desenvolve uma pesquisa a partir de diferentes métodos e abordagens e, consequentemente, gerando formas específicas de comunicação científica. E encontramos, inclusive, dentro de um mesmo campo como, por exemplo, a Psicologia e outros, diferentes modos de se "fazer investigação".
\end{abstract}

Meadows (1999) destaca que o processo de fusão de campos da ciência para a criação de especialidades garante a exploração de territórios intermediários, bem como pode ocasionar o surgimento de áreas 
interdisciplinares. Para Japiassu (apud DIAS, 2008, p. 202), em razão da "[...] complexidade cada vez maior dos problemas colocados pela sociedade em plena mutação, exige-se a análise interdisciplinar para que estes sejam resolvidos".

Segundo Domingues (apud DIAS, 2008), nas diversas áreas da ciência existe forte traço de interdisciplinaridade, sendo a pesquisa dessa natureza caracterizada pela aproximação de diferentes campos científicos e pelo compartilhamento de metodologias que visam à resolução de problemas específicos. França (2001, p. 6) coloca que os "[...] estudos ou campos interdisciplinares referem-se à emergência de novas temáticas que começam a ser estudadas a partir do referencial das áreas já constituídas".

Para Gómez e Orrico (2004) a interdisciplinaridade pode ser entendida como:

\begin{abstract}
o exercício transversal da racionalidade (perpassando não só as fronteiras das disciplinas quanto as das atividades setoriais, no escopo e abrangência da produção e transmissão do conhecimento científico) emerge hoje não só como um projeto, uma forma da vontade de saber, mas como um fatum que passa a ser de consideração iniludível nos fóruns acadêmicos, administrativos e políticos da ciência e da tecnologia e da educação - em todos os seus níveis.
\end{abstract}

Em estudo realizado em 1992, Kodama (apud BALANCIERI et al., 2005) comprovou que o aumento dos campos interdisciplinares tem motivado a colaboração científica, e que alguns dos mais importantes avanços da ciência originaram-se da fusão de campos anteriormente separados.

A especialização, seja por brotamento ou fusão, é de vital importância para o desenvolvimento científico, pois possibilita que lacunas ocasionadas pela sua especialização possam ser incorporadas ao saber da humanidade.

A ciência moderna é caracterizada pela intensa especialização e, segundo Ezponda (2008, p. 543), neste contexto:

Estar al día en los avances que se producen en una determinada especialidad científica lleva mucho tiempo y requiere una sólida formación en la materia, puesto que las observaciones y los experimentos hay que comprobarlos y repetirlos, por si acaso a sus proponentes se les hubiera escapado algún detalle o hubieran 


\begin{abstract}
cometido un error. Salvo en momentos muy determinados, las revoluciones científicas, la ciencia normal avanza a pequeños pasos, mediante sutiles mejoras y perfeccionamientos. Dichos progresos sólo pueden ser plenamente entendidos por unos pocos científicos, precisamente aquellos que siguen atentamente sus investigaciones respectivas y son capaces de criticar fundadamente algunos aspectos de los resultados obtenidos. Normalmente, dichos científicos se citan los unos a los otros, y con frecuencia son los evaluadores anónimos de las aportaciones que sus colegas hacen. Como también resaltó Kuhn, las comunidades científicas son pequeñas, no más de cien personas, debido al alto grado de especialización que ha llegado a tener la ciencia.
\end{abstract}

As diferentes áreas científicas guardam especificidades impostas por conjunturas históricas e econômicas das sociedades, que atribuem características específicas à dinâmica de produção da informação científica. Para Gomes (2012), as comunidades científicas apresentam processos distintos de pesquisa, resultando em diferenças não apenas na velocidade de produção de informação científica, como no seu compartilhamento, recuperação, uso e preservação. Tais diferenças podem ser acentuadas por distintos contextos regionais e institucionais/acadêmicos, impactando na maior ou menor aceitação de certos artefatos tecnológicos ou de outras transformações ocorridas no âmbito da comunicação científica.

Segundo KUNZ (2011, p. 89):

Cada área define, por razões históricas, assim como pela trajetória de institucionalização que cada uma delas teve, as suas próprias características para gerar uma determinada dinâmica de produção de conhecimento e, a partir daí, criar uma série de normas orientadas ao controle social da ciência. Há diferenças nas formas como os pesquisadores interagem para divulgar suas pesquisas e para estabelecer a maneira de organização acadêmica.

Ao longo de décadas, inúmeros estudos foram realizados com o objetivo de identificar as especificidades de determinadas áreas científicas. Mugnaini, Packer e Meneghini (2008), comparando pesquisadores da Academia Brasileira de Ciências com os da National Academy of Sciences of the USA, identificaram padrões distintos no Índice $\mathrm{H}$ para as diferentes disciplinas científicas, com tendências semelhantes em ambas às academias com base na mediana do índice $\mathrm{H}$ dos membros por área, e desvio absoluto mediano: "[...] valores elevados para biomédica, saúde e química, valores 
intermediários para física, ciências biológicas e agricultura e valores baixos para matemática e ciências humanas [...]" (tradução nossa), conforme dados apresentados na Tabela 2.

Tabela 2. Mediana e mediana absoluta derivada do Índice $\mathrm{H}$ para os membros da Academia Brasileira de Ciências e da National Academy of Sciences of the USA

\begin{tabular}{|c|c|c|c|c|c|c|}
\hline \multirow[t]{2}{*}{ Categories } & \multicolumn{3}{|c|}{ Brazilian Academy of Sciences } & \multicolumn{3}{|c|}{ National Academy of Sciences, USA } \\
\hline & Median & $\begin{array}{c}\text { Median absolute } \\
\text { deviation }\end{array}$ & $\begin{array}{l}\text { Deviation/ } \\
\text { Median }\end{array}$ & Median & $\begin{array}{l}\text { Median absolute } \\
\text { deviation }\end{array}$ & $\begin{array}{c}\text { Deviation/ } \\
\text { Median }\end{array}$ \\
\hline Biomedical sciences & 22 & 7 & 0.32 & 66 & 15 & 0.23 \\
\hline Health sciences & 20 & 4 & 0.20 & 82.5 & 24 & 0.29 \\
\hline Chemistry & 18 & 5.5 & 0.31 & 56 & 9 & 0.16 \\
\hline Physics & 16 & 3.5 & 0.22 & 37 & 9 & 0.24 \\
\hline Biological sciences & 12 & 3 & 0.25 & 44 & 8 & 0.18 \\
\hline Agriculture & 10 & 3 & 0.30 & 36 & 9 & 0.25 \\
\hline Earth sciences & 9 & 4 & 0.44 & 37 & 9 & 0.24 \\
\hline Engineering & 8 & 3.5 & 0.44 & 39.5 & 18 & 0.46 \\
\hline Mathematics & 8 & 3 & 0.38 & 18.5 & 5.5 & 0.30 \\
\hline Human sciences & 3 & 1 & 0.33 & 16 & 4 & 0.25 \\
\hline
\end{tabular}

Fonte: MUGNAINI, PACKER e MENEGHINI, 2008, p. 259.

No mesmo ano, Huang e Chang (2008) publicaram os resultados de estudo que visou analisar as características da produção científica dos pesquisadores da University of Hong Kong, das áreas de ciências sociais e humanidades. Além de confirmar a preferências pela utilização dos livros nessas duas áreas, a pesquisa identificou divergências entre algumas disciplinas das ciências sociais - psicologia, economia, negócios e gestão, biblioteconomia e ciência da informação - quanto à citação de artigos de periódicos científicos. Os autores observaram que essas disciplinas citam mais os artigos de periódicos, apresentando características das ciências duras.

Mueller (2008), em estudo realizado com o objetivo de investigar a relação entre as áreas do conhecimento, financiamento e editoras brasileiras, constatou o agrupamento dos periódicos em dois conjuntos: o primeiro, formado pelas áreas de ciências exatas, ciências naturais e engenharia; e o segundo, constituído por periódicos de ciências humanas e ciências sociais aplicadas. De acordo com a autora, os resultados 
encontrados sugerem que a natureza das áreas de conhecimento influencia os hábitos e as necessidades da comunidade científica, bem como a produção dos periódicos.

Brambilla e Stumpf (2012), em trabalho que analisou a produção científica da Universidade Federal do Rio Grande do Sul (UFRGS) representada na Web of Science, no período de 2000 a 2009, mediram o índice de atividade e a produtividade nas diferentes áreas do conhecimento, em específico das ciências biológicas, ciências exatas e da terra, ciências da saúde, ciências agrárias e engenharias. Como resultado, os autores indicaram que as ciências biológicas (28\%), as exatas e da terra (23\%) e as da saúde $(23 \%)$ detiveram mais de $70 \%$ do total da produção científica da instituição.

Por sua vez, o estudo de Piro, Aksnes e Rørstad (2013) avaliou a produtividade científica em cinco áreas temáticas, a partir da produção científica de pesquisadores de universidades norueguesas. Dentre os seus achados, pode-se destacar que os pesquisadores de medicina, ciências naturais e tecnologia são mais produtivos quando se utiliza a contagem de artigos por autor, enquanto os das ciências humanas e sociais são mais produtivos quando o número de artigos é dividido pelo número total de autores.

As diferentes áreas científicas utilizam de formas distintas os vários tipos de documentos, seja no momento de citar um tipo de literatura científica ou de comunicar um resultado de pesquisa, dando preferência a canais de comunicação mais adequados às suas necessidades, bem como à dinâmica de produção do conhecimento estabelecida pela área.

Meadows (1999) apresenta os resultados de um levantamento sobre publicações científicas produzidas por universidades britânicas, identificando os canais preferenciais para a comunicação de resultados de pesquisa. Tal levantamento apontou a existências de dois grupos: o primeiro, composto pelas áreas de ciência, tecnologia e medicina; e o segundo, pelas ciências sociais e humanidades. Para o primeiro grupo a utilização dos artigos de periódicos para a comunicação dos resultados de uma pesquisa é 
preferência entre os pesquisadores; para o segundo, o livro é o mais utilizado.

Na Tabela 3, é possível identificar cenário semelhante ao relatado por Meadows, quando são analisados os dados referentes à distribuição das citações por tipos de documentos, considerando as grandes áreas do conhecimento. Para o primeiro grupo - constituído pelas áreas de ciências da saúde, biológicas, ciências exatas e da terra, ciências agrárias e engenharias - o artigo científico constitui o tipo de documento mais utilizado no processo de geração de informação científica, recebendo entre 69\% a 86\% das citações; já no segundo grupo - formado pelas áreas de ciências sociais aplicadas, humanas e linguística, letras e artes - o livro adquire relevância, recebendo porcentagem de citações semelhante ou superior à recebida pelos artigos.

Tabela 3. Distribuição das citações concedidas pelos periódicos da Coleção

SciELO Brasil, em 2009, por área temática e segundo o tipo de literatura citada

\begin{tabular}{|l|c|c|c|c|}
\hline Área temática & periódicos & livros & anais & teses \\
\hline Ciências da Saúde & $86 \%$ & $12 \%$ & $1 \%$ & $1 \%$ \\
\hline Ciências Biológicas & $85 \%$ & $12 \%$ & $1 \%$ & $1 \%$ \\
\hline Ciências Exatas e da Terra & $79 \%$ & $16 \%$ & $3 \%$ & $2 \%$ \\
\hline Ciências Agrárias & $72 \%$ & $19 \%$ & $5 \%$ & $4 \%$ \\
\hline Engenharias & $69 \%$ & $22 \%$ & $5 \%$ & $4 \%$ \\
\hline Ciências Sociais Aplicadas & $48 \%$ & $45 \%$ & $4 \%$ & $3 \%$ \\
\hline Ciências Humanas & $49 \%$ & $46 \%$ & $2 \%$ & $4 \%$ \\
\hline Linguística, Letras e Artes & $39 \%$ & $52 \%$ & $3 \%$ & $6 \%$ \\
\hline
\end{tabular}

Fonte: PACKER, 2011

As diferenças entre as áreas científicas também são constadas quando é verificada a distribuição dos artigos por idioma de publicação, conforme dados apresentados no Gráfico 1. Nesse caso, os periódicos das áreas de ciências biológicas e ciências exatas e da terra publicam mais de $50 \%$ dos artigos no idioma inglês, enquanto as demais publicam menos de $50 \%$. 
Gráfico 1. Distribuição dos artigos por idioma de publicação e áreas do conhecimento

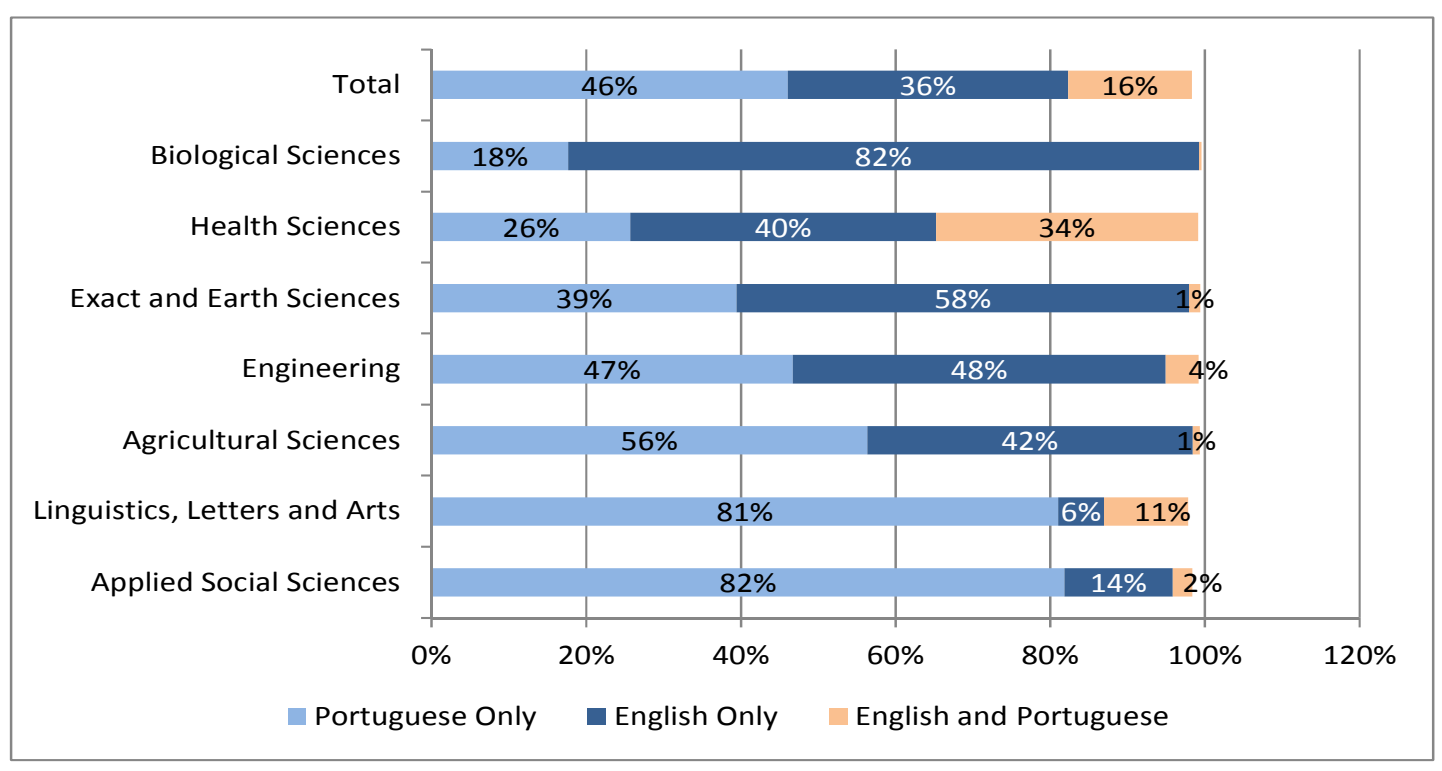

Fonte: PACKER, 2011

A introdução das tecnologias de informação na comunicação científica motivou a realização de outros estudos para identificar as especificidades no uso dos documentos eletrônicos pelas diferentes áreas. É o caso de Lindholm-Romantschuk e Warner (apud COSTA, 2008), que, em 1996, verificaram o uso dos meios eletrônicos por pesquisadores das ciências físicas, naturais e matemática em comparação com os das ciências sociais e humanas. O estudo evidenciou um fato bem conhecido: nas ciências sociais e humanas há uma tendência de haver padrões de comunicação diferentes dos das ciências físicas, naturais e matemáticas.

O surgimento do movimento de acesso aberto também deu origens a novas investigações, que identificaram especificidades entre as diferentes áreas científicas quanto à publicação e uso de conteúdos abertos. Um exemplo é o trabalho de Carr et al. (apud COSTA, 2008), referente ao auto arquivamento de livros eletrônicos, que confirmou que nas pesquisas realizadas nas áreas de artes e humanidades são utilizados predominantemente livros, mais do que artigos de periódicos científicos.

Gumieiro e Costa (2012), em estudo que objetivou identificar o uso de modelos de negócios por diferentes áreas científicas, no contexto da 
atividade de publicação de periódicos científicos eletrônicos de acesso aberto, concluíram que a configuração de modelos de negócios de publicações das ciências exatas e naturais diferencia-se fortemente dos das demais áreas. Por outro lado, nos periódicos das ciências sociais e humanas e das artes e humanidades foram identificadas significativas semelhanças entre os modelos de negócios adotados.

Ainda no que tange às investigações realizadas sob a temática do acesso aberto nas diferentes áreas científicas, são exemplos as de Antelman (apud COSTA, 2008), referente ao impacto da pesquisa publicada em artigos disponíveis em acesso aberto; e as de Björk et al. (2010), que verificaram a quantidade de artigos de acesso aberto de várias áreas do conhecimento.

Os diversos estudos dedicados à compreensão dos padrões de comunicação e uso da informação científica pelos pesquisadores das diferentes áreas temáticas acumulam-se na literatura científica e atestam sua importância para a gestão das unidades de informação e o estabelecimento de estratégias para a política científica. Eles também são importantes para os processos de avaliação da produção científica dos vários campos do conhecimento, realizados por instituições de fomento à pesquisa e bases de dados.

\subsection{TIPOS DE DOCUMENTOS E A COMUNICAÇÃO CIENTÍFICA}

A informação desempenha importante papel no desenvolvimento das nações, pois subsidia as atividades científicas e tecnológicas e contribui para a transformação da cultura do homem e da sociedade como um todo.

Buckland (1991, p. 351) indica os três principais usos da palavra informação, distinguindo-as entre tangível e intangível:

a) Informação-como-processo: relaciona-se com a comunicação de um fato ou ocorrência e é intangível;

b) Informação-como-conhecimento: é responsável por reduzir a incerteza e pode ser caracterizada como intangível; 
c) Informação-como-coisa: constitui-se em informação expressa, descrita ou documentada e, portanto, é considerada tangível.

Davenport e Prusak (apud VALENTIM, 2002, p. 2) ao conceituarem informação, colocam-na como ponto de conexão entre dados brutos e conhecimento (Quadro 6):

Quadro 6. Diferenças entre dados, informação e conhecimento

\begin{tabular}{|c|c|c|}
\hline Dados & Informação & Conhecimento \\
\hline $\begin{array}{l}\text { Simples observações sobre o } \\
\text { estado do mundo }\end{array}$ & $\begin{array}{l}\text { Dados dotados de relevância e } \\
\text { propósito }\end{array}$ & $\begin{array}{l}\text { Informação valiosa da mente } \\
\text { humana Inclui reflexão, } \\
\text { síntese, contexto }\end{array}$ \\
\hline Facilmente estruturado & Requer unidade de análise & De difícil estruturação \\
\hline $\begin{array}{l}\text { Facilmente obtido por } \\
\text { máquinas }\end{array}$ & $\begin{array}{l}\text { Exige consenso em relação ao } \\
\text { significado }\end{array}$ & De difícil captura em máquinas \\
\hline Freqüentemente quantificado & $\begin{array}{l}\text { Exige necessariamente } \\
\text { amediação }\end{array}$ & Freqüentemente tácito \\
\hline Facilmente transferível & humana & De difícil transferência \\
\hline
\end{tabular}

FONTE: DAVENPORT, PRUSAK apud VALENTIM, 2002, p. 2.

McGarry (apud VALENTIM, 2002, p. 2) relaciona as seguintes atribuições ao termo informação:

- considerada como um quase sinônimo do termo fato;

- um reforço do que já se conhece;

- a liberdade de escolha ao selecionar uma mensagem;

- a matéria-prima da qual se extrai o conhecimento;

- aquilo que é permutado com o mundo exterior e não apenas recebido passivamente;

- definida em termos de seus efeitos no receptor;

- algo que reduz a incerteza em determinada situação.

De acordo com a sua função, a informação pode ser classificada em: informação tecnológica, informação industrial, informação para negócios, informação econômica, informação para cidadania, informação científica, dentre outras.

A informação científica constitui-se em "[...] todo conhecimento que resulta - ou está relacionado com o resultado - de uma pesquisa científica". 
Possui como funções: divulgar o conhecimento gerado a partir de uma pesquisa científica, assegurando a "prioridade intelectual (autoria)" de quem a desenvolveu; subsidiar o desenvolvimento de novas pesquisas, contribuindo, desta maneira, para o desenvolvimento da ciência; e fornecer informações metodológicas, possibilitando aos outros pesquisadores confirmar os resultados alcançados (AGUIAR, 1991, p. 10).

O desenvolvimento da ciência e a construção de novos conhecimentos se dão por meio de informação gerada a partir de uma pesquisa científica e devidamente registrada que referencia determinado campo ou área temática. Segundo Frohmann (apud ORTEGA, 2010, p. 15), "[...] a informação científica depende, para sua emergência, de práticas documentarias culturalmente específicas, historicamente determinadas e institucionalmente disciplinadas".

A informação científica é registrada a partir de diferentes tipos de documentos que se complementam e atendem às necessidades específicas de cada fase da pesquisa, desde seu início até após o seu término. No conjunto, tais documentos compõem o que podemos chamar de literatura científica, podendo variar (MUELLER, 2000, p. 22):

no formato (relatórios, trabalhos apresentados em congressos, palestras, artigos de periódicos, livros e outros), no suporte (papel, meio eletrônico e outros), audiências (colegas, estudantes, público em geral) e função (informar, obter reações, registrar autoria, indicar e localizar documentos, entre outras).

Mueller (2000, p. 30), ao analisar o estudo desenvolvido pelos pesquisadores americanos Garvey e Griffith, na década de 70, indica os documentos gerados pelas diversas atividades desenvolvidas por um pesquisador, bem como o surgimento dos domínios formal e informal:

o início da pesquisa é logo seguido por relatórios preliminares e comunicações de pesquisas em andamento; um pouco antes e logo após o término da pesquisa há uma sucessão de seminários, colóquios, conferências e relatórios, que geram trabalhos escritos completos ou resumos (publicados geralmente em anais) e que já serão indexados em fontes adequadas; ao submeter o seu original para publicação em periódico científico, aparecem as versões preliminares (preprints), distribuídas à comunidade de pares; após a publicação do artigo em periódico haverá normalmente uma série de notícias sobre ele, em veículos de alerta, índices e 


\begin{abstract}
resumos e talvez, também, em obras que realizam ensaios bibliográficos sobre as tendências de pesquisa e desenvolvimento da área, tipo annual reviews. Se a pesquisa teve o impacto desejado pelo seu autor, citações ao trabalho começam a aparecer assim que o artigo se toma disponível. Nesse modelo é fácil perceber que a informação flui por muitos canais e que diferentes tipos de documentos são produzidos, cujas características variam conforme o estágio da pesquisa e tipo de público a que se destina e o objetivo de quem a comunica. Com base em modelos como esse, os canais de informação foram classificados como canais informais ou canais formais.
\end{abstract}

Os domínios formal e informal são atribuídos aos canais utilizados pelos pesquisadores para a disseminação de informação. Segundo Silva e Menezes (apud SCHWEITZER; RODRIGUES; RADOS, 2011, p. 87), os canais informais possuem como função a "[...] disseminação de informação entre os pares, e os canais formais são responsáveis pela comunicação oficial dos resultados de uma pesquisa", possibilitando o controle de qualidade, o reconhecimento da autoridade e a preservação do conhecimento.

Para Targino (2000, p. 19):

Os sistemas formal e informal servem a fins distintos quanto à operacionalização das pesquisas. Ambos são indispensáveis à comunicabilidade da produção científica, mas são utilizados em momentos diversos e obedecem a cronologias diferenciadas. A disseminação através de canais informais precede a finalização do projeto de pesquisa e até mesmo o início de sua execução, pois há propensão para se abandonar um projeto, quando os pares não demonstram interesse. Em contrapartida, a trajetória da comunicação formal é demorada, como exemplificado, em detalhes, por Garvey, Griffith (1979) e Garvey, Lin, Nelson (1979), os quais concordam que há sempre um longo caminho, mas há diferenças significativas entre áreas e especializações.

Meadows (1999, p. 7) destaca que, na comunicação formal, a informação permanece disponível "[...] por longos períodos de tempo para um público amplo", citando como exemplos de canais formais de comunicação os periódicos e livros. Oliveira e Noronha (2005, p. 78) colocam que a comunicação científica formal é realizada a partir da escrita, disseminada por meio de periódicos científicos, livros, relatórios técnicos, dentre outros documentos. 
A principal vantagem apresentada pela comunicação formal é a permanência da publicação, proporcionando maior facilita de recuperação e localização da informação científica. Além disso, a informação científica publicada em canais formais passa pela avaliação de algumas instâncias pesquisadores, bases de dados, instituições de fomento à pesquisa - que Ihe conferem maior credibilidade (OLIVEIRA; NORONHA, 2005, p. 78).

O paradigma da comunicação escrita ou formal vem a reduzir os problemas identificados na comunicação interpessoal, servindo como um meio de apoio e aferindo veracidade ao que estava sendo comunicado, conforme características transcritas a seguir (CÔRTES, 2006, p. 46):

- Facilidade de reprodução do texto original, permitindo sua distribuição e utilização em diversos locais;

- Redução dos custos de difusão;

- Alta possibilidade de retenção e documentação por parte do receptor (o texto impresso, quando bem cuidado, pode ser utilizado por décadas ou mesmo centenas de ano);

- Facilidade de comparação de idéias e da evolução do conhecimento sobre determinados temas;

- Eliminação quase total da ocorrência de distorções e acréscimos de interpretações pessoais ao longo da cadeia de difusão do conhecimento;

- Níveis bem mais elevados de difusão do conhecimento, atingindo um número maior de pessoas e locais geograficamente distantes;

- Aumento significativo da velocidade de difusão;

- Criação de jornais e revistas científicas, incrementando a troca de idéias e incentivando o debate.

Por sua vez, a comunicação informal "[...] é em geral efêmera, sendo posta à disposição apenas de um público limitado. A maior parte da informação falada é, portanto, informal, do mesmo modo que a maioria das cartas pessoais" (MEADOWS, 1999, p. 7).

Os canais informais são definidos por Targino (2000, p. 55) como aqueles "[...] em que a transferência da informação ocorre através de contatos interpessoais e de quaisquer recursos destituídos de formalismo, como reuniões científicas, participação em associações profissionais e colégios invisíveis".

Para Mueller (1994, p. 312), os canais informais apresentam as seguintes vantagens: 
eficiência na identificação da relevância da informação para interesses individuais; possibilidade de discussão sobre erros ou tentativas malsucedidas, alternativas etc.; flexibilidade suficiente para permitir ao cientista dirigir o processo de comunicação para satisfação de suas necessidades específicas; possibilidade de obtenção, para o comunicador, de reações imediatas.

Mueller (1994, p. 312), destaca ainda que os canais informais constituem-se nas "[...] fontes de informação primárias e orais, embora nem sempre, e incluem conversa cara a cara, por telefone ou meio eletrônico, visitas a laboratórios ou outros centros, correspondência etc". Ainda segundo a autora, a comunicação informal "[...] provou ser especialmente útil para satisfazer as necessidades de disciplinas científicas emergentes durante os anos de formação".

Côrtes (2006, p. 44) chama a atenção para alguns dos problemas encontrados na comunicação interpessoal ou informal e que justificam a saturação quanto ao seu uso, bem como a mudança de paradigma, ocorrido no final da Idade Média e início da Renascença:

- Baixa retenção por parte do receptor;

- Possibilidade reduzida de documentação da idéia transmitida (a não ser sob a forma de cartas ou de anotações pessoais);

- Facilidade de ocorrência de distorção e acréscimos de interpretações pessoais ao longo da cadeia de difusão do conhecimento;

- Baixa difusão (atinge um pequeno número de pessoas);

- Baixa velocidade de difusão (demora para atingir um número pequeno de pessoas).

Os canais informais estão diretamente relacionados à expressão 'colégios invisíveis', fazendo-se necessário defini-los mesmo que brevemente. Os colégios invisíveis podem ser definidos como "[...] comunidades informais de pesquisadores que se comunicavam, trocavam informações e experiências e também publicavam formalmente seus resultados no campo do conhecimento científico" (BALANCIERI et al., 2005, p. 54).

Moreira (2005, p. 58), em estudo realizado com o objetivo discutir as mudanças na comunicação formal e informal promovidas pelas tecnologias de informação e comunicação, faz uma analogia entre os termos colégio 
invisível e colégio virtual, colocando o segundo como resultado de uma evolução do primeiro. O colégio virtual poder ser definido como uma comunidade que se mantem atualizada a partir dos seus respectivos trabalhos, realizando intercâmbio de informação por correio eletrônico, listas de discussões, outros meios. "O colégio virtual atua como rede de comunicação e intercâmbio, como fórum de educação e de socialização dos novos cientistas".

A expressão colégio invisível (GOMES, 2012, p. 51):

foi resgatada por Price com o sentido de uma rede social constituída de indivíduos no âmbito de uma determinada especialização. As pesquisas realizadas pelos membros são acrescidas de contributos advindos da troca informal entre os contatos, de conhecimentos específicos, via conferências e outros fóruns, mantendo os especialistas, muitas vezes, a par das tendências atuais de sua área. [...] E, a própria história, acabou por imprimir, nesse cenário, uma maior 'socialização' das informações através da 'abertura', mesmo que não por completa, dessas redes, antes dificultosas pelas questões de ordem financeira, a um número significativo de investigadores via os atuais 'colégios invisíveis virtuais', que potencializam os contributos científicos graças ao uso das tecnologias.

Dentre as questões que envolvem a expressão colégios invisíveis virtuais, destacam-se as propostas por Matzat (apud MOREIRA, 2005, p. 65) e que se encontram presentes nos diversos estudos que compõem a área:

- Os colégios virtuais são prioritariamente fontes para obtenção de informação ou fontes para estabelecimento de contatos?

- O efeito periférico existe? Os colégios virtuais são mais importantes para pesquisadores periféricos e mais jovens que para os já estabelecidos?

- Os colégios virtuais cumprem funções diferentes nas humanidades, por um lado, e nas ciências naturais, por outro? Como essas diferenças disciplinares podem ser explicadas?

- Que tipo de pesquisadores são os provedores de informação nestes grupos?

- O que determina se um pesquisador se torna um participante ativo em uma discussão em um colégio virtual, ou se permanece passivo?

Os canais formais e informais ocupam diferentes lugares no fluxo da comunicação científica e com o advento das tecnologias de comunicação e informação, em especial a Internet, estão passando por modificações significativas. Este contexto faz suscitar algumas questões quanto à validade 
da aplicação destes domínios, uma vez que tais classificações não se adequam muito bem ao ambiente eletrônico. Segundo Weitzel (2006, p. 85), a comunicação científica em meio eletrônico coloca em debate várias questões e, dentre elas, pode-se destacar a "[...] a fragilidade dos domínios formal e informal".

Dentre os vários casos em que a categorização dos canais nos domínios formais e informais não se ajusta ao meio eletrônico, Meadows (1999, p. 38) destaca que "[...] a distinção entre uma mensagem de correio eletrônico e um artigo numa revista eletrônica não é clara [...]", pois ambos podem ser vistos por um mesmo número de pessoas e por meio de computadores. Além deste exemplo, a literatura científica reuniu outros desde o surgimento da publicação eletrônica.

Para Targino (2000, p. 23), o ambiente eletrônico atribuiu um caráter híbrido aos canais eletrônicos de comunicação, que passaram a guardar tanto características dos sistemas formais como dos sistemas informais. $\mathrm{O}$ Quadro 7, confronte as características dos canais formais, informais e eletrônicos:

Quadro 7. Diferenças entre canais formais, informais e eletrônicos

\begin{tabular}{|c|c|c|}
\hline Canais Formais & Canais Informais & Canais Eletrônicos \\
\hline $\begin{array}{l}\text { Público potencialmente } \\
\text { grande }\end{array}$ & Público restrito & $\begin{array}{l}\text { Público potencialmente } \\
\text { grande }\end{array}$ \\
\hline $\begin{array}{l}\text { Informação armazenada e } \\
\text { recuperável }\end{array}$ & $\begin{array}{l}\text { Informação não } \\
\text { armazenada e não } \\
\text { recuperável }\end{array}$ & $\begin{array}{l}\text { Armazenamento e } \\
\text { recuperação complexos }\end{array}$ \\
\hline $\begin{array}{l}\text { Informação relativamente } \\
\text { antiga }\end{array}$ & Informação recente & Informação recente \\
\hline $\begin{array}{l}\text { Direção do fluxo } \\
\text { selecionada pelo usuário }\end{array}$ & $\begin{array}{l}\text { Direção do fluxo } \\
\text { selecionada pelo produtor }\end{array}$ & $\begin{array}{l}\text { Direção do fluxo } \\
\text { selecionada pelo usuário }\end{array}$ \\
\hline Redundância moderada & $\begin{array}{l}\text { Redundância, às vezes, } \\
\text { significativa }\end{array}$ & $\begin{array}{l}\text { Redundância, às vezes, } \\
\text { significativa }\end{array}$ \\
\hline Avaliação prévia & Sem avaliação prévia & $\begin{array}{l}\text { Sem avaliação prévia, em } \\
\text { geral }\end{array}$ \\
\hline $\begin{array}{l}\text { Feedback irrisório para o } \\
\text { autor }\end{array}$ & $\begin{array}{l}\text { Feedback significativo para } \\
\text { o autor }\end{array}$ & $\begin{array}{l}\text { Feedback significativo para } \\
\text { o autor }\end{array}$ \\
\hline
\end{tabular}

FONTE: elaborado com base em Targino (2000) 
Complementando o indicado por Oliveira e Noronha (2005, p. 82) colocam que a comunicação científica realizada por canais eletrônicos guarda características informais e formais:

Como comunicação informal, ela possibilita o contato entre os pesquisadores, favorecendo a troca rápida de informações e o feedback imediato ao desenvolvimento das pesquisas. Como comunicação formal favorece a divulgação do conhecimento produzido para um público amplo, em tempo menor do que a impressa. Neste panorama, a comunicação eletrônica realizada através do meio informal é feita com o uso de correio eletrônico, listas de discussão e bate-papos, e formalmente com a publicação de periódicos, livros, obras de referência, entre outros, editados no formato eletrônico.

Ainda segundo as autoras, os canais informais foram devidamente adaptados ao meio eletrônico e adotados de forma considerável pela comunidade científica, o que poder ser constatado "[...] pela utilização maciça do correio eletrônico entre os pesquisadores e, em menor escala, de outras ferramentas como participação em listas de discussão, teleconferências, salas virtuais" (OLIVEIRA; NORONHA, 2005, p. 85). Os canais formais em meio eletrônico, por sua vez, encontram-se em estágios distintos de desenvolvimento, coexistindo com suas respectivas versões em suporte impresso:

\footnotetext{
Assim, as bibliografias e os anais de conferências estão disponibilizados quase que completamente em meio eletrônico; os periódicos científicos eletrônicos firmam-se cada vez mais no cenário dos recursos utilizados pelos pesquisadores tanto na busca da informação quanto na divulgação de suas descobertas; os livros estão realizando essa transição do impresso para o eletrônico de forma mais lenta.
}

Somando ao exposto por Oliveiro e Noronha, cabe acrescentar aqui, alguns desdobramentos dos documentos eletrônicos que vêm ocorrendo desde o advento das tecnologias de informação e comunicação, em especial da Internet: os eventos científicos passam a ter anais eletrônicos em texto completo, com indexação em bases de dados como a WoS; os livros eletrônicos iniciam uma nova fase com indexação em bases de dados e controle de qualidade mais rigoroso; os repositórios se proliferam e, 
juntamente com os periódicos em acesso aberto, oferecem à comunidade científica possibilidades sem precedentes.

De fato, o que vemos atualmente é a presença marcante dos vários tipos de documentos científicos no ambiente eletrônico, porém, como forma de reprodução de suas versões impressas. Poucos veículos em cada categoria utilizam-se dos vários recursos proporcionados pelo ambiente eletrônico, como, por exemplo, utilização de áudio e vídeo. Verifica-se também uma migração dos processos de produção de alguns destes documentos, porém, também neste contexto, nem sempre a migração do processo de produção para o ambiente eletrônico resulta em uma circulação efetivamente mais rápida dos conteúdos científicos. Muitas vezes, a publicação da versão eletrônica de um periódico, por exemplo, ainda está vinculada à publicação de seu suporte impresso.

Se, por um lado, a Internet possibilitou avanços notáveis no campo da publicação científica, alterando os processos de produção, manipulação, uso e armazenamento da informação científica - como anais de eventos, repositórios, livros e periódicos eletrônicos - bem como abrindo novas possibilidades de comunicação informal entre os pesquisadores - correio eletrônico, blogs, listas de discussão, twitter, facebook; por outro lado, vemos ainda um rol de possibilidades a explorar.

\subsubsection{Periódico Científico: origem e evolução}

$\mathrm{Na}$ literatura científica, são encontradas diversas definições para o periódico científico, desde definições de origem documental até definições que contextualizam $\mathrm{o}$ periódico na comunicação científica. Fachin e Hillesheim (2006, p. 28) definem o periódico científico como publicação editada em números e fascículos independentes, em qualquer suporte físico, com ordem sequencial e cronológica e que atende a normas de controle bibliográfico. Pode trazer contribuições de âmbito geral ou de uma área temática em específico. 
Para Stumpf (1998, p. 2), o periódico científico constitui-se em uma categoria das publicações seriadas - juntamente com outras categorias como jornais, anuários, anais de sociedades científicas - apresentando como características específicas, a publicação:

em partes ou fascículos, numeradas progressiva ou
cronologicamente, reunidas sob um título comum, editadas em
intervalos regulares, com a intenção de continuidade infinita,
formadas por contribuições, na forma de artigos assinados, sob a
direção de um editor, com um plano definido que indica a
necessidade de um planejamento prévio.

Por sua vez, Barbalho (apud MIRANDA, 2012, p. 29) define o periódico científico como um: "[...] canal de disseminação da ciência, publicado em períodos de tempo predefinidos, reunindo artigos de diversas autorias, e que apresentam rigor científico e metodológico".

A partir do exposto, podemos defini-lo como um canal formal de comunicação científica, da categoria de publicação seriada, editado com periodicidade recorrente e contínua. Sua publicação é realizada a partir de fascículos, organizados em volumes e compostos por artigos de diferentes autores e instituições e que foram, previamente, aprovados pelo processo de revisão por pares (peer review). Sua edição é realizada sob a direção de um ou mais editores chefes e de um corpo editorial, composto por pesquisadores da(s) área(s) de abrangência do periódico.

O periódico constitui-se em um importante canal formal de disseminação de informação científica que possibilita o registro do processo de construção e reconstrução do conhecimento científico. Dentre as funções que Ihes são atribuídas, pode-se citar (MUELLER, 1994; MIRANDA, 1996; SANTOS, 2010; GUANAES; GUIMARAES, 2012; RODRIGUES; OLIVEIRA, 2012):

- Estabelecimento da ciência certificada, com a validação dos resultados de pesquisa pela comunidade científica, a partir do processo de revisão por pares (peer review);

- Canal de comunicação e divulgação da informação científica, com o acesso sendo realizado a partir de serviços de informação e 
bibliotecas. O acesso aos conteúdos resultam em visibilidade para os periódicos, seus autores e editores científicos.

- Arquivo ou memória científica, permitindo o registro da evolução da ciência com a publicação das descobertas e resultados de pesquisa nos vários campos científicos;

- Registro da prioridade e propriedade intelectual, conferindo aos autores o reconhecimento pelas descobertas e pelos resultados de pesquisa obtidos;

- Ascensão do cientista para efeito de promoção, conferindo prestígio e reconhecimento a autores, editores e revisores;

- Instrumento de avaliação de desempenho individual dos pesquisadores, a partir da análise da qualidade dos periódicos;

- Papel educacional, promovendo a atualização profissional e educação continuada de pesquisadores, bem como promovendo a formação de novos autores, editores e revisores e evolução das comunidades científicas.

Miranda (2012, p. 30), ao analisar as funções atribuídas ao periódico científico, sob a ótica de diferentes autores, destaca como principal a função de 'registro oficial da informação', complementando com mais 13 funções:

\begin{abstract}
a) registrar o conhecimento; b) constituir-se na memória da ciência; c) disseminar o conhecimento; d) salvaguardar a prioridade das descobertas e estabelecer a propriedade intelectual; e) aprovar os novos conhecimentos produzidos, fortalecendo a geração de saberes; f) conferir prestígio e recompensar autores, editores e membros do conselho editorial; g) definir e legitimar novas disciplinas e campos de estudo; $h$ ) servir como fonte de informação para novos estudos; i) indicar a evolução de uma ciência; j) indicar o andamento de atividades científicas realizadas por pesquisadores, grupos de pesquisadores e instituições; k) fomentar a integração entre autores, editores, revisores, pesquisadores, enfim, entre todos os envolvidos no processo de produção e disseminação do conhecimento científico; I) manter o padrão da qualidade da ciência; m) ser um canal de comunicação que viabiliza o desenvolvimento científico da área e do país onde é publicado.
\end{abstract}

Para o cumprimento destas funções, Miranda (1996, p. 376) destaca a necessidade de os periódicos científicos se consolidarem como veículo de 
uma determinada área científica e coloca que o maior ou menor desenvolvimento destes veículos depende:

\begin{abstract}
do estágio de desenvolvimento da área científica cujas ideias eles veiculam; de uma comunidade engajada na atividade de pesquisa e da afluência de artigos para publicação; da existência de grupos e instituições que desempenham funções típicas de edição, avaliação, publicação, disseminação e recuperação; da existência de mercado representado por uma comunidade de usuários que o legitimem; de infraestrutura para distribuição, recuperação e acesso às informações.
\end{abstract}

O periódico científico teve sua origem na segunda metade do século XVII, em um momento em que prevalecia a comunicação das descobertas científicas por meio de comunicação oral, correspondência pessoal e livros. Em especial, sua origem está associada à necessidade de se estabelecer um canal formal mais eficiente para a comunicação dos resultados de pesquisa a um público crescente e cada vez mais interessado em descobertas científicas (MEADOWS, 1999).

Os precursores dos periódicos científicos modernos surgiram, simultaneamente, na Europa, em 1665. O primeiro a aparecer foi o Journal des Sçavans, criado pelo parisiense Denis de Sallo, na França, com o primeiro fascículo publicado em 5 de janeiro. O segundo, Philosophical Transacrions, surgiu três meses depois, na Inglaterra, por determinação da Royal Society e tendo a frente de sua edição Henry Oldenburg (MEADOWS, 1999, p. 6).

As diferenças entre os dois periódicos faz suscitar opiniões divergentes quando é necessário precisar qual foi o primeiro periódico realmente científico a ser criado. O Journal des Sçavans, apesar de ter surgido três meses antes do periódico inglês, publicava além de registros de experimentos, outros temas, como questões legais ou teológicas e alguns pesquisadores defendem que sua publicação era destinada a transmitir conhecimentos científicos ao público leigo. Por sua vez, o Philosophical Transacrions se dedicava exclusivamente a publicação de experimentos realizados por membros da Royal Society e correspondência com seus pares europeus, estando sua publicação dirigida à comunidade científica e 
não ao público leigo. Tais divergências se devem ao fato de que, na época, as diferenças entre público leigo e comunidade científica não eram claras (CARIBÉ, 2011).

Mugnaini (2013, p. 1, no prelo) destaca que, já na ocasião da criação do primeiro periódico científico, estabeleceram-se princípios fundamentais que os regem até a atualidade - periodicidade, a revisão por pares - bem como outros princípios foram fortalecidos, como a prioridade autoral.

Enquanto os dois primeiros periódicos - francês e inglês - eram produzidos no continente europeu, o continente Ibero-América vivia o segundo século como colônia e sob a Contrarreforma ${ }^{14}$ portuguesa e espanhola, ocasião em que não se circulavam, nem mesmo se produziam conteúdos científicos (LOPEZ ESPINOSA, 2000; SANTOS, 2010).

No século XVIII, ocorreu a proliferação dos periódicos científicos pelo continente europeu e surgem os primeiros veículos especializados em áreas científicas - como a física, química, biologia, agricultura e medicina - em decorrência da especialização da ciência, iniciada no final do século XXVII, e do aumento significativo no número de sociedades científicas e de associações profissionais (MEADOWS, 1999; PANZA; PRESAS apud CARIBÉ, 2011; SANTOS, 2010; MIRANDA, 2012). Neste mesmo período, em específico em 1772, surge o primeiro periódico ibero-americano, intitulado Mercúrio Volante, no México, que tratava da difusão do conhecimento científico na área médica (LOPEZ ESPINOSA, 2000).

O século XIX foi marcado pelo aumento expressivo do número de pesquisadores e do crescimento da produção do conhecimento científico, como consequência da industrialização e da profissionalização da ciência que tomavam conta do continente europeu. Tais fatos levaram a um aumento no número de periódicos científicos que, na ocasião, já apresentavam as características dos periódicos contemporâneos (MEADOWS, 1999).

\footnotetext{
${ }^{14}$ Contrarreforma ou Reforma Católica é o nome dado ao movimento que surgiu no seio da Igreja Católica e que, segundo alguns autores, teria sido uma resposta à Reforma Protestante iniciada com Lutero, a partir de 1517.
} 
Com a grande massa de literatura disponível no final do século XIX, os pesquisadores encontravam dificuldades em localizar a informação que precisavam. "Parte do problema era a falta de normalização bibliográfica na elaboração dos relatos de pesquisa (e a correspondente omissão de dados relevantes)" (MEADOWS, 1999, p. 30).

Neste mesmo período, em específico em 1808, surge o periodismo brasileiro propiciado por uma política colonial portuguesa mais liberal, advinda da transformação do Brasil Colônia em sede da Corte Portuguesa (FREITAS, 2006).

$\mathrm{Na}$ metade do século $\mathrm{XX}$, o surgimento do computador e 0 desenvolvimento das tecnologias de informação e comunicação que culminaram na criação da Internet, influenciaram fortemente a comunicação científica, bem como estabeleceram as condições necessárias para a criação, evolução e proliferação dos periódicos científicos eletrônicos.

A evolução do periódico científico em ambiente eletrônico é marcada pela sua passagem do formato impresso para as microformas, ocorrida na década de 1960, que, apesar de apresentarem vantagens quanto ao custo de assinaturas e remessas e de armazenamento, não foi aceito por assinantes particulares, nem por usuários dos centros de informação. A partir da década de 1970, os avanços na editoração eletrônica possibilitaram o aprimoramento da qualidade dos periódicos, bem como tornaram mais ágeis os processos de produção editorial. Posteriormente, vieram os disquetes e CD-ROMs que não alteraram o formato inicial dos periódicos, porém foram úteis às bases de dados que os utilizaram para o armazenamento menos oneroso de coleções completas de periódicos (STUMPF, 1996). Porém, é na década de 1990 que surge o periódico eletrônico, promovendo mudanças significativas em seu formato inicial e alterando os padrões, até então conhecidos, de produção, uso, acesso e armazenamento da informação científica.

O periódico científico constitui-se no veículo de maior impacto e prestígio utilizado pela comunidade científica para registro e comunicação dos resultados de pesquisa, tendo se consolidado como principal canal para 
acesso, uso e produção de informação científica nas áreas de ciências da saúde, ciências biológicas e ciências exatas e da terra; bem como para parte significativa das ciências agrárias e engenharias; e para parcela menor das ciências sociais aplicadas, ciências humanas e de linguística, letras e artes. Em tais áreas, o periódico divide com o livro a importante missão de disseminar o conhecimento científico, apesar das incessantes pressões exercidas pelas comunidades científicas de outras áreas, em prol da priorização da publicação em periódicos científicos. 


\section{PROCEDIMENTOS METODOLÓGICOS}

O estudo teve como objetivo identificar as especificidades da comunicação científica em biodiversidade, por meio da avaliação dos periódicos que veiculam os resultados de pesquisa na área. A partir do objetivo definido e do quadro teórico traçado para subsidiar o seu desenvolvimento, definiu-se um plano metodológico que incluiu duas etapas complementares: a) análise dos indicadores bibliométricos dos periódicos; e b) análise dos aspectos formais dos periódicos.

Desenvolveu-se uma pesquisa descritiva e exploratória, visando a avaliação quali-quantitativa dos periódicos científicos classificados pelo Programa Qualis/CAPES da Área de Biodiversidade, em específico de periódicos das áreas: Botânica, Oceanografia, Zoologia e Ecologia (BOZE $\left.{ }^{6}\right)$.

A pesquisa descritiva busca conhecer situações "[...] que ocorrem na vida social, política, econômica e demais aspectos do comportamento humano, tanto do indivíduo tomado isoladamente como de grupos e comunidades mais complexas" (CERVO; BERVIAN, 1996, p. 49). $\mathrm{Na}$ pesquisa descritiva, o pesquisador procura conhecer e interpretar as informações coletadas no presente, sem manipulá-las. Ela pode aparecer sob diversas formas como, por exemplo, por meio da pesquisa de motivação, pesquisa de opinião, pesquisa para análise de trabalho, pesquisa documental, entre outras (RUDIO, 1986, p. 56-57).

A pesquisa exploratória possibilita ao pesquisador maior proximidade com o problema do estudo, bem como sua melhor compreensão. É utilizada "[...] em casos nos quais é necessário definir o problema com maior precisão e identificar cursos relevantes de ação ou obter dados adicionais antes que se possa desenvolver uma abordagem". Para sua implementação, são empregados os seguintes métodos: "[...] levantamentos em fontes secundárias (bibliográficas, documentais, etc.), levantamentos de experiência, estudos de casos selecionados e observação informal (a olho nu ou mecânico)" (VIEIRA, 2002, p. 65). 
O caráter descritivo é atribuído ao estudo devido à necessidade de se conhecer os periódicos científicos nacionais e internacionais que comunicam resultados de pesquisa na área de biodiversidade, o que foi realizado a partir da análise dos indicadores bibliométricos e do levantamento de seus aspectos formais. Por sua vez, o caráter exploratório do estudo se deve à necessidade de elucidar as diferenças existentes entre às áreas temáticas de Botânica, Oceanografia, Zoologia e Ecologia, aqui denominadas BOZE, para um melhor entendimento da comunicação científica em biodiversidade.

A Figura 4 apresenta a partes que compõem os procedimentos metodológicos empregados para o desenvolvimento do estudo e, nos itens que se seguem, seu devido detalhamento. 
Figura 4. Procedimentos Metodológicos

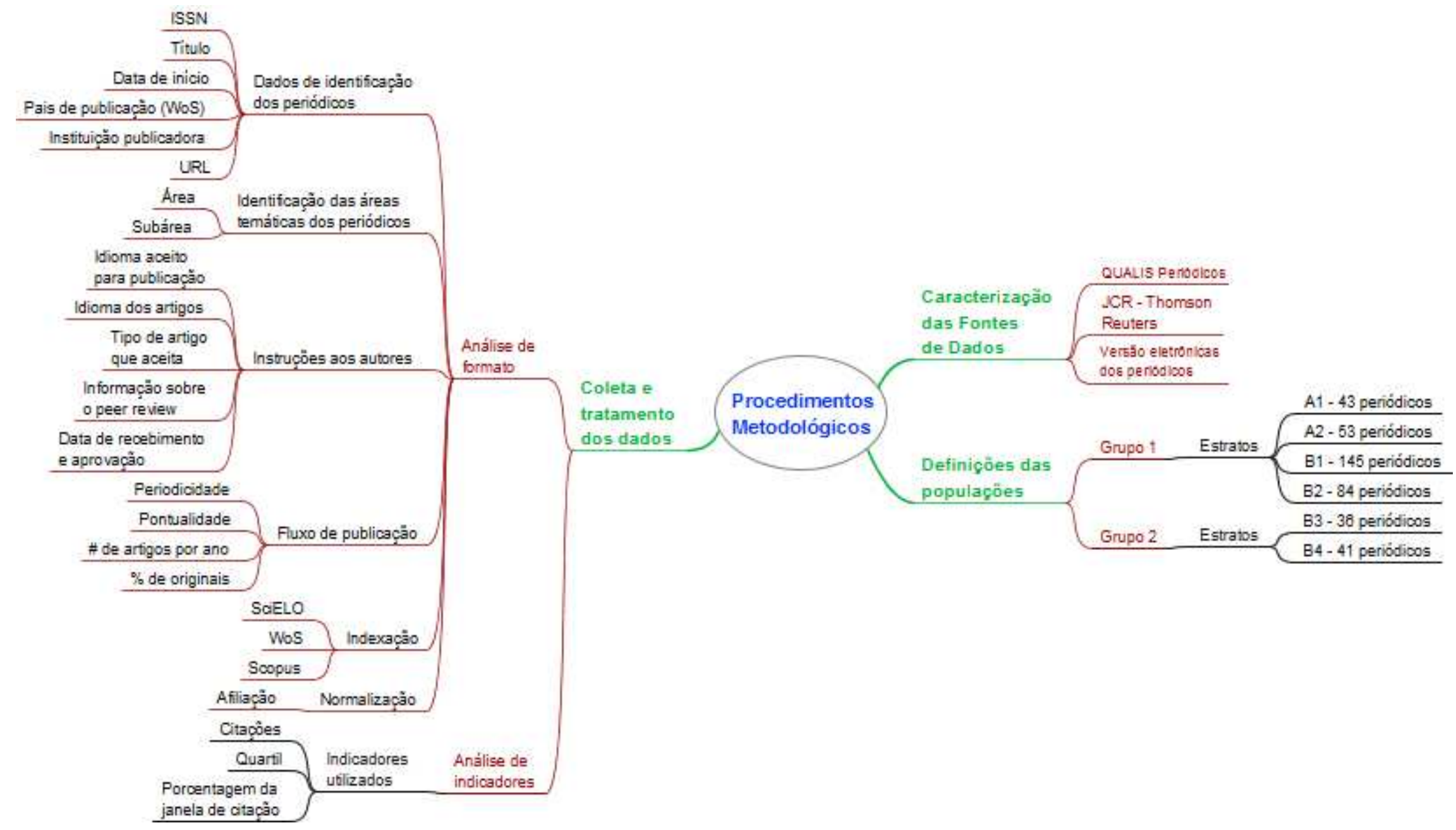




\subsection{CARACTERIZAÇÃO DAS FONTES DE DADOS}

Ao longo do desenvolvimento do plano metodológico, definiu-se pela utilização de três fontes de dados complementares, que possibilitaram a realização das análises a partir dos indicadores bibliométricos e dos aspectos formais:

- Qualis Periódicos: constitui-se em parte do Programa Qualis/CAPES e visa à estratificação da qualidade da produção intelectual dos programas de pós-graduação, de forma indireta, a partir da análise da qualidade dos periódicos científicos. Em específico, utilizou-se os dados do Qualis Periódicos da Área de Biodiversidade, com coleta realizada em setembro de 2012. Os dados foram acessados a partir do aplicativo WebQualis que permitiu a consulta ao Qualis da área, bem como aos critérios utilizados para a classificação dos periódicos. Do WebQualis, foram utilizados os seguintes dados: título do periódico, ISSN e Estrato Qualis (A1, A2, B1, B2, B3, B4 B5 e C).

- Journal Citation Reports (JCR): da empresa Thomson Reuters, apresenta a lista anual de Fator de Impacto dos periódicos com pelo menos dois anos de indexação na Web of Science. Foram utilizados os indicadores publicados anualmente pelo JCR, correspondentes ao período de 2007 a $2011^{15}$, com coleta de dados realizada em outubro de 2012 e utilização dos dados dos seguintes campos: ISSN, total de citação que o periódico recebeu no ano, Fator de Impacto e número de artigos que o periódico publicou no ano.

- Versões online dos periódicos: foram utilizadas como fontes as páginas dos periódicos disponíveis na Internet, em acesso aberto ou a partir do Portal de Periódicos da CAPES.

${ }^{15}$ É importante destacar que, do conjunto de periódicos do qualis da área (2012), foram tomados os respectivos indicadores num período de 5 anos, apenas para possibilitar uma variação temporal. Periódicos que não estavam indexados no período completo não deixaram de ser incluídos. 


\subsection{DEFINIÇÃO DAS POPULAÇÕES}

O estudo partiu dos periódicos científicos, nacionais e estrangeiros, classificados no Qualis Periódicos da Área de Biodiversidade, referente ao ano 2012, com coleta realizada em setembro de 2012 que inclui 2.001 títulos.

Conforme especificado no documento de Critérios QUALIS para a área de Biodiversidade $\left(\right.$ CAPES $\left.^{8}, 2013\right)$, a estratificação dos periódicos foi realizada considerando os cálculos de mediana dos fatores de impacto (ano base 2010), a indexação dos periódicos em bases de dados e o uso ${ }^{16}$ dos mesmos.

Os estratos A1, A2 e B1 correspondem aos periódicos indexados no JCR e, portanto, com Fl; o estrato B2 inclui os periódicos indexados na base Web of Science ou na base de dados Scopus, da Elsevier; o estrato B3 é representando pelos periódicos ingressados no SciELO e periódicos com uso igual ou superior a 10; B4 é constituído por periódicos com uso superior a quatro; $\mathrm{B} 5$ e $\mathrm{C}$ reúnem periódicos que foram considerados impróprios pela área.

Os 2.001 periódicos classificados pelo Qualis Periódicos da Área de Biodiversidade foram analisados conforme a distribuição nos oito estratos de qualidade (Gráfico 2). Para a classificação dos periódicos nos estratos, a CAPES recomenda que: $A 1$ seja menor que $A 2$ e que juntos somem no máximo $25 \%$ dos periódicos; enquanto que $A 1$, $A 2$ e $B 1$ devem somar no máximo $50 \%$ dos títulos; B2, B3, B4, B5 e C devem reunir pelo menos $50 \%$ dos periódicos $\left(\right.$ CAPES $\left.^{8}, 2013\right)$.

Conforme dados apresentados no Gráfico 2, a distribuição dos periódicos da área de biodiversidade nos estratos está próximo ao recomendado pela CAPES, referente à proporcionalidade, reunindo nos estratos: A1 e A2 $23,9 \%$ dos periódicos e concentrando $76,1 \%$ nos estratos B1, B2, B3, B4, B5 e C; os estratos A1, A2 e B1 concentram $48,4 \%$ dos

\footnotetext{
${ }^{16}$ Uso se refere à quantidade de artigos publicados pelos pesquisadores da área.
} 
títulos; a soma dos periódicos classificados nos estratos B2, B3, B4, B5 e C resultam em $51,5 \%$ do total.

Gráfico 2. Distribuição do número de periódicos por estrato Qualis

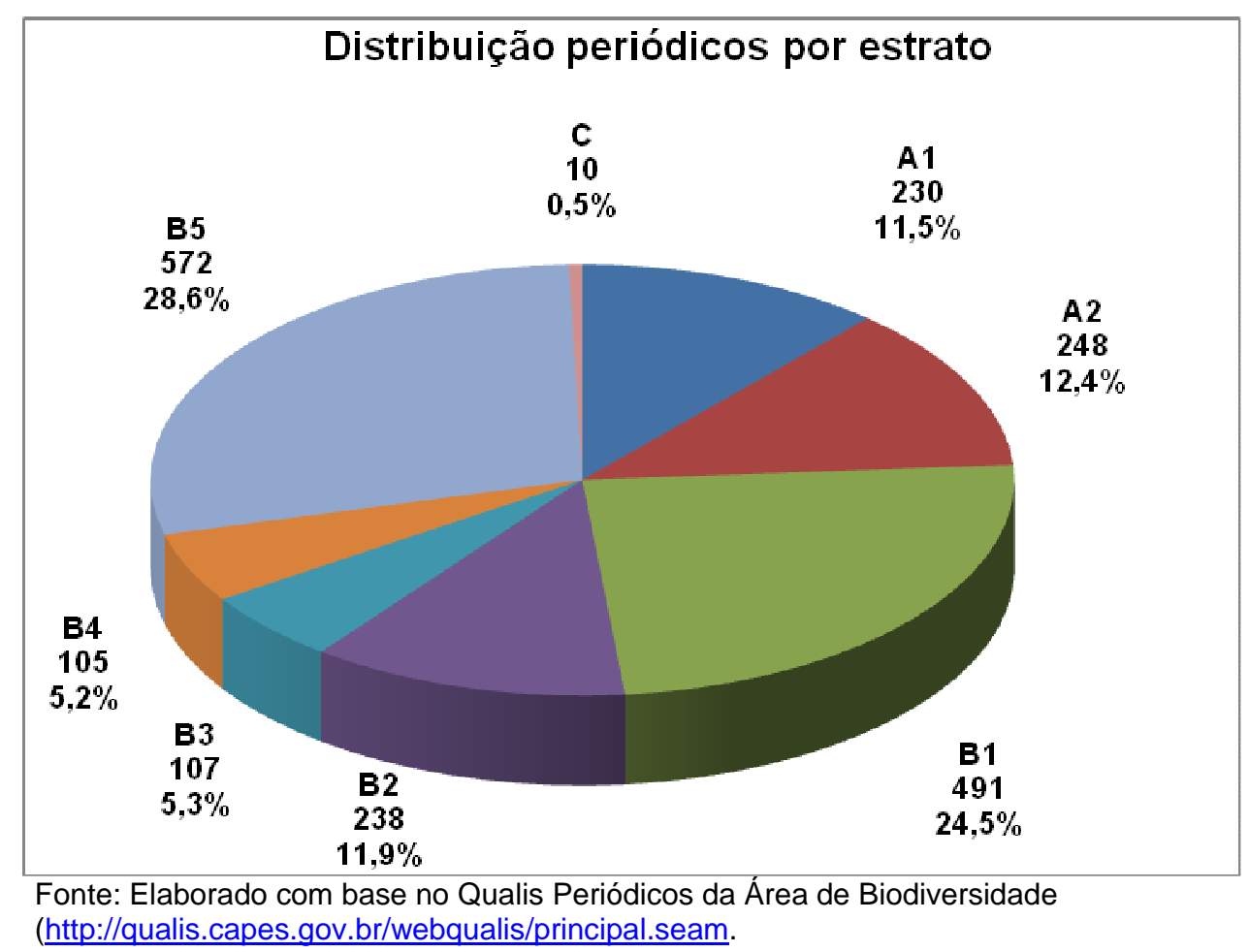

Do total de 2.001 periódicos classificados no Qualis Biodiversidade, 710 títulos foram desconsiderados no início do estudo, pelas razões indicadas a seguir, ficando, portanto, 1.291 títulos:

a) 583 periódicos classificados nos estratos B5 e C por serem considerados impróprios pela área;

b) Duplicações de 118 periódicos apresentados em mais de um formato (impresso, online, CD-ROM) na lista Qualis Biodiversidade, visando eliminar a repetição desnecessária de títulos;

c) 5 proceedings e 9 revistas de divulgação científica por não se enquadrarem no tipo de documento considerado pelo estudo. 
A Tabela 4 apresenta dados referentes ao primeiro recorte aplicado para a identificação dos periódicos, com distribuição dos títulos entre os Estratos do Qualis de Biodiversidade:

Tabela 4. Distribuição do número de periódicos por Estrato

\begin{tabular}{|c|c|c|c|c|}
\hline \multirow{2}{*}{ Estrato Qualis } & \# Títulos & \multirow{2}{*}{$\%$} & \# Títulos & \multirow{2}{*}{$\%$} \\
\hline & lista geral & & 10. Recorte & \\
\hline$\overline{\mathbf{A 1}}$ & 230 & 11,5 & 220 & 17,0 \\
\hline A2 & 248 & 12,4 & 236 & 18,3 \\
\hline B1 & 491 & 24,5 & 441 & 34,2 \\
\hline$\overline{B 2}$ & 238 & 11,9 & 214 & 16,6 \\
\hline B3 & 107 & 5,3 & 86 & 6,7 \\
\hline B4 & 105 & 5,2 & 94 & 7,3 \\
\hline B5 & 572 & 28,6 & - & - \\
\hline $\bar{C}$ & 10 & 0,5 & - & - \\
\hline Total & 2001 & 100 & 1291 & 100 \\
\hline
\end{tabular}

Fonte: Quais Periódicos da Área de Biodiversidade

Os 1.291 periódicos pertencentes aos estratos A1, A2, B1, B2, B3 e B4 foram classificados em áreas e grandes áreas temáticas, conforme Tabela de Áreas do Conhecimento do CNPq (CNPq ${ }^{17}$, s.d.), com o objetivo de identificar os periódicos pertencentes às áreas BOZE. Vale destacar que a opção pela avaliação dos periódicos destas áreas se deu em conformidade com as áreas que compõem o novo Qualis da Área de Biodiversidade.

A classificação dos periódicos em áreas e grandes áreas temáticas incluiu quatro etapas, conforme descritas a seguir:

Primeira Etapa - Levantamento das classificações temáticas dos periódicos em fontes de informação

- Foram extraídas as classificações em especialidades/subáreas/áreas temáticas recebidas pelos periódicos nas seguintes fontes de informação: a) JCR; e b) Catálogo Coletivo Nacional de Publicações

17 Documento não paginado da web, disponível a partir de http://200.17.161.80/prppg/projetos/tabelaareas-do-conhecimento-cnpq.pdf?PHPSESSID=80c785c0a871a440259e6d12fb6c47c9. Acesso em: 10 junho de 2012. 
Seriadas (CCN) do Instituto Brasileiro de Informação em Ciência e Tecnologia (IBICT).

Segunda Etapa - Classificação temática dos periódicos não disponíveis no JCR e CCN/IBICT

- Para os periódicos não disponíveis no JCR ou CCN/IBICT, foram realizadas as classificações em especialidades/subáreas/áreas temáticas, conforme a Tabela de Áreas do Conhecimento do CNPq e a partir de consultas às páginas dos periódicos na versão online, com posterior validação das classificações pela Biblioteca do Museu de Zoologia da USP. Para 0 entendimento das especialidades/subáreas/áreas temáticas, utilizou-se os conteúdos do ThesBio: thesaurus em biodiversidade (ThesBio $\left.{ }^{5}, 2012\right)$ :

Terceira Etapa - Compatibilização das classificações temáticas

- Com vistas a diminuir o grau de subjetividade nas classificações temáticas dos periódicos, as 3 classificações recebidas - JCR, CCN/IBICT e Classificação por Bibliotecário - foram compatibilizadas e se chegou a classificação final dos títulos.

Quarta Etapa - Identificação das áreas e grandes áreas temáticas

- Para os periódicos classificados em especialidades ou subáreas temáticas, fez-se necessário situá-los em áreas e grandes áreas temáticas para, então, identificar os periódicos das áreas BOZE.

A partir da identificação dos periódicos das áreas BOZE, foi possível aplicar o segundo recorte e definir a lista de periódicos para a análise a partir dos indicadores bibliométricos e dos aspectos formais. Considerando a necessidade de conhecer as diferenças existentes entre as áreas consideradas no estudo, não foram incluídos os periódicos com escopo abrangendo duas ou mais áreas temáticas. 
A Tabela 5 apresenta a distribuição entre os Estratos Qualis dos 402 periódicos das áreas BOZE:

Tabela 5. Distribuição dos periódicos de BOZE por Estrato Qualis

\begin{tabular}{|l|c|c|c|c|c|}
\hline Estratos Qualis & Botanica & Oceanografia & Zoologia & Ecologia & Total \\
\hline A1 & 10 & 2 & 1 & 30 & 43 \\
\hline A2 & 20 & 7 & 14 & 12 & 53 \\
\hline B1 & 34 & 7 & 75 & 29 & 145 \\
\hline B2 & 22 & 7 & 41 & 14 & 84 \\
\hline B3 & 9 & 5 & 15 & 7 & 36 \\
\hline B4 & 6 & 1 & 21 & 13 & 41 \\
\hline Total & 101 & 29 & 167 & 105 & 402 \\
\hline
\end{tabular}

Fonte: elaborado a partir do Qualis da área de Biodiversidade do ano de 2012

Para a realização das análises dos indicadores bibliométricos e dos aspectos formais, os 402 periódicos considerados no estudo foram agrupados da seguinte forma:

a) Grupo 1: incluiu 325 periódicos dos estratos A1, A2, B1 e B2 para a análise dos indicadores bibliométricos;

b) Grupo 2: considerou 77 periódicos dos estratos B3 e B4 para a análise dos aspectos formais.

A Figura 5 apresenta os recortes aplicados ao longo do desenvolvimento do estudo e que resultou na definição da lista dos periódicos para a realização das análises: 
Figura 5. Filtros aplicados para a seleção dos periódicos participantes do estudo

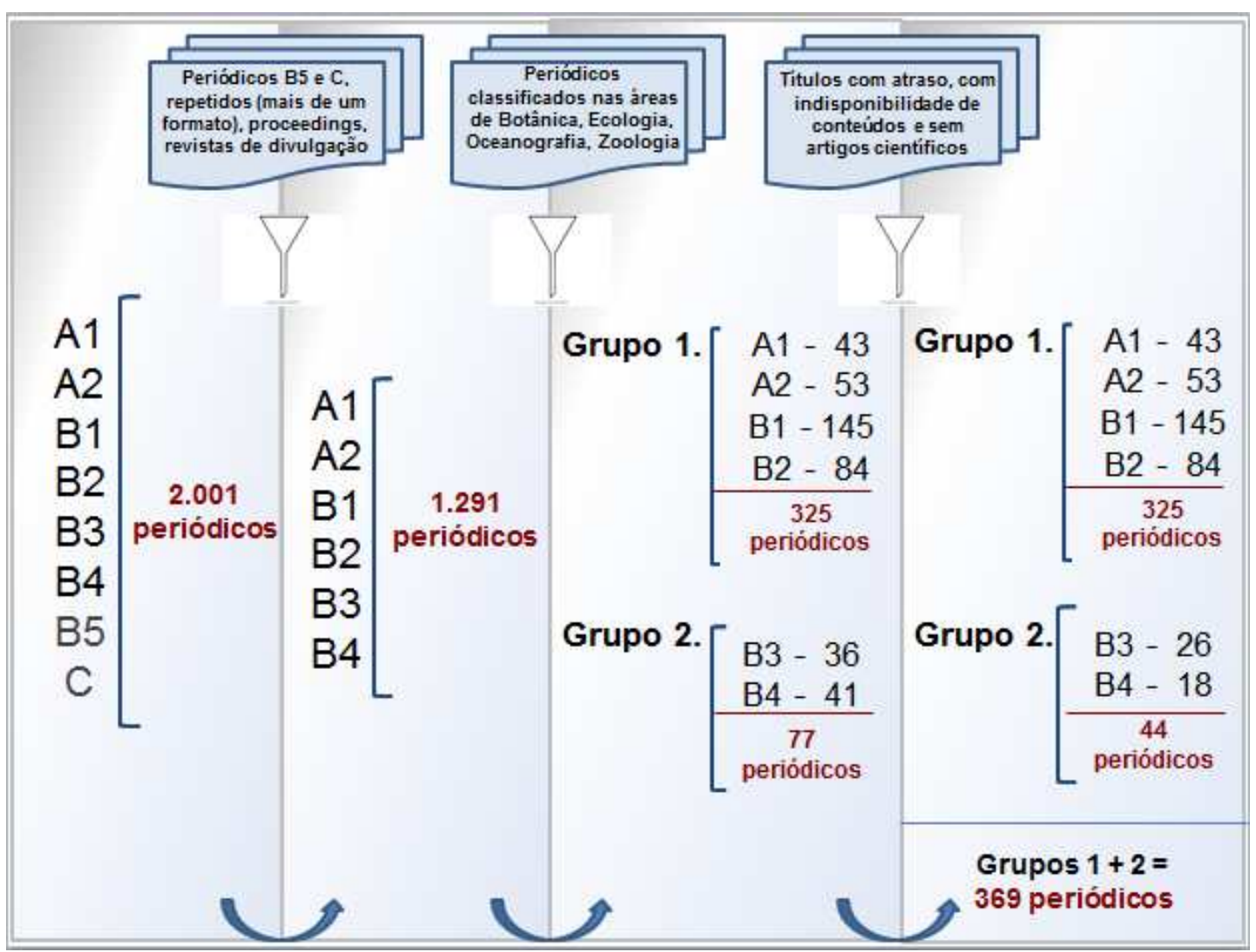

\subsection{COLETA E TRATAMENTO DE DADOS}

A coleta dos dados ocorreu em 2 etapas - para a análise dos indicadores bibliométricos e dos aspectos formais - que são descritas em detalhes nos itens que se seguem.

5.3.1 Indicadores Bibliométricos: periódicos dos estratos A1, A2, B1 e B2 (Grupo 1)

Os periódicos classificados como A1, A2, B1 e B2 pelo Qualis da Área de Biodiversidade dependem do valor do Fator de Impacto no JCR ou da indexação nas bases de dados Web of Science ou Scopus. Devido à limitação do indicador quando utilizado para comparar periódicos de diferentes áreas, pretendeu-se verificar a disparidade do comportamento dos 
periódicos classificados pelo Qualis Biodiversidade, considerando-se as características especificas das áreas de botânica, oceanografia, zoologia e ecologia.

Para tanto, o Fator de Impacto foi tomado não somente em seu valor absoluto, mas também em sua posição no ranking estabelecido no próprio Qualis da Área de Biodiversidade. A posição no ranking foi representada por estatísticas de ordem, mais especificamente, os Quartis.

Outro aspecto analisado concerne à adequação do indicador Fator de Impacto, que considera em seu cômputo as citações recebidas por artigos de um ou dois anos de idade. Em se tratando de áreas com uma dinâmica de pesquisa mais imediata - que tende a citar artigos mais recentes - podese verificar que o indicador abarca grande porcentagem das citações recebidas pelo periódico naquele ano. Por outro lado, áreas em que a citação se dá a artigos mais antigos acabam penalizadas, uma vez que os dois anos considerados no indicador representam uma baixa porcentagem das citações recebidas, ainda que o periódico tenha quantidade satisfatória de citação.

Um exemplo é apresentado na Figura 6 que identifica, com barras em tom de azul mais claro, as citações a artigos de um e dois anos de idades (segunda e terceira barras, respectivamente): 
Figura 6. Exemplo ilustrativo da distribuição das citações recebidas no JCR em 2008, pelo periódico Ethology, segundo ano dos artigos citados

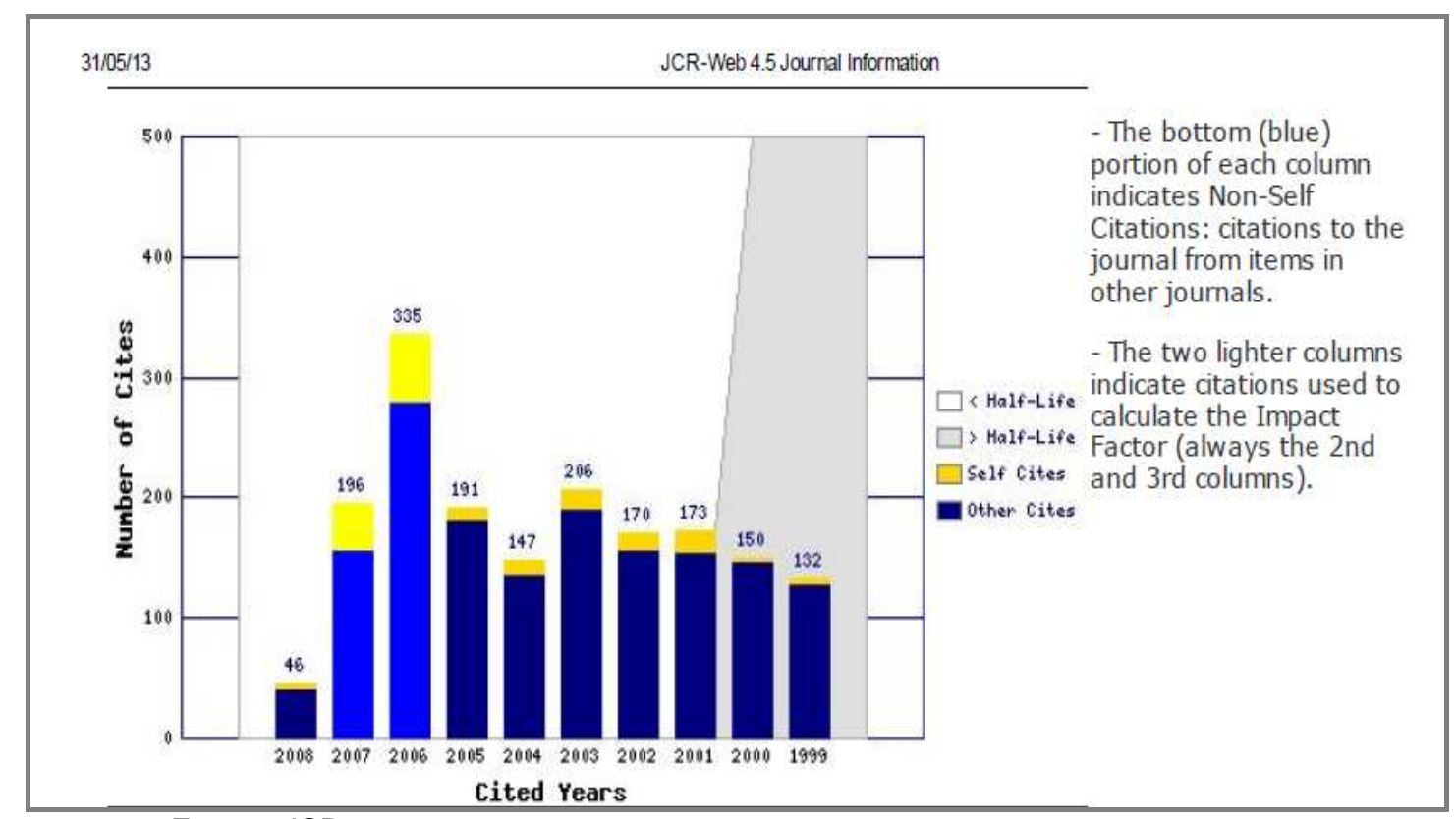

Fontes: JCR 2008

A porcentagem correspondente à janela de citação de dois anos inerente ao Fator de Impacto - que consiste do percentual representado pelas barras azuis claras, em relação ao total de barras (Figura 6) - é um indicador que pode expressar a inadequação do mesmo quando utilizado na avaliação dos periódicos de algumas áreas. Por essa razão, pretendeu-se verificar se alguma das áreas - botânica, oceanografia, zoologia ou ecologia - vem sendo prejudicada, considerando os critérios de classificação atuais adotados pelo Qualis da Área de Biodiversidade.

\subsubsection{Aspectos Formais: periódicos dos estratos B3 e B4 (Grupo 2)}

A coleta de dados para a análise dos aspectos formais foi realizada entre os meses de maio e agosto de 2013, utilizando como fontes as páginas dos 77 periódicos classificados nos estratos B3 e B4 do Qualis da Área de Biodiversidade, disponíveis na Internet, em acesso aberto ou a partir do Portal de Periódicos da CAPES. 
Considerando os objetivos do estudo, foi utilizada uma matriz para o registro dos periódicos, bem como coleta dos aspectos formais. Para a identificação dos títulos, foram reunidos os seguintes dados: a) número de ISSN, b) título do periódico, c) instituição publicadora, d) país de publicação, e) endereço eletrônico do site do periódico, f) área temática e g) grande área temática.

Dentre os vários critérios utilizados na avaliação de periódicos científicos, para este estudo, optou-se pela utilização de aspectos formais que pudessem verificar o atendimento a critérios mínimos de qualidade, bem como identificar especificidades das áreas de botânica, oceanografia, zoologia e ecologia, quanto à dinâmica de publicação de informação científica, complementando, desta forma, a análise dos veículos a partir dos indicadores bibliométricos.

Desta forma, foram considerados os seguintes aspectos:

- Tempo de existência ou duração: calculado a partir da data de criação, este critério reflete a tradição de um periódico, bem como sua continuidade de publicação. Os dados necessários para a realização da análise deste aspecto foram extraídos do Portal do ISSN ${ }^{18}$.

- Pontualidade: refere-se à publicação regular dos fascículos de um periódico científico, respeitando o intervalo de tempo definido pela sua periodicidade. A pontualidade na publicação foi verificada a partir do suporte eletrônico dos periódicos, disponíveis na internet. Não foram consideradas as versão impressas dos mesmos.

- Periodicidade: é a quantidade de fascículos publicados por ano por um periódico científico e se constitui em um indicador do fluxo de produção de informação científica em determinada área temática. Os dados referentes à periodicidade foram, inicialmente, extraídos do Portal do ISSN, com confirmação posterior do dado a partir das páginas dos respectivos veículos

\footnotetext{
${ }^{18}$ Disponível em: http://portal.issn.org/cgi-bin/gw/chameleon). Acessado em: maio de 2013.
} 
- Quantidade de artigos publicados por ano, porcentagem de artigos de pesquisa e datas de recebimento e aprovação: os dados necessários para a realização da análise destes aspectos foram extraídos dos fascículos dos periódicos, referentes ao ano de 2012.

- Revisão por pares e idiomas de publicação: a análise destes aspectos foi realizada a partir da verificação das páginas de Instruções aos Autores dos periódicos do Grupo 2.

Dos 77 periódicos do Grupo 2, 33 periódicos - 10 títulos do estrato B3 e 23 títulos do estrato B4 - apresentaram restrições que inviabilizaram a realização da análise dos aspectos formais, conforme motivos especificados a seguir:

a) Atraso na publicação dos fascículos: 16 títulos apresentaram atraso na publicação dos fascículos da versão eletrônica, com fascículos publicados somente até 2011. Para a análise dos aspectos formais, foram considerados os títulos com fascículos em 2012 publicados;

b) Indisponibilidade dos textos completos na Internet: não foi possível acessar os textos completos de 15 periódicos, seja por indisponibilidade dos sites por problemas técnicos; inexistência de textos completos, com disponibilização apenas dos sumários dos fascículos; ou por inexistência de versão eletrônica dos periódicos;

c) Inexistência de artigos: um veículo apresentava apenas relatórios técnicos e não realizava revisão por pares dos conteúdos publicados e, portanto não se caracterizava como um periódico científico.

Desta forma, foram submetidos à avaliação completa dos aspectos formais 44 periódicos nacionais e internacionais, das áreas de botânica, oceanografia, zoologia e ecologia. 


\section{RESULTADOS E DISCUSSÃo}

\subsection{ANÁLISE POR INDICADORES}

Nos tópicos a seguir são apresentados os resultados referentes às análises dos periódicos das áreas de botânica, oceanografia, zoologia e ecologia, a partir da classificação recebida no Programa Qualis da Área de Biodiversidade e de indicadores bibliométricos - em específico do fator de impacto e sua respectiva porcentagem de citações captada pela janela de citações de dois anos utilizada para seu cômputo - com vistas a verificar o desempenho dos títulos, bem como identificar as características específicas das respectivas áreas temáticas.

\subsubsection{Classificação Qualis}

A análise a distribuição dos periódicos, considerando suas respectivas classificações em grandes áreas temáticas, conforme Tabela de Áreas de Conhecimento do CNPq, bem como sua distribuição por países de publicação e por bases de indexação, é apresentada a seguir. Para estas análises, não foram considerados os periódicos classificados nos estratos B5 e C, nem os periódicos duplicados e proceedings, resultando em uma redução para 1.291 periódicos, conforme demonstrado na Tabela 4 apresentada anteriormente nos procedimentos metodológicos.

Na Tabela 6, é apresentada a distribuição dos periódicos por grandes áreas temáticas, permitindo verificar um predomínio de títulos provenientes da área de ciências biológicas, que representa $56,91 \%$ do total, porém com presença significativa das demais áreas do conhecimento: ciências exatas e da terra constitui-se na segunda área com maior concentração de títulos (15,03\%); ciências agrárias com 11,67\% dos periódicos; e as demais áreas (ciências da saúde, ciências humanas, engenharias, ciências sociais aplicadas e outros) perfazem $16,39 \%$ dos títulos. 
Destaca-se que, nesta análise, a soma dos periódicos supera 1.291, pois os títulos classificados em mais de uma grande área temática, foram contabilizados mais de uma vez.

Tabela 6. Distribuição dos periódicos classificados no Qualis Biodiversidade por grandes áreas

\begin{tabular}{|l|c|c|}
\hline Grandes Áreas & \# Periódicos & $\%$ Periódicos \\
\hline CIENCIAS BIOLOGICAS & 795 & 56,91 \\
\hline CIENCIAS EXATAS E DA TERRA & 210 & 15,03 \\
\hline CIENCIAS AGRARIAS & 163 & 11,67 \\
\hline CIENCIAS DA SAUDE & 89 & 6,37 \\
\hline CIENCIAS HUMANAS & 51 & 3,65 \\
\hline ENGENHARIAS & 40 & 2,86 \\
\hline OUTROS & 33 & 2,36 \\
\hline CIENCIAS SOCIAIS APLICADAS & 16 & 1,15 \\
\hline Total & 1397 & 100,00 \\
\hline
\end{tabular}

Considerando que o Qualis inclui periódicos nacionais e estrangeiros e que parte das críticas da comunidade científica ao modelo de avaliação adotado pelo programa se refere à exclusão dos periódicos nacionais dos estratos superiores, faz-se necessário analisar a procedência dos periódicos classificados pela área de biodiversidade, a partir dos dados referentes ao país de publicação e dos estratos Qualis.

Os dados apresentados na Tabela 7 indicam que os artigos gerados no contexto dos programas de pós-graduação do país são publicados majoritariamente $(78,7 \%)$ por periódicos originários de cinco países, a citar em ordem decrescente: Estados Unidos, Inglaterra, Brasil, Países Baixos e Alemanha. Dentre os países com maior representatividade, o Brasil é o único que não apresenta periódicos classificados no estrato A1 e com apenas um periódico no estrato A2. Além dos cinco países indicados anteriormente, os artigos dos programas de pós-graduação da área de biodiversidade também foram difundidos em periódicos procedentes de outros 43 países de diferentes regiões do mundo. 
Um aspecto importante a se destacar é a porcentagem (27,5\%) de periódicos de outros países que, juntamente com o Brasil (17,1\%), são classificados como megadiversos ${ }^{19}$ : Estados Unidos (23,3\%), Austrália $(1,1 \%)$, Índia $(0,9 \%)$, Colômbia $(0,8 \%)$, México $(0,5 \%)$, África do Sul $(0,3 \%)$, Venezuela $(0,3 \%)$, Republica Popular da China $(0,2 \%)$ e Peru $(0,1 \%)$.

19 Países megadiversos: grupo de países que abrigam a maioria das espécies da Terra e são, portanto, considerado extremamente biodiversos. O Centro de Monitorização de Conservação Ambiental, uma agência das Nações Unidas para o ambiente, identificou 17 países megadiversos, a $\begin{array}{llcc}\text { maioria } & \text { localizada } & \text { nos } & \text { Disponíve } \\ \text { http://pt.wikipedia.org/wiki/Pa\%C3\%ADses_megadiversos. Acesso em: } 29 \text { ago. } 2013 .\end{array}$ 
Tabela 7. Distribuição do número de periódicos por país de publicação e estratos Qualis Biodiversidade

\begin{tabular}{|c|c|c|c|c|c|c|c|c|}
\hline \multirow{2}{*}{ País de Publicação } & \multicolumn{6}{|c|}{ Estratos Qualis } & \multirow{2}{*}{ Total } & \multirow{2}{*}{$\%$} \\
\hline & A1 & $\mathbf{A 2}$ & B1 & B2 & B3 & B4 & & \\
\hline ESTADOS UNIDOS & 84 & 61 & 112 & 34 & 2 & 8 & 301 & 23,3 \\
\hline INGLATERRA & 80 & 62 & 77 & 11 & 1 & 1 & 232 & 18,0 \\
\hline BRASIL & & 1 & 24 & 69 & 65 & 62 & 221 & 17,1 \\
\hline PAISES BAIXOS & 34 & 53 & 64 & 7 & 2 & 3 & 163 & 12,6 \\
\hline ALEMANHA & 11 & 27 & 49 & 9 & 1 & 2 & 99 & 7,7 \\
\hline FRANCA & 1 & 3 & 15 & 9 & & 2 & 30 & 2,3 \\
\hline JAPAO & & 3 & 14 & 2 & & 1 & 20 & 1,5 \\
\hline SUICA & 1 & 7 & 7 & 2 & & & 17 & 1,3 \\
\hline AUSTRALIA & & 4 & 8 & 1 & & 1 & 14 & 1,1 \\
\hline CANADA & 1 & 3 & 7 & 2 & & & 13 & 1,0 \\
\hline REINO UNIDO & 1 & 3 & 2 & 3 & 1 & 3 & 13 & 1,0 \\
\hline INDIA & & 1 & 3 & 6 & & 1 & 11 & 0,9 \\
\hline ESPANHA & & 1 & 1 & 5 & 2 & 2 & 11 & 0,9 \\
\hline POLONIA & & 1 & 6 & 3 & & & 10 & 0,8 \\
\hline ITALIA & & & 5 & 5 & & & 10 & 0,8 \\
\hline COLOMBIA & & & & 7 & 2 & 1 & 10 & 0,8 \\
\hline DINAMARCA & 2 & & 6 & 1 & & & 9 & 0,7 \\
\hline CHILE & & & 2 & 5 & 2 & & 9 & 0,7 \\
\hline REPUBLICA CHECA & & & 8 & & & & 8 & 0,6 \\
\hline ARGENTINA & & & & 4 & 4 & & 8 & 0,6 \\
\hline AUSTRIA & 1 & 1 & 3 & 1 & & 1 & 7 & 0,5 \\
\hline INTERNATIONAL & & & 2 & 2 & & 3 & 7 & 0,5 \\
\hline MEXICO & & & 1 & 4 & 2 & & 7 & 0,5 \\
\hline IRLANDA & 2 & 2 & 2 & & & & 6 & 0,5 \\
\hline NORUEGA & & 1 & 4 & & & & 5 & 0,4 \\
\hline NOVAZELANDIA & & & 2 & 2 & 1 & & 5 & 0,4 \\
\hline AFRICA DO SUL & & & 3 & & 1 & & 4 & 0,3 \\
\hline VENEZUELA & & & & 4 & & & 4 & 0,3 \\
\hline REPUBLICA POPULAR DA CHINA & 1 & & 2 & & & & 3 & 0,2 \\
\hline ESCOCIA & & 1 & 1 & 1 & & & 3 & 0,2 \\
\hline COREIADO SUL & & & 3 & & & & 3 & 0,2 \\
\hline ESLOVAQUIA & & & 2 & 1 & & & 3 & 0,2 \\
\hline HUNGRIA & & & 2 & 1 & & & 3 & 0,2 \\
\hline RUSSIA & & & & 3 & & & 3 & 0,2 \\
\hline ROMENIA & 1 & & 1 & & & & 2 & 0,2 \\
\hline CINGAPURA & & & 1 & 1 & & & 2 & 0,2 \\
\hline FINLANDIA & & & 1 & 1 & & & 2 & 0,2 \\
\hline CUBA & & & & 1 & & 1 & 2 & 0,2 \\
\hline NIGERIA & & & & 1 & & 1 & 2 & 0,2 \\
\hline SUECIA & & 1 & & & & & 1 & 0,1 \\
\hline TAIWAN & & & 1 & & & & 1 & 0,1 \\
\hline BELGICA & & & & 1 & & & 1 & 0,1 \\
\hline COSTA RICA & & & & 1 & & & 1 & 0,1 \\
\hline CROACIA & & & & 1 & & & 1 & 0,1 \\
\hline GRECIA & & & & 1 & & & 1 & 0,1 \\
\hline ISRAEL & & & & 1 & & & 1 & 0,1 \\
\hline QUENIA & & & & 1 & & & 1 & 0,1 \\
\hline PERU & & & & & & 1 & 1 & 0,1 \\
\hline Total Geral & 220 & 236 & 441 & 214 & 86 & 94 & 1291 & 100 \\
\hline
\end{tabular}

Fonte: elaborado com base no Qualis Periódicos da Área de Biodiversidade (http://qualis.capes.gov.br/webqualis/principal.seam. 
A indexação em bases de dados constitui-se em um dos aspectos observados em processos de avaliação de periódicos científicos. Dentre as funções exercidas pelas bases de dados, pode-se destacar a aplicação de critérios de seleção para a formação e desenvolvimento de suas respectivas coleções. Devido a esta função, as bases de dados exercem importante papel no controle de qualidade dos periódicos científicos. A Tabela 8 apresenta dados que relacionam a quantidade de periódicos com indexação em bases de dados à classificação nos estratos Qualis.

A classificação do Qualis inclui em seus critérios a indexação em bases de dados, conforme segue: A1, A2, B1 e B2 devem incluir títulos com indexação no WoS e Scopus; e B3 deve reunir periódicos incluídos no SciELO. Desta forma, é esperado um predomínio de periódicos indexados no WoS e Scopus nos estratos mais elevados, conforme apresentado na Tabela 8. Porém, nota-se a existência de periódicos indexados nestas bases em extratos inferiores (B3 e B4), o que pode significar um equívoco quanto à classificação destes veículos ou que os mesmos foram indexados nas referidas bases, após 2010. O mesmo foi constado quanto à indexação em SciELO.

Analisando concentração de títulos em SciELO, verifica-se que 96 títulos, que representam $78 \%$ do total disponível nesta fonte de informação, concentram-se nos estratos superiores - A2, B1, B2 - o que representa uma coerência de indexação entre as bases de dados e o SciELO quanto à seleção dos títulos, bem como pode significar um indicativo dos periódicos mais representativos. 
Tabela 8. Distribuição dos periódicos por estratos

Qualis e por bases de indexação

\begin{tabular}{|l|c|c|c|c|c|c|c|}
\hline $\begin{array}{l}\text { Estrato } \\
\text { Qualis }\end{array}$ & SciEL_O & $\begin{array}{c}\text { Não } \\
\text { SciELO }\end{array}$ & WoS & $\begin{array}{c}\text { Não } \\
\text { WoS }\end{array}$ & $\begin{array}{c}\text { Não } \\
\text { Scopus }\end{array}$ & $\begin{array}{c}\text { Total } \\
\text { Seriódicos } \\
\text { por estrato }\end{array}$ \\
\hline A1 & 0 & 220 & 214 & 6 & 218 & 2 & $\mathbf{2 2 0}$ \\
\hline A2 & 1 & 235 & 228 & 8 & 233 & 3 & $\mathbf{2 3 6}$ \\
\hline B1 & 24 & 417 & 422 & 19 & 422 & 19 & $\mathbf{4 4 1}$ \\
\hline B2 & 71 & 143 & 154 & 60 & 192 & 22 & $\mathbf{2 1 4}$ \\
\hline B3 & 25 & 61 & 5 & 81 & 12 & 74 & $\mathbf{8 6}$ \\
\hline B4 & 1 & 93 & 2 & 92 & 8 & 86 & $\mathbf{9 4}$ \\
\hline Total & 123 & & 1025 & & 1085 & & 1291 \\
\hline Geral & & & & & & & \\
\hline
\end{tabular}

Fonte: Elaborado com base no Qualis Periódicos da Área de Biodiversidade

(http://qualis.capes.gov.br/webqualis/principal.seam)

Uma última análise da classificação dos periódicos no Qualis Biodiversidade refere-se à distribuição dos títulos segundo as áreas que o compõem: botânica, oceanografia, zoologia e ecologia. Vale destacar que os periódicos da BOZE que foram considerados para a avaliação deste aspecto constituem-se no grupo que será considerado também nas análises de indicadores bibliométricos e de aspectos formais. Para a seleção deste grupo, não foram considerados os periódicos com escopo abrangendo duas ou mais áreas temáticas simultaneamente, o que resultou em uma redução para 402 títulos, conforme Tabela 5 apresentada anteriormente nos procedimentos metodológicos.

Ao analisar os dados disponíveis no

Gráfico 3, é possível verificar a desproporção quanto às porcentagens de periódicos classificados nos estratos superiores, quando comparadas as áreas BOZE. No estrato $A 1$, botânica possui $10 \%$ dos periódicos, oceanografia $7 \%$, zoologia $1 \%$ e ecologia $29 \%$ dos títulos. A desproporção também é observada quando comparados os percentuais para o estrato A2: botânica $20 \%$, oceanografia $24 \%$, zoologia $8 \%$ e ecologia $11 \%$. Nota-se que 
dentre as áreas BOZE, a área de zoologia distingue-se fortemente das demais.

Gráfico 3. Distribuição de periódicos pelas áreas BOZE e estratos Qualis

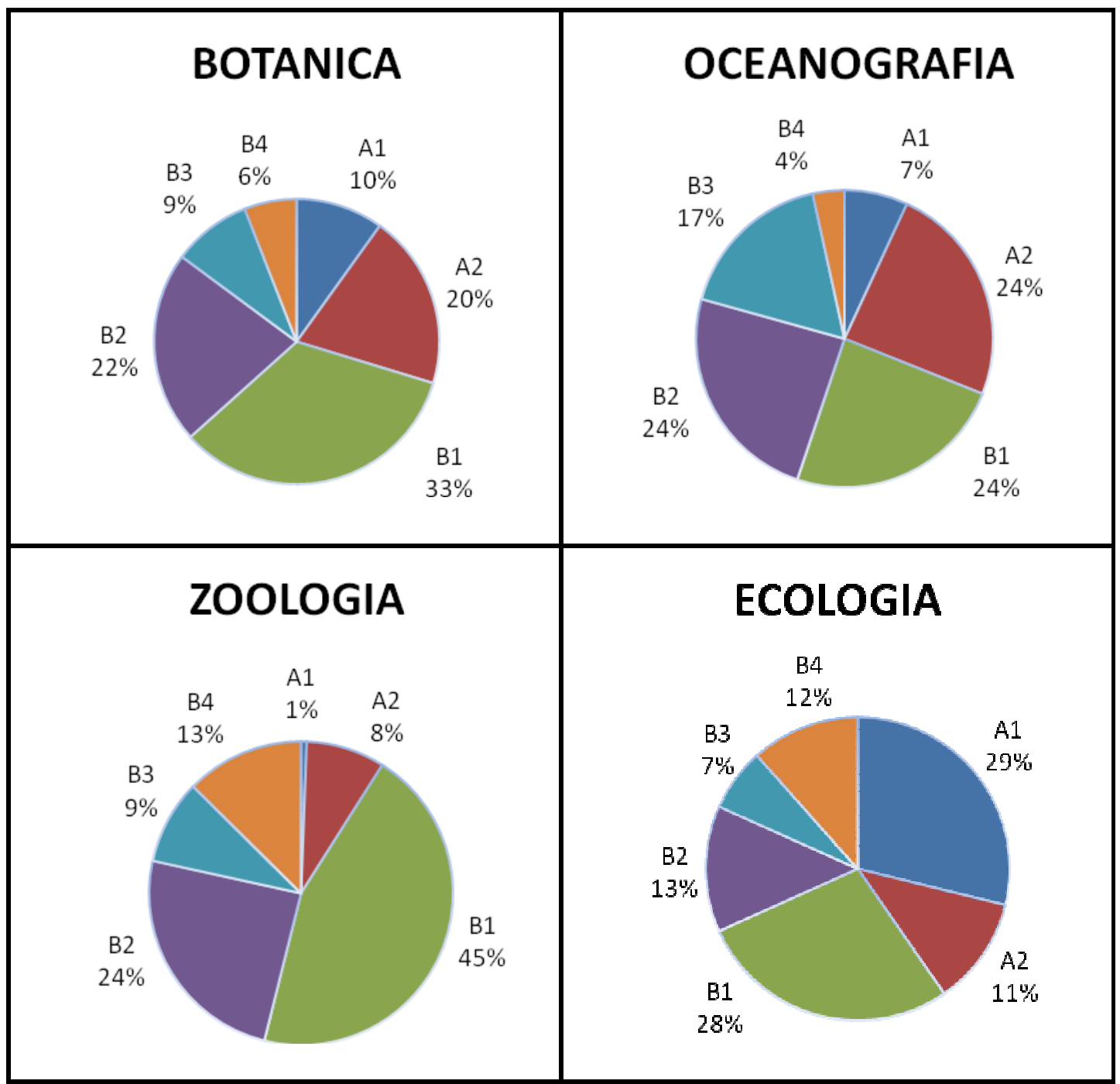

Fonte: Elaborado com base no Qualis Periódicos da Área de Biodiversidade (http://qualis.capes.gov.br/webqualis/principal.seam

Tais dados comprovam a veracidade das críticas da comunidade científica, referentes à junção de áreas tão heterogêneas como a botânica, oceanografia, zoologia e ecologia, bem como da utilização do Fator de Impacto como critério único de avaliação de áreas com dinâmicas tão distintas de geração e citação de informação científica (MACHADO; ZAHER, 
2010). Tais evidências suscitam a necessidade de uma análise mais aprofundada sobre as diferenças entre as áreas BOZE e a limitação do Fator de Impacto para evidenciá-las.

6.1.2 Indicadores Bibliométricos: periódicos dos estratos A1, A2, B1 e B2 (Grupo 1)

Neste tópico serão discutidos os resultados da análise dos indicadores bibliométricos, realizada a partir do fator de impacto e da janela de citações de dois anos, considerando o Grupo 1 que é composto por 325 periódicos das áreas de botânica, oceanografia, zoologia e ecologia, classificados no Qualis Biodiversidade. Os dados referem-se ao período de 2007 a 2011, pois a coleta de dados foi realizada durante o ano de 2012.

Segundo estudo de Archambault e Larivière (apud MUGNAINI, 2013, p. 13), a janela de citação de dois anos constitui-se em um dos cinco aspectos mais criticados quanto à utilização do fator de impacto para a avaliação de periódicos de diferentes áreas científicas. Sua aplicação neste estudo se deve à necessidade de verificar possível inadequação de um critério de avaliação baseado estritamente no Fator de Impacto, considerando-se que a área de biodiversidade avalia um conjunto de periódicos tão díspares, como os das áreas BOZE.

Nos gráficos a seguir - Gráficos 4, 5, 6 e 7 - são apresentados dados do conjunto dos periódicos das áreas de botânica, oceanografia, zoologia e ecologia, referentes às médias, mínimas e máximas, respectivamente: a) da porcentagem na janela de citações em dois anos; b) da variação do fator de impacto ao longo dos anos; c) da distribuição da porcentagem da janela de citações dos periódicos por quartil; e d) da distribuição do fator de impacto dos periódicos por quartil.

O Gráfico 4 apresenta os valores médio, mínimo e máximo da porcentagem captada pela janela de citação do $\mathrm{FI}$ dos periódicos BOZE classificados nos estratos A1, A2, B1 e B2 do Qualis Biodiversidade. 
Pode-se notar que, em 2007, havia periódicos com 99\% das citações incluídas na janela de 2 anos. Por outro lado, o percentual mínimo fica entre 1 e $3 \%$, no período, o que indica a limitação do $\mathrm{FI}$ no caso de alguns periódicos. E a média das porcentagens, correspondentes aos periódicos de cada ano, apresenta valores entre 14 e 15\%, revelando, portanto, um baixo nível percentual para o grupo de periódicos BOZE.

Gráfico 4. Distribuição dos títulos BOZE segundo valores mínimo, médio e máximo da porcentagem da janela de citação e ano do Journal Citation Reports

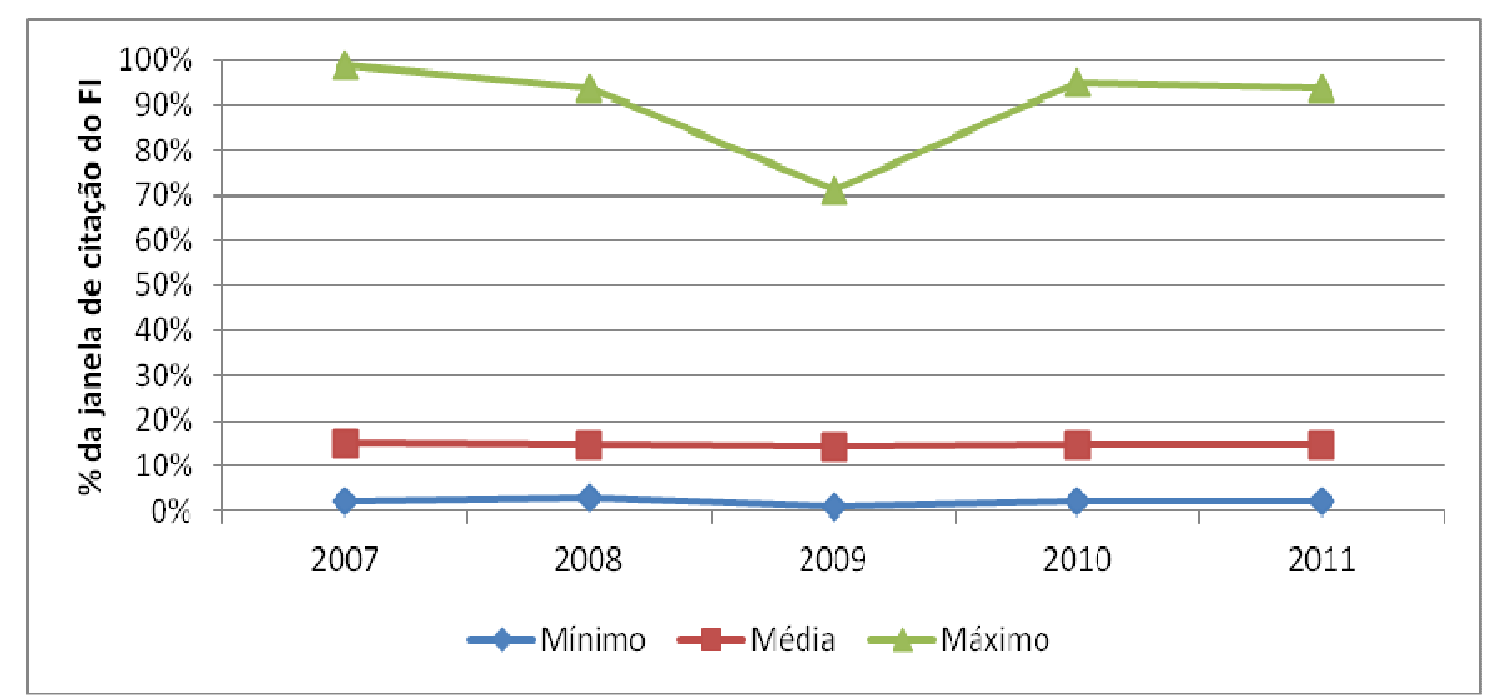

A variação do Fator de Impacto ao longo dos anos é visualizada a partir dos dados contidos no Gráfico 5. A linha que representa o valor máximo do Fator de Impacto mostra uma variação acentuada de crescimento, tendo seus valores passados de 9,2 para 17,6, o que permite afirmar que os pesquisadores da área biodiversidade vêm publicando em periódicos de maior impacto, a cada ano. Já as linhas de valores médios e mínimos para o Fator de Impacto, considerando o mesmo período, mantiveram seus valores inalterados e em patamares bem baixos, em torno de 1,8 e 0,2 , respectivamente. 
Gráfico 5. Distribuição dos títulos BOZE segundo valores mínimo, médio e máximo do Fator de Impacto e ano do Journal Citation Reports

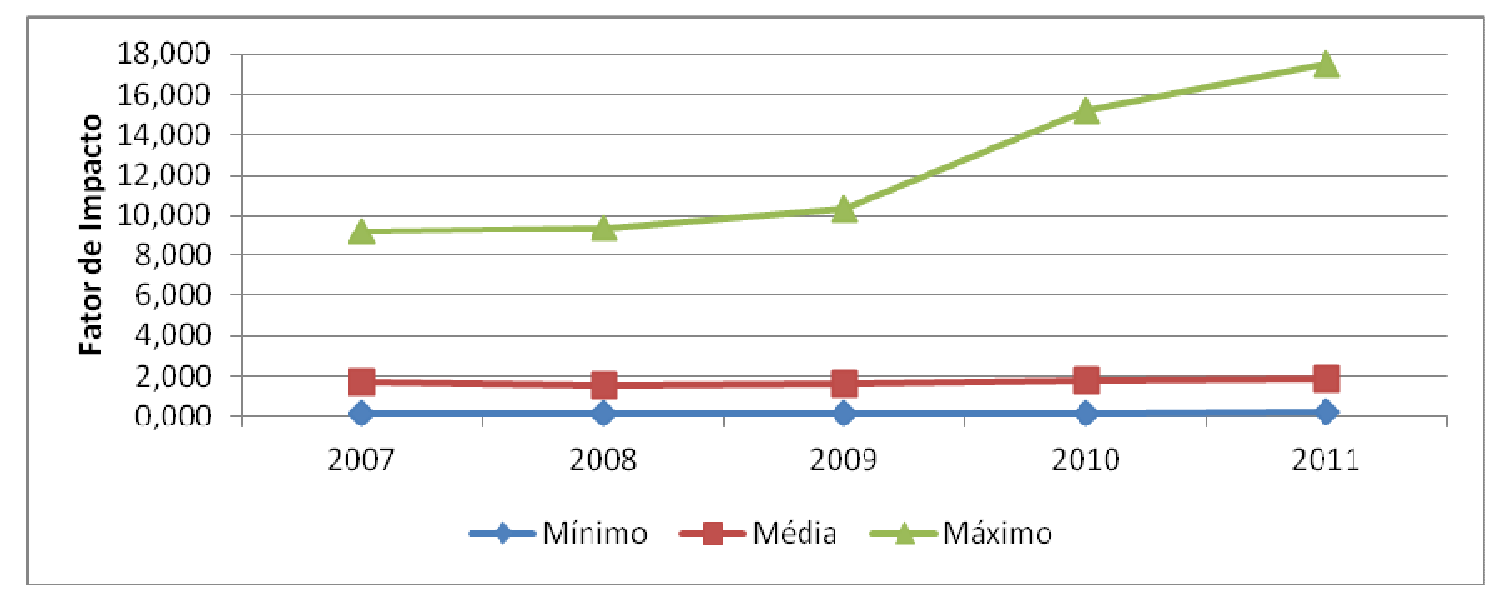

Significa dizer que os periódicos classificados pelo Qualis Biodiversidade apresentam uma baixa média, tanto da porcentagem da janela de citação, como do próprio Fator de Impacto, estando de acordo com as leis de dispersão que mostram alta concentração em baixos valores e pouca concentração em valores altos, fazendo com que a média se aproxime dos valores mais baixos. Tal comportamento faz com que a mediana seja uma medida de tendência central mais apropriada que a média, como se pode observar nos Gráficos 6 e 7.

A análise da distribuição da porcentagem da janela de citação dos periódicos por quartil pode ser realizada a partir dos dados do Gráfico 6 . Observa-se que $75 \%$ dos periódicos possuem cerca de $20 \%$ de suas citações consideradas pelo Fator de Impacto - de acordo com o primeiro quartil, que permanece inalterado entre 2008 e 2011. Já o segundo quartil, ou mediana, concentra-se entre $12 \%$ e $13 \%$, no mesmo período, significando que $50 \%$ dos periódicos captam apenas este percentual das citações; e os do terceiro quartil apresentam esse percentual abaixo de $8 \%$. 
Gráfico 6. Distribuição dos títulos BOZE segundo quartil 1, mediana e quartil 3 da porcentagem da janela de citação e ano do Journal Citation Reports

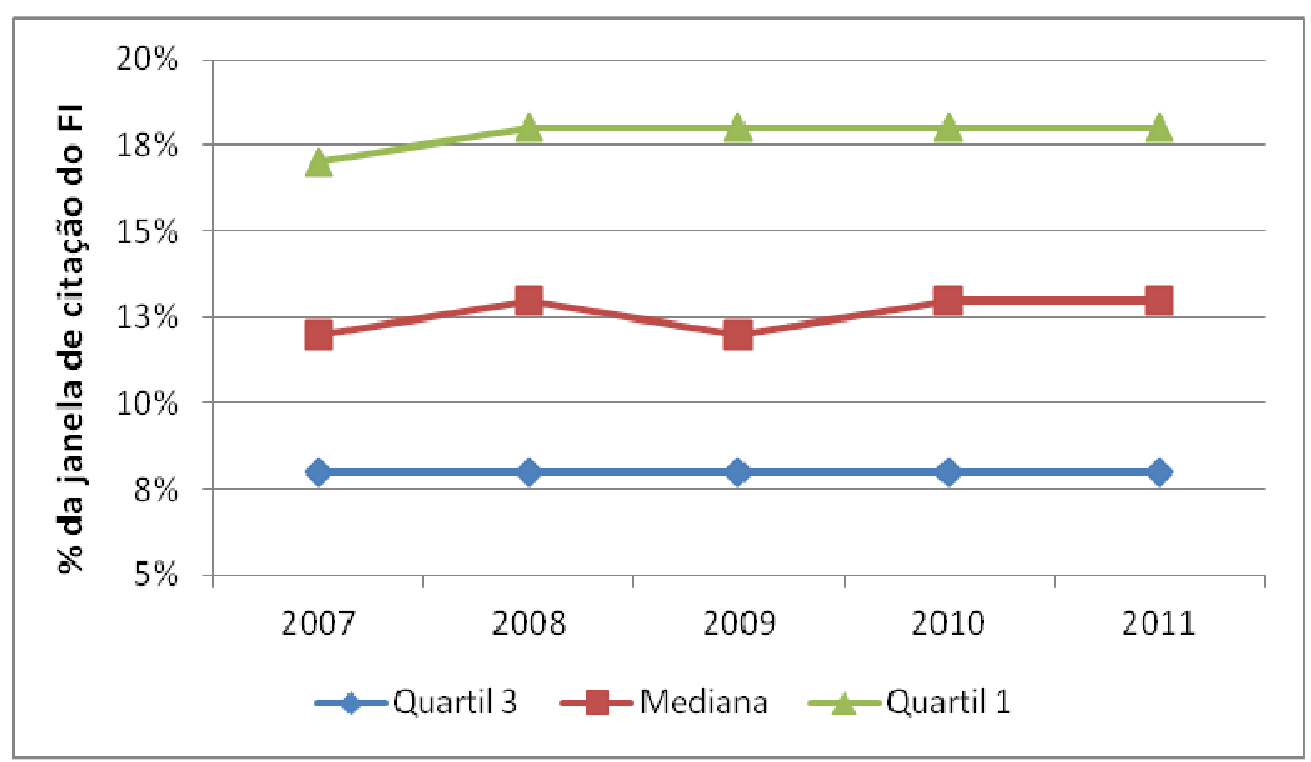

Quanto ao Fator de Impacto (Gráfico 7), observa-se que $25 \%$ dos periódicos possuem valores superiores a 2,0. Porém, nota-se que o Fator de Impacto apresenta ligeiro aumento ao longo do período, contrariamente ao comportamento da porcentagem de janela de citações que, como se pôde observar, permanece inalterada. As linhas intermediárias aos demais quartis, no período, apresentam variação entre 1,2 e 1,5 para o segundo quartil e em torno de 0,8 para o terceiro, estando abaixo desta última os $25 \%$ dos periódicos com os menores Fatores de Impacto.

Estas estatísticas de ordem (quartis) são utilizadas por diversas áreas, para poder separar as faixas percentuais, de maneira a atender as exigências da CAPES, segundo o percentual limite de periódicos nos diversos estratos. 
Gráfico 7. Distribuição dos títulos BOZE segundo quartil 1, mediana e quartil 3 do Fator de Impacto e ano do Journal Citation Reports

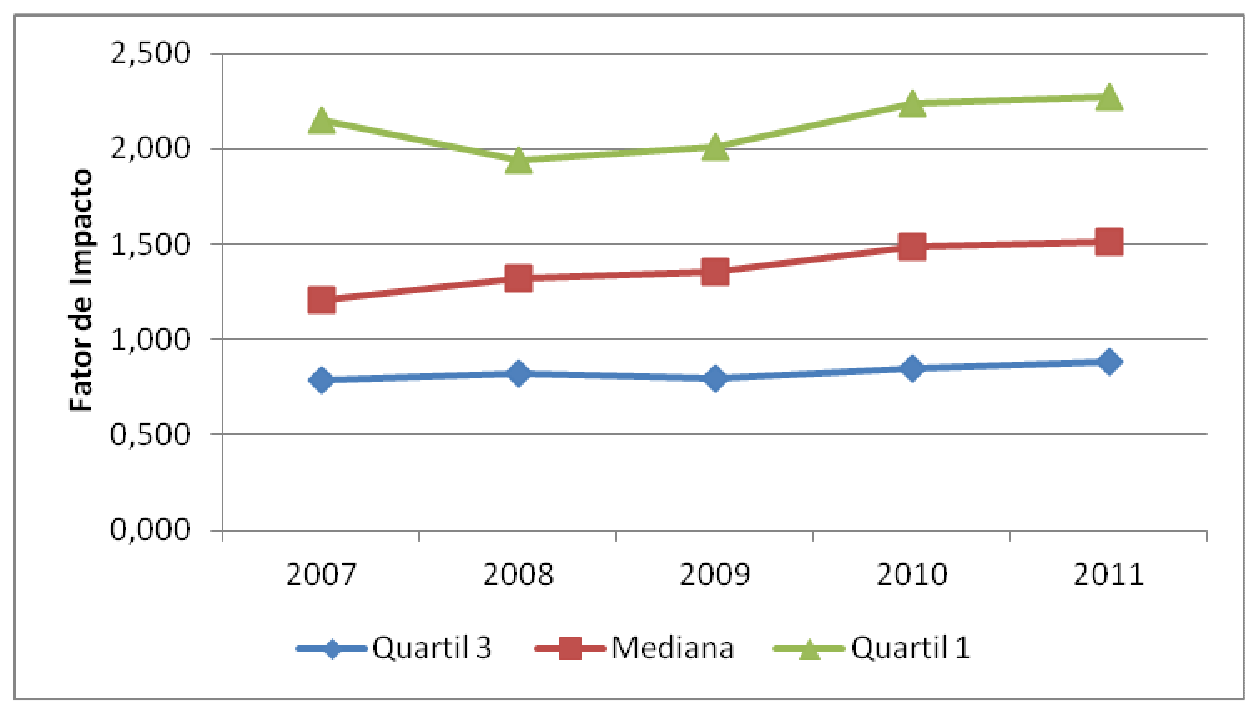

Passando da análise do conjunto (periódicos da área de biodiversidade) para a análise comparativa dos indicadores bibliométricos dos periódicos das áreas BOZE, passa a ser interessante observar qual é a representatividade de cada área em cada um dos 4 subgrupos de periódicos definidos pelos quartis.

O Gráfico 8 representa a evolução por ano da porcentagem da janela de citações de cada área dentro de cada subgrupo. O subgrupo 1 congrega os periódicos cuja janela de citação do FI capta as maiores porcentagens, sendo exemplos de casos em que o Fl é mais adequado. Verifica-se uma alta concentração de periódicos da área de ecologia, com $40 \%$ dos periódicos em 2007, com oscilações durante o período. Neste mesmo subgrupo, as demais áreas apresentam um número menor de periódicos: cerca de $30 \%$ são de botânica, próximo a 30\% para zoologia e entre mínimo para oceanografia.

Percorrendo os demais subgrupos, verifica-se uma diminuição no percentual de periódicos de ecologia e significativo aumento de zoologia. Observa-se que, enquanto ecologia mostra mais adequação ao Fator de Impacto, pois apresenta uma cultura de citação aos documentos publicados mais recentemente; zoologia tem os periódicos cujas citações se dão a 
artigos mais antigos, sendo, portanto, prejudicada quando o Fator de Impacto é tomado como critério único de classificação.

Gráfico 8. Distribuição percentual dos periódicos das áreas BOZE, anualmente, nos diferentes quartis da porcentagem da janela de citação entre o conjunto de periódicos do Grupo1

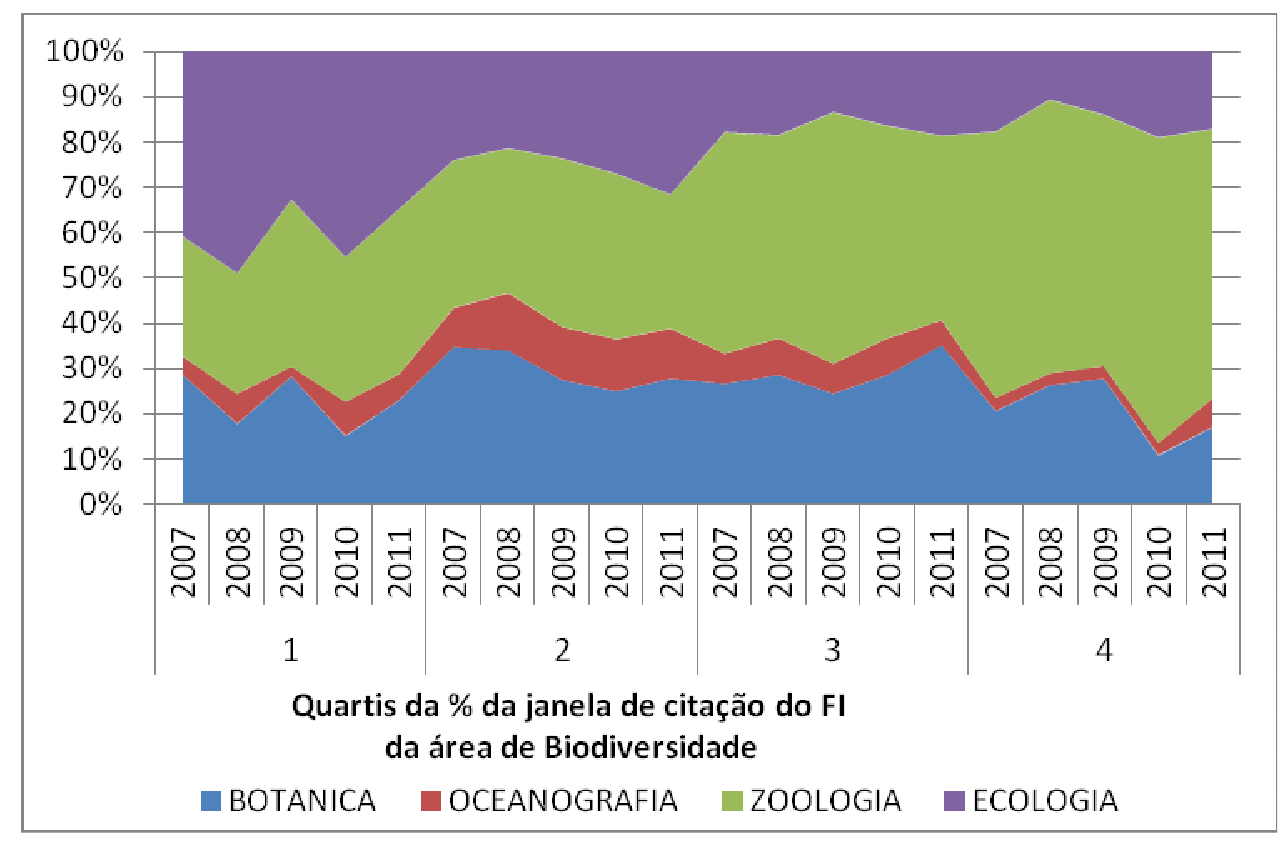

No Gráfico 9, cujos subgrupos foram definidos pelos quartis do Fator de Impacto, o contraste entre ecologia e zoologia supracitado é ainda mais acentuado. Neste caso, a questão que suscita é se os periódicos de ecologia do subgrupo 1, ou seja, com maior Fator de Impacto (Gráfico 10) são os mesmos que do subgrupo 1 do Gráfico 9, sugerindo que: pelo fato de concentrar um maior percentual do total de citações, o valor do Fator de Impacto é maior.

No outro extremo, indaga-se se os periódicos da área de zoologia, predominando o subgrupo 4 nos mesmos gráficos, apresentam menor Fator de Impacto, em virtude da captação de um diminuto percentual do total de citações. 
Gráfico 9. Distribuição percentual dos periódicos das áreas BOZE, anualmente, nos diferentes quartis do Fator de Impacto entre o conjunto de periódicos do Grupo1

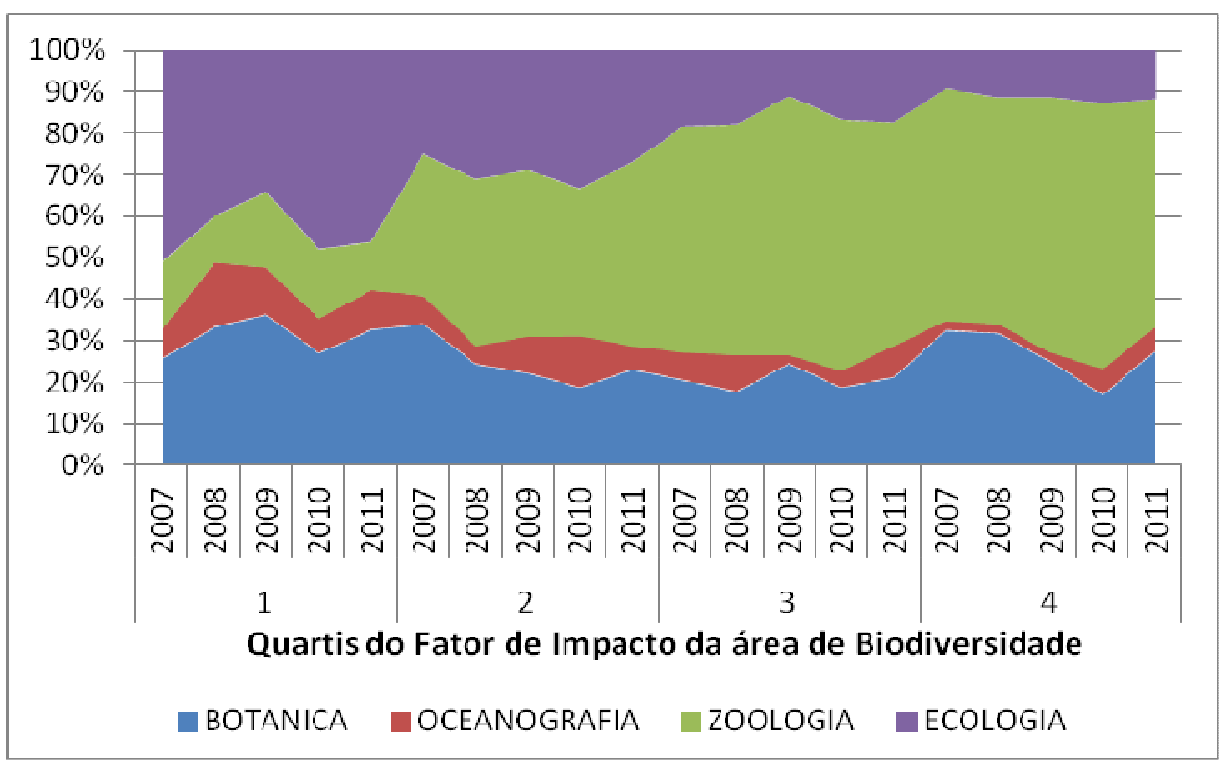

Para investigar esta questão, duas variáveis devem que ser analisadas conjuntamente. Os quatro gráficos que se seguem - Gráficos 10, 11, 12 e 13 - representam o desempenho dos periódicos quanto ao Fator de Impacto versus a porcentagem da janela de citações, no ano mais recente (2011), respectivamente, das áreas de botânica, oceanografia, zoologia e ecologia.

Em cada um deles, foram inseridas duas grades - horizontais e verticais - que representam os quartis 1 e 3 . Ou seja, fora da área determinada por estas grades, pode-se identificar os subgrupos 4 para ambos indicadores. Neste retângulo, que se forma na parte inferior esquerda, concentram-se os periódicos cuja janela de citação capta um percentual muito pequeno das citações, sendo o Fator de Impacto prejudicado.

Uma primeira observação é que a área que concentra o maior número de periódicos neste retângulo é notoriamente a zoologia (13 periódicos, segundo Gráfico 13). Para as demais áreas - ecologia (Gráfico 10), botânica (Gráfico 11) e Oceanografia (Gráfico 12) - encontram-se, respectivamente: 2, 3 e 1 periódicos. 
A seguir, são listados os periódicos dos subgrupos 4 (Tabela 9):

Tabela 9. Periódico dos subgrupos 4

\begin{tabular}{|c|c|c|c|c|c|c|c|c|}
\hline \# & Título & Area_BOZE & Estrato & $\begin{array}{l}\text { Porc } \\
\text { Jan } 2\end{array}$ & Cits_all & \begin{tabular}{|c|} 
Fator \\
Impacto \\
\end{tabular} & \begin{tabular}{|l|} 
Quartil \\
FI JCR \\
\end{tabular} & Area_melhor_quart \\
\hline 1 & $\begin{array}{l}\text { NEW ZEALAND JOURNAL OF } \\
\text { BOTANY }\end{array}$ & BOTANICA & B1 & $4,0 \%$ & 946 & 0,745 & $3 Q$ & PLANT SCIENCES \\
\hline 2 & JOURNAL OF PLANT NUTRITION & BOTANICA & B1 & $7,0 \%$ & 3081 & 0,641 & $3 Q$ & PLANT SCIENCES \\
\hline 3 & ADANSONIA & BOTANICA & B2 & $6,0 \%$ & 217 & 0,325 & $4 Q$ & PLANT SCIENCES \\
\hline 4 & THE SOUTHWESTERN NATURALIST & ECOLOGIA & B2 & $5,0 \%$ & 1005 & 0,309 & $4 Q$ & $\begin{array}{l}\text { BIODIVERSITY } \\
\text { CONSERVATION }\end{array}$ \\
\hline 5 & REVUE D'ECOLOGIE & ECOLOGIA & B2 & $4,0 \%$ & 363 & 0,236 & $4 Q$ & ECOLOGY \\
\hline 6 & CIENCIAS MARINAS & $\begin{array}{l}\text { OCEANOGRA } \\
\text { FIA }\end{array}$ & B2 & $6,0 \%$ & 432 & 0,452 & $4 Q$ & $\begin{array}{l}\text { MARINE \& } \\
\text { FRESHWATER } \\
\text { BIOLOGY }\end{array}$ \\
\hline 7 & VIE ET MILIEU (1980) & ZOOLOGIA & B2 & $2,0 \%$ & 567 & 0,421 & $4 Q$ & ECOLOGY \\
\hline 8 & THE JOURNAL OF ARACHNOLOGY & ZOOLOGIA & B1 & $5,0 \%$ & 1481 & 0,626 & 30 & ENTOMOLOGY \\
\hline 9 & THE COLEOPTERISTS BULLETIN & ZOOLOGIA & B2 & $6,0 \%$ & 577 & 0,404 & $4 Q$ & ENTOMOLOGY \\
\hline 10 & REVUE SUISSE DE ZOOLOGIE & ZOOLOGIA & B2 & $3,0 \%$ & 783 & 0,351 & $4 Q$ & ZOOLOGY \\
\hline 11 & ODONATOLOGICA (UTRECHT) & ZOOLOGIA & B2 & $6,0 \%$ & 365 & 0,355 & $4 Q$ & ENTOMOLOGY \\
\hline 12 & $\begin{array}{l}\text { JOURNAL OF THE KANSAS } \\
\text { ENTOMOLOGICAL SOCIETY }\end{array}$ & ZOOLOGIA & B1 & $3,0 \%$ & 1040 & 0,493 & 30 & ENTOMOLOGY \\
\hline 13 & JOURNAL OF SHELLFISH RESEARCH & ZOOLOGIA & B1 & $7,0 \%$ & 2263 & 0,793 & $4 Q$ & FISHERIES \\
\hline 14 & $\begin{array}{l}\text { INVERTEBRATE REPRODUCTION \& } \\
\text { DEVELOPMENT }\end{array}$ & ZOOLOGIA & B2 & $4,0 \%$ & 580 & 0,478 & $4 Q$ & $\begin{array}{l}\text { REPRODUCTIVE } \\
\text { BIOLOGY }\end{array}$ \\
\hline 15 & CYBIUM (PARIS) & ZOOLOGIA & B2 & $5,0 \%$ & 658 & 0,404 & $4 Q$ & ZOOLOGY \\
\hline 16 & CRUSTACEANA (LEIDEN. PRINT) & ZOOLOGIA & B1 & $6,0 \%$ & 1780 & 0,464 & $4 Q$ & $\begin{array}{l}\text { MARINE \& } \\
\text { FRESHWATER } \\
\text { BIOLOGY }\end{array}$ \\
\hline 17 & BELGIAN JOURNAL OF ZOOLOGY & ZOOLOGIA & B2 & $4,0 \%$ & 349 & 0,531 & $4 Q$ & ZOOLOGY \\
\hline 18 & $\begin{array}{l}\text { AUSTRALIAN JOURNAL OF ZOOLOGY } \\
\text { (PRINT) }\end{array}$ & ZOOLOGIA & B1 & $4,0 \%$ & 1611 & 0,722 & 30 & ZOOLOGY \\
\hline 19 & $\begin{array}{l}\text { ANNALES DE LA SOCIETE } \\
\text { ENTOMOLOGIQUE DE FRANCE }\end{array}$ & ZOOLOGIA & B1 & $2,0 \%$ & 1154 & 0,537 & 30 & ENTOMOLOGY \\
\hline
\end{tabular}

Vale destacar que para a apresentação destes gráficos foram desconsiderados 2 títulos das áreas de zoologia e ecologia, devido à discrepância dos indicadores apresentados. Desta forma, retirou-se respectivamente: o periódico Zoologia, por apresentar porcentagem da janela de citação de 94\%; e o periódico Ecology Letters, por apresentar Fator de Impacto de 17,557. 
Gráfico 10. Distribuição dos periódicos de ecologia quanto ao Fator de Impacto versus a porcentagem da janela de citações, ano 2012

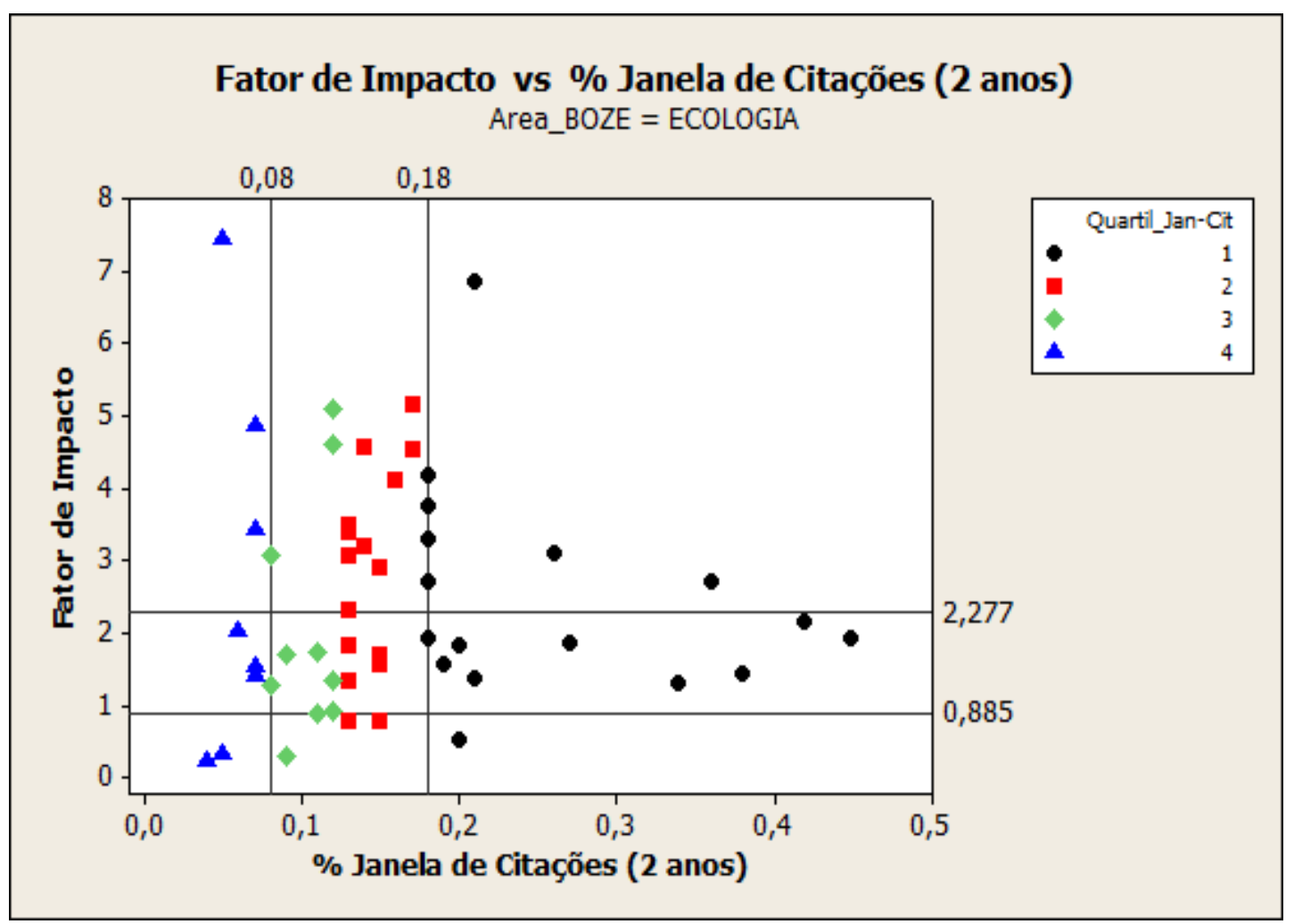

Gráfico 11. Distribuição dos periódicos de botânica quanto ao Fator de Impacto versus a porcentagem da janela de citações, ano

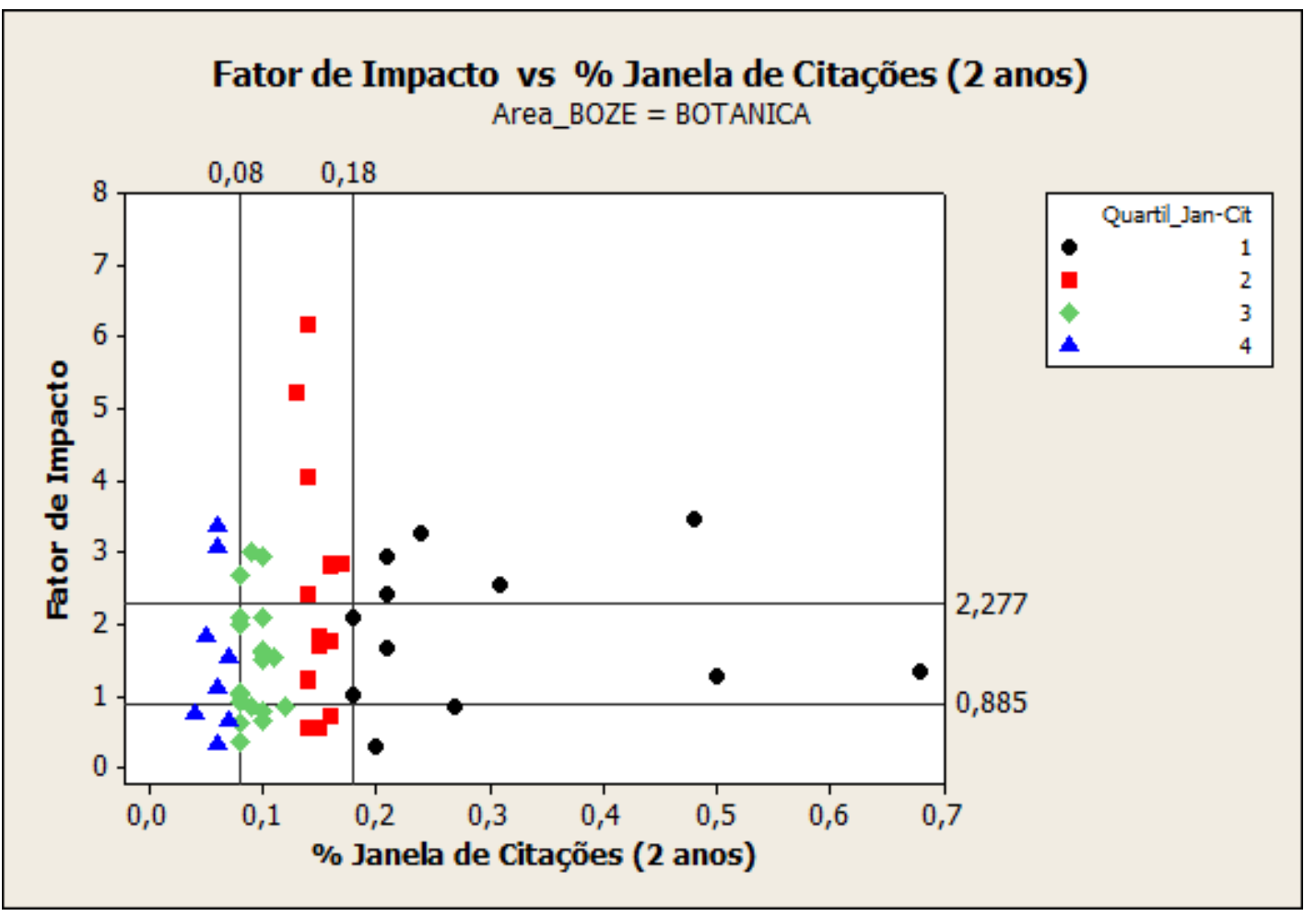


Gráfico 12. Distribuição dos periódicos de oceanografia quanto ao Fator de Impacto versus a porcentagem da janela de citações, ano 2012

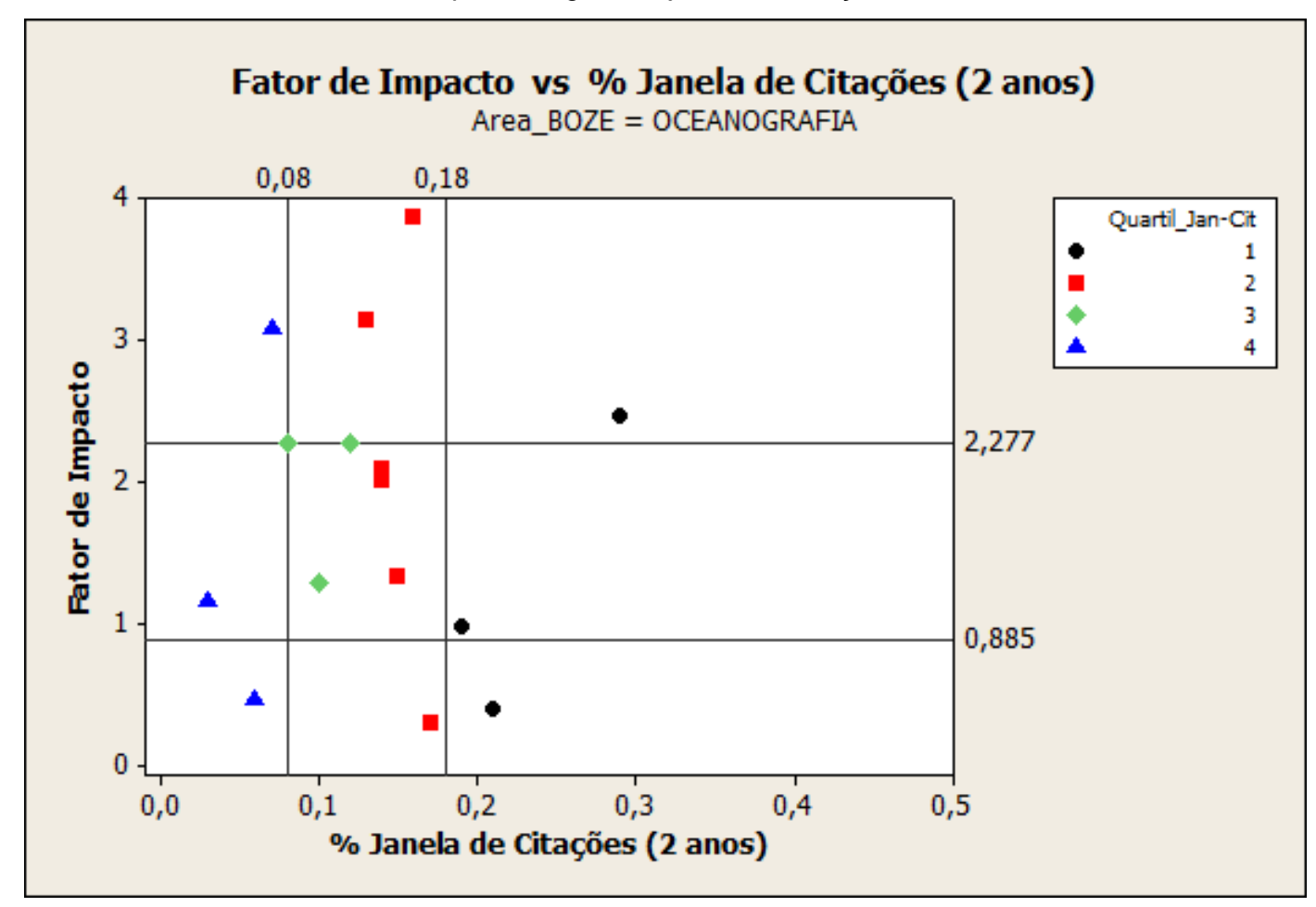

Gráfico 13. Distribuição dos periódicos de zoologia quanto ao Fator de Impacto versus a porcentagem da janela de citações, ano 2012

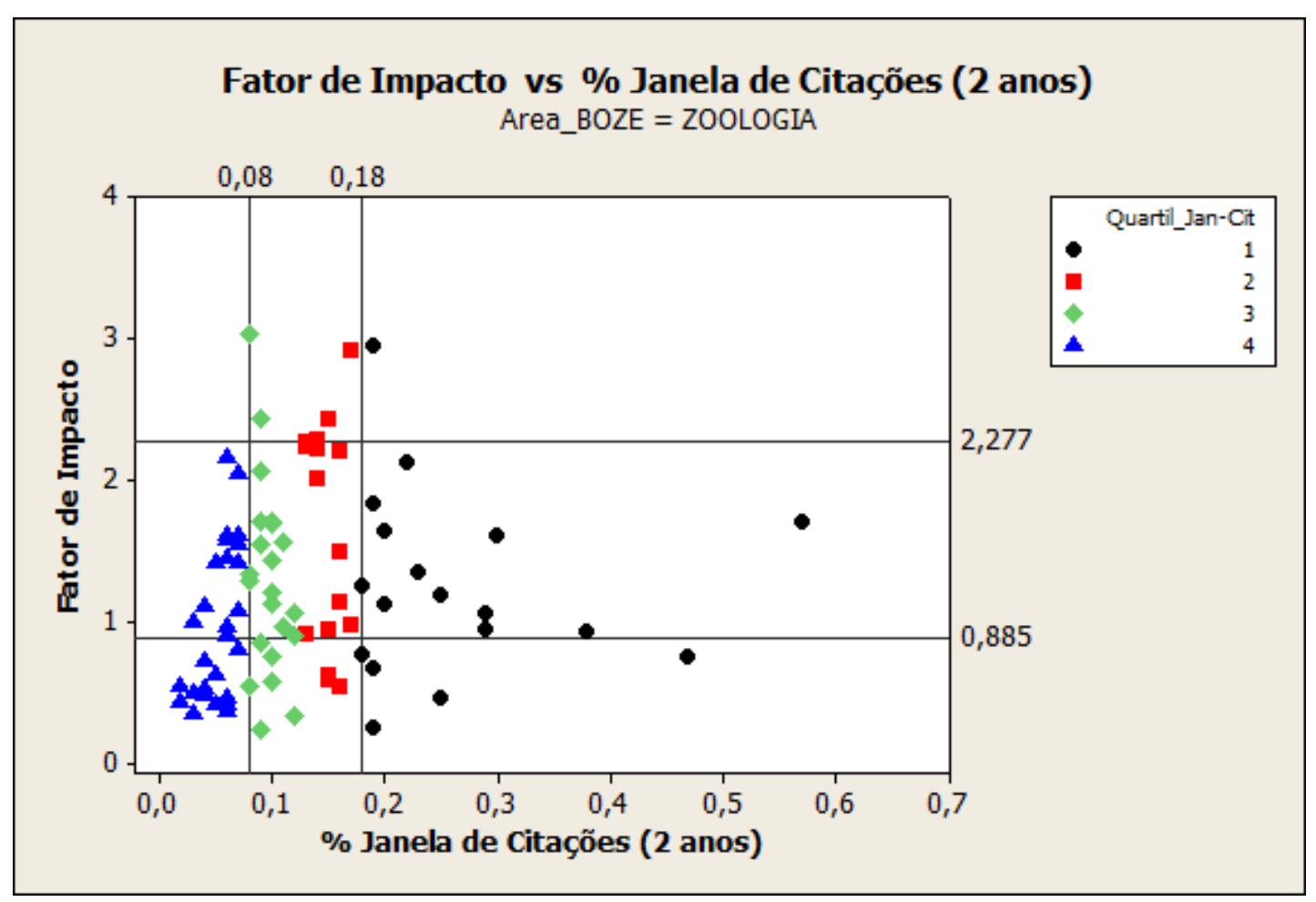


Nesta etapa, considerou-se interessante analisar também o número de periódicos nos subgrupos 1, que reúnem os periódicos de maior Fator de Impacto e maior porcentagem de citações captadas pela janela de 2 anos.

A seguir, são listados os periódicos dos subgrupos 1 (Tabela 10):

Tabela 10. Periódicos dos subgrupos 1

\begin{tabular}{|c|c|c|c|c|c|c|c|c|}
\hline$\#$ & Tit_compl & Area_BOZE & Estrato & $\begin{array}{l}\text { Porc } \\
\text { Jan_2 } \\
\end{array}$ & Cits_all & $\begin{array}{c}\text { Fator } \\
\text { Impacto } \\
\end{array}$ & $\begin{array}{l}\text { Quartil } \\
\text { FI_JCR } \\
\end{array}$ & Area_melhor_quart \\
\hline 1 & PLANT BIOLOGY (STUTTGART) & BOTANICA & $\mathrm{A} 2$ & $21 \%$ & 2485 & 2,395 & $2 Q$ & PLANT SCIENCES \\
\hline 2 & PHYTOMEDICINE (STUTTGART) & BOTANICA & $A 2$ & $24 \%$ & 4731 & 3,268 & 10 & $\begin{array}{l}\text { CHEMISTRY, } \\
\text { MEDICINAL }\end{array}$ \\
\hline 3 & $\begin{array}{l}\text { JOURNAL OF INTEGRATIVE PLANT } \\
\text { BIOLOGY (PRINT) }\end{array}$ & BOTANICA & B1 & $31 \%$ & 1783 & 2,534 & $2 Q$ & PLANT SCIENCES \\
\hline 4 & $\begin{array}{l}\text { FUNCTIONAL PLANT BIOLOGY } \\
\text { (PRINT) }\end{array}$ & BOTANICA & $\mathrm{A} 2$ & $21 \%$ & 2970 & 2,929 & 10 & PLANT SCIENCES \\
\hline 5 & BMC PLANT BIOLOGY (ONLINE) & BOTANICA & A1 & $48 \%$ & 3198 & 3,447 & 10 & PLANT SCIENCES \\
\hline 6 & $\begin{array}{l}\text { SCIENCE OF THE TOTAL } \\
\text { ENVIRONMENT }\end{array}$ & ECOLOGIA & $\mathrm{A} 1$ & $18 \%$ & 25057 & 3,286 & 10 & $\begin{array}{l}\text { ENVIRONMENTAL } \\
\text { SCIENCES }\end{array}$ \\
\hline 7 & $\begin{array}{l}\text { GLOBAL ENVIRONMENTAL } \\
\text { CHANGE }\end{array}$ & ECOLOGIA & A1 & $21 \%$ & 3816 & 6,868 & 1Q & $\begin{array}{l}\text { ENVIRONMENTAL } \\
\text { SCIENCES }\end{array}$ \\
\hline 8 & $\begin{array}{l}\text { ENVIRONMENTAL POLLUTION } \\
(1987)\end{array}$ & ECOLOGIA & $\mathrm{A} 1$ & $18 \%$ & 19146 & 3,746 & 10 & $\begin{array}{l}\text { ENVIRONMENTAL } \\
\text { SCIENCES }\end{array}$ \\
\hline 9 & ECOLOGY LETTERS (PRINT) & ECOLOGIA & $\mathrm{A} 1$ & $18 \%$ & 14561 & 17,557 & 1Q & ECOLOGY \\
\hline 10 & ECOLOGICAL INDICATORS & ECOLOGIA & A1 & $36 \%$ & 2028 & 2,695 & 10 & $\begin{array}{l}\text { ENVIRONMENTAL } \\
\text { SCIENCES }\end{array}$ \\
\hline 11 & ECOLOGICAL ENGINEERING & ECOLOGIA & $A 2$ & $26 \%$ & 4607 & 3,106 & 10 & $\begin{array}{l}\text { ENGINEERING, } \\
\text { ENVIRONMENTAL }\end{array}$ \\
\hline 12 & $\begin{array}{l}\text { ECOLOGICAL ECONOMICS } \\
\text { (AMSTERDAM) }\end{array}$ & ECOLOGIA & $\mathrm{A} 2$ & $18 \%$ & 8115 & 2,713 & 1Q & ECONOMICS \\
\hline 13 & ECOGRAPHY (COPENHAGEN) & ECOLOGIA & $\mathrm{A} 1$ & $18 \%$ & 5317 & 4,188 & $1 Q$ & $\begin{array}{l}\text { BIODIVERSITY } \\
\text { CONSERVATION }\end{array}$ \\
\hline 14 & $\begin{array}{l}\text { OCEAN MODELLING (OXFORD. } \\
\text { PRINT) }\end{array}$ & $\begin{array}{l}\text { OCEANOGRA } \\
\text { FIA }\end{array}$ & $\mathrm{A} 2$ & $29 \%$ & 1593 & 2,462 & 10 & OCEANOGRAPHY \\
\hline 15 & $\begin{array}{l}\text { SYSTEMATIC ENTOMOLOGY } \\
\text { (PRINT) }\end{array}$ & ZOOLOGIA & $\mathrm{A} 2$ & $19 \%$ & 1367 & 2,943 & 10 & ENTOMOLOGY \\
\hline
\end{tabular}

Devido à alta porcentagem de periódicos de zoologia no subgrupo 4 do Fator de Impacto e subgrupo 4 da janela de citações, faz-se necessária a análise da evolução do número de periódicos com estas características ao longo dos anos, o que analogamente, deve ser feito para os subgrupos 1 .

Os Gráficos 14 e 15 referentes ao subgrupo mostram o desempenho destacado da área de ecologia, em detrimento do desempenho inferior da área de zoologia e oceanografia. Tal resultado pode ser constatado a partir da avaliação dos dados do Gráfico 15, referentes aos subgrupos 4, onde fica 
evidente a alta concentração dos periódicos da área de zoologia no quartil mais baixo, com uma tendência que se acentua ao longo do período.

Vale destacar que, devido ao pequeno número de periódicos da área de Oceanografia, a análise do desempenho destes títulos deve ser feita com devida cautela.

Gráfico 14. Distribuição do número de periódicos BOZE dos subgrupos 1 , que reúnem os periódicos de maior Fator de Impacto e maior porcentagem de citações captadas pela janela de 2 anos, anos 2007-2011

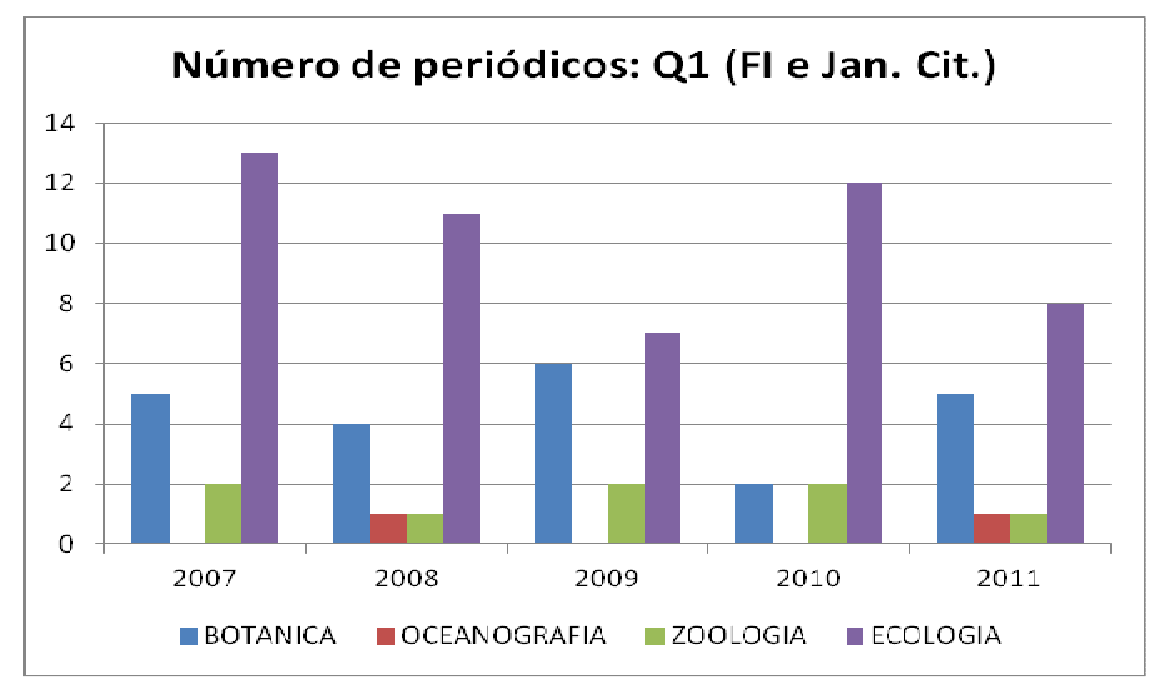

Gráfico 15. Distribuição do número de periódicos BOZE dos subgrupos 4, que reúnem os periódicos de menor Fator de Impacto e menor porcentagem de citações captadas pela janela de 2 anos, anos 2007-2011

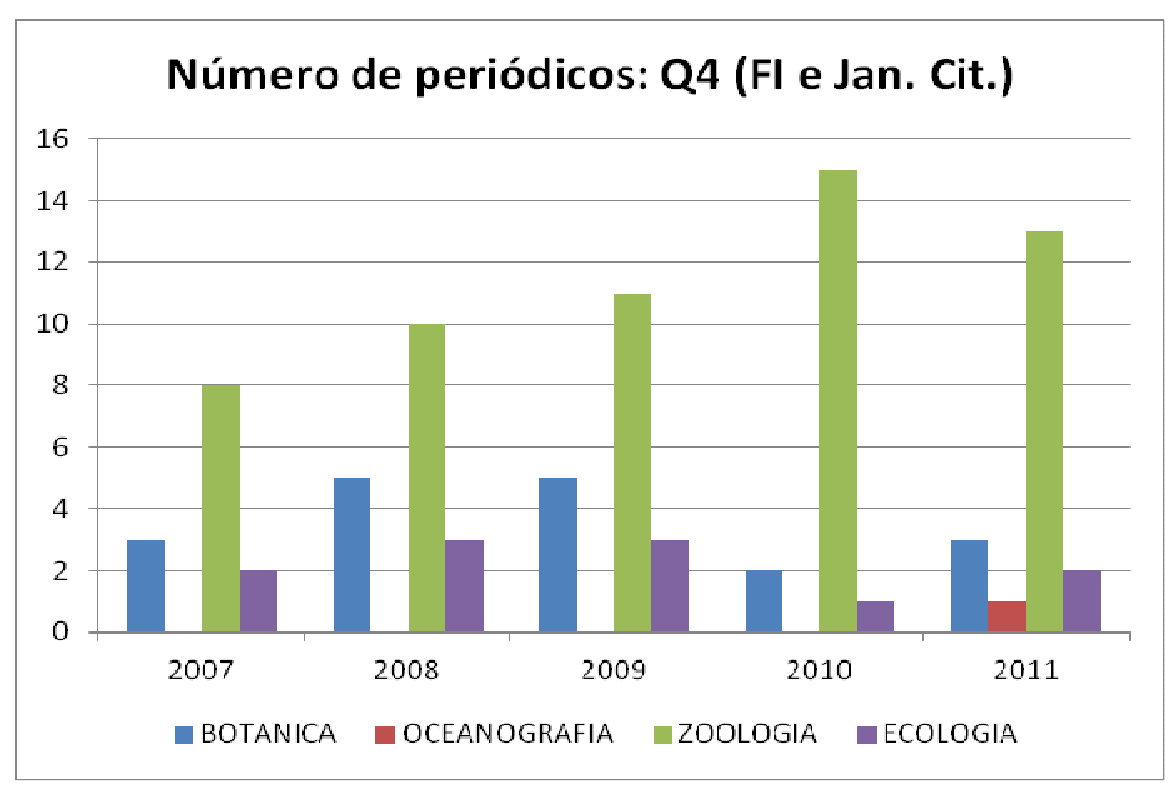


A análise dos periódicos das áreas BOZE, a partir de indicadores bibliométricos, demonstrou haver diferenças significativas quanto à dinâmica de citações da produção científica, com destaque para as áreas de ecologia (maior obsolescência da literatura) e zoologia (menor obsolescência da literatura) que ocupam os extremos quando avaliado o desempenho dos periódicos. Os dados também evidenciaram que, principalmente, a área de zoologia vem sendo prejudicada, considerando-se os critérios de classificação atuais adotados pelo Qualis da Área de Biodiversidade.

\subsection{ASPECTOS FORMAIS: PERIÓDICOS DOS ESTRATOS B3 E B4 (GRUPO 2)}

A análise de aspectos formais incluiu 44 periódicos nacionais e estrangeiros, das áreas de botânica, oceanografia, zoologia e ecologia, classificados nos estratos B3 e B4 do Qualis da Área de Biodiversidade, identificado no estudo como o Grupo 2.

$\mathrm{Na}$ análise, foram considerados aspectos formais que possibilitassem verificar o atendimento a critérios mínimos de qualidade, bem como identificar especificidades das áreas de botânica, oceanografia, zoologia e ecologia, quanto à dinâmica de publicação de informação científica, que são apresentados à continuação.

\section{a) Tempo de existência ou duração}

Dentre os aspectos formais considerados na avaliação de periódicos científicos, o tempo de existência ou duração constitui-se em um critério de qualidade que reflete a tradição e continuidade na publicação (STUMPF, 2003). Embora o tempo de existência não seja suficiente para caracterizar um periódico como de qualidade, a observação deste aspecto deve ser considerada nos processos de avaliação, juntamente com outros indicadores. 
A análise do tempo de existência do conjunto de periódicos do Grupo 2 (Gráfico 16) possibilitou identificar um predomínio de periódicos com criação recente (36,2\%), com $59,6 \%$ dos títulos com até 20 anos de criação. Vale destacar a existência de $19,2 \%$ dos títulos com mais de 41 anos de existência, o que corresponde dizer que, entre os periódicos classificados nos estratos B3 e B4, existem títulos com significativo legado histórico.

Gráfico 16. Distribuição dos periódicos por tempo de existência

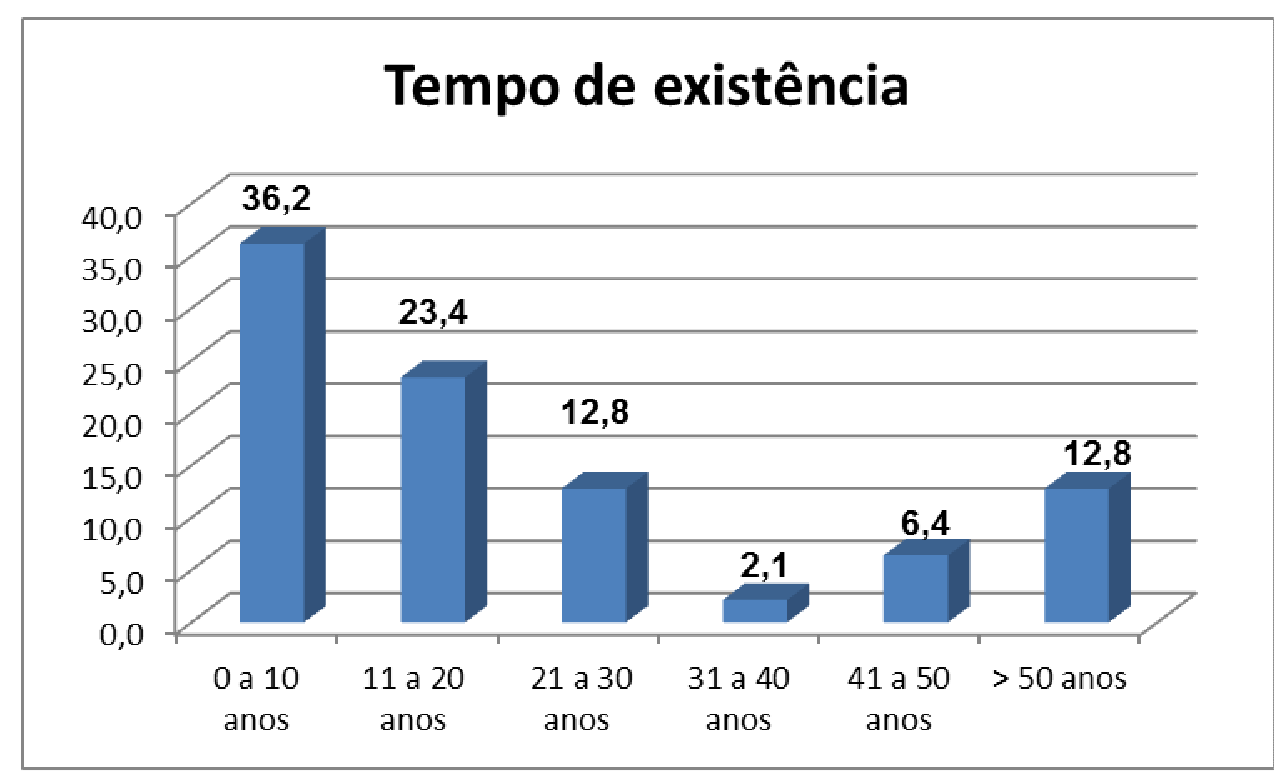

Fonte: elaborado a partir dos dados do Portal do ISSN (http://portal.issn.org/cgi-bin/gw/chameleon)

Considerando o grupo analisado, o periódico com maior tempo de existência é o Zoologische Mededelingen, da área de Zoologia, que foi criado em 1915, nos Países Baixos; dentre os periódicos com menor tempo de existência, podemos citar três títulos criados em 2009: a) Phytotaxa, da área de Botânica (Nova Zelândia); b) AOB Plants, também de Botânica (Reino Unido); c) Journal of Ecology And The Natural Environment (JENE), da área de Ecologia (Nigéria).

Ao analisar de forma comparativa o tempo de existências das áreas BOZE, verificou-se que os periódicos da área ecologia não possuem títulos com mais de 31 anos de existência. Por outro lado, a área de botânica apresentou a maior porcentagem (40\%) de periódicos com mais de 41 anos 
de criação. Zoologia e oceanografia apresentaram índices próximos, com $18,2 \%$ e $25 \%$ respectivamente (Tabela 11 ).

Tabela 11. Distribuição dos periódicos por áreas BOZE e tempo de existência

\begin{tabular}{|l|c|c|c|c|}
\hline Tempo de existencia & Botânica & Oceanografia & Zoologia & Ecologia \\
\hline 0 a 10 anos & 3 & 1 & 7 & 6 \\
\hline 11 a 20 anos & 1 & 2 & 5 & 3 \\
\hline 21 a 30 anos & 1 & 0 & 3 & 2 \\
\hline 31 a 40 anos & 1 & 0 & 0 & 0 \\
\hline 41 a 50 anos & 1 & 1 & 1 & 0 \\
\hline > 50 anos & 3 & 0 & 3 & 0 \\
\hline
\end{tabular}

Fonte: elaborada a partir dos dados do Portal do ISSN (http://portal.issn.org/cgi-bin/gw/chameleon)

\section{b) Pontualidade}

A pontualidade ou regularidade na publicação é um aspecto relacionado ao fluxo de publicação do periódico científico e pode ser definida como a publicação dos fascículos de um determinado periódico, conforme periodicidade adotada pelo veículo. $\mathrm{Na}$ avaliação dos aspectos formais de periódicos científicos, constitui-se em um importante indicador de qualidade que pode demonstra, dentre outros, a eficiência da gestão editorial (SANTOS, 2010).

A análise dos 44 periódicos das áreas de botânica, oceanografia, zoologia e ecologia revelou que $82 \%$ dos periódicos atendem a este quesito e $18 \%$ apresentam atraso na publicação, porém com fascículos publicados no ano de 2012. Quanto analisada a porcentagem de periódicos com restrições quanto à pontualidade na publicação dos fascículos em cada área BOZE, os seguintes resultados são encontrados: 10\% são de Botânica, $18,2 \%$ de Ecologia e $26,3 \%$ de Zoologia. O não atendimento da pontualidade pode ser consequência de uma gestão editorial inadequada ou dificuldade na captação de artigos que possibilitem manter a regularidade. 


\section{c) Periodicidade e quantidade de artigos}

A periodicidade é definida como o intervalo de tempo pré-fixado para a publicação dos fascículos de um mesmo periódico científico que, quando editado de forma regular, pode assumir periodicidade anual, semestral, quadrimestral, trimestral, bimestral ou mensal, dentre outras (ABNT, 2003).

Constitui-se em um dos aspectos formais considerado na avaliação de periódicos científicos, embora tenha perdido a relevância, após a migração destes veículos para o formato eletrônico, em específico a partir da criação do ahead of print, recurso que possibilita que os artigos sejam publicados um a um, após a realização do processo de peer review e antes do fechamento de seu respectivo fascículo.

Pode ser considerado um reflexo da dinâmica de geração de informação científica em um determinado campo do conhecimento, predominando em áreas com maior velocidade de comunicação, os periódicos com intervalos mais curtos de publicação dos fascículos.

Conforme dados apresentados no Gráfico 17, 63,6\% dos periódicos das áreas de botânica, oceanografia, zoologia e ecologia adotam as periodicidades anual, semestral ou quadrimestral, embora seja esperada a adoção de uma periodicidade, minimamente, trimestral para periódicos classificados nestas áreas. Dentre os 44 títulos analisados, quatro não possuem uma periodicidade definida e, embora sejam classificados com periodicidade irregular, publicam os artigos de forma contínua, sem constituição de fascículos. São eles: Papéis Avulsos de Zoologia e Insecta Mundi de Zoologia; Phytotaxa e AOB Plants de Botânica. 
Gráfico 17. Distribuição dos periódicos por periodicidade

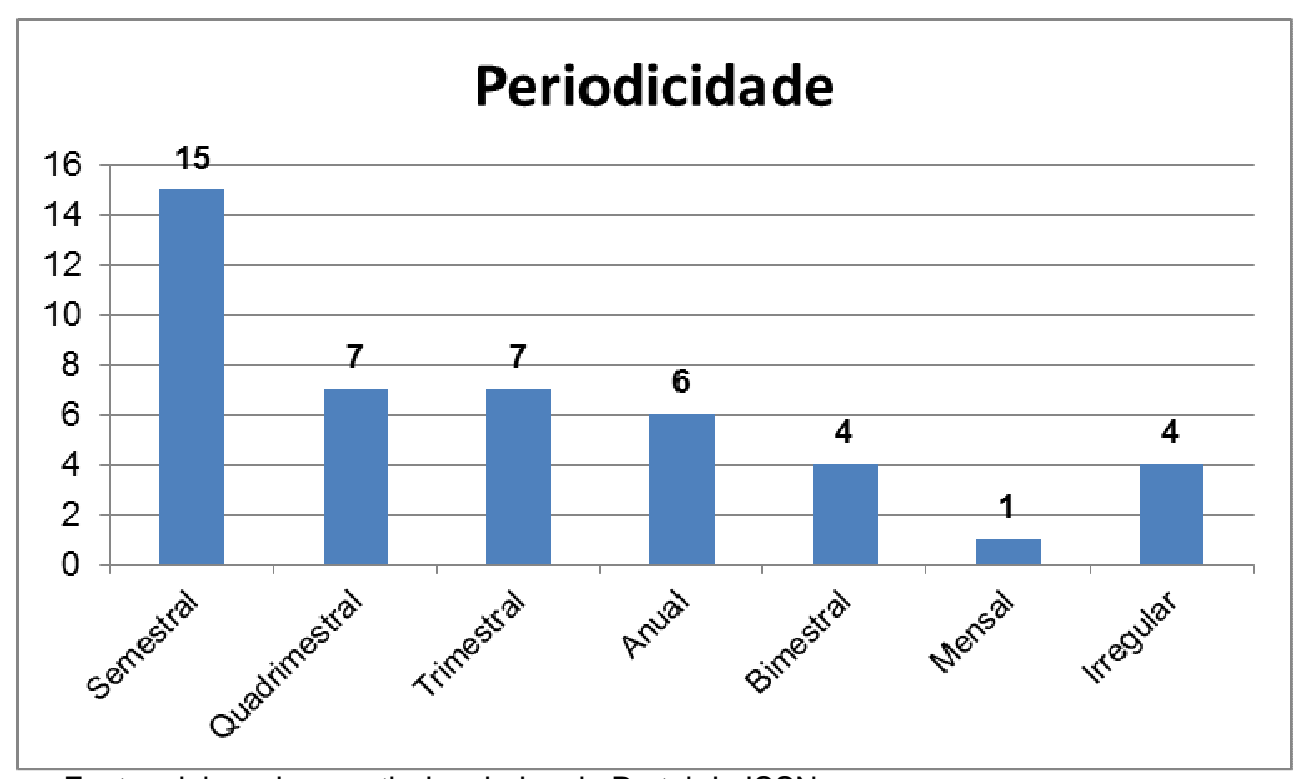

Fonte: elaborado a partir dos dados do Portal do ISSN (http://portal.issn.org/cgi-bin/gw/chameleon)

A quantidade de artigos publicados por ano é aspecto relacionado ao fluxo de publicação do periódico científico e reflete a capacidade de produção de artigos em determinada área ou campo científico, bem como à capacidade do periódico em atrair membros da comunidade científica para a submissão de contribuições. Pode revelar características específicas quanto à dinâmica na produção de informação científica em determinado campo do conhecimento.

A análise do conjunto dos periódicos das áreas BOZE publicam em média 35 artigos por ano, valor considerado baixo quando comparado a outros periódicos da grande área de ciências biológicas. A Tabela 12 relaciona, para cada área, as médias e medianas referentes à quantidade de artigos publicados por ano. Quando a média é considerada, os dados possibilitam constatar que as áreas de botânica e ecologia reúnem os periódicos com o maior número de artigos publicados por ano, 44,1 e 47,7\% respectivamente. Já a análise da mediana revela valores próximos para a área de botânica e zoologia, 29,5 e 26. Porém, em ambas as análises os periódicos de ecologia apresentaram as maiores porcentagens para a quantidade de artigos publicados por ano. 
Tabela 12. Média e mediana da quantidade de artigos publicados por ano

\begin{tabular}{|l|c|c|}
\hline \multirow{2}{*}{\multicolumn{1}{c|}{ Área }} & \multicolumn{2}{|c|}{ \# artigos publicados por ano } \\
\cline { 2 - 3 } & Média & Mediana \\
\hline BOTANICA & 44,1 & 29,5 \\
\hline OCEANOGRAFIA & 17,5 & 18,5 \\
\hline ZOOLOGIA & 28,0 & 26,0 \\
\hline ECOLOGIA & 47,7 & 40,0 \\
\hline
\end{tabular}

\section{d) Porcentagem de artigos de pesquisa}

A publicação de artigos de pesquisa constitui-se em um dos aspectos utilizado na avaliação do caráter científico dos periódicos e é parte dos aspectos considerados neste estudo. A Tabela 13 apresenta os resultados referentes à porcentagem de artigos originais publicados pelos periódicos BOZE. Quando avaliados no conjunto, 79,5\% dos periódicos BOZE possuem mais de $50 \%$ de seus conteúdos dedicados a artigos de pesquisa. A análise das áreas possibilitou identificar índices semelhantes:

Tabela 13. Distribuição dos periódicos por porcentagem de artigos originais

\begin{tabular}{|c|c|c|c|c|c|c|c|c|}
\hline \multirow{2}{*}{ Classificação Área } & \multicolumn{2}{|c|}{0 a $25 \%$} & \multicolumn{2}{|c|}{26 a $50 \%$} & \multicolumn{2}{|c|}{51 a $75 \%$} & \multicolumn{2}{|c|}{76 a $100 \%$} \\
\hline & $\#$ & $\%$ & $\#$ & $\%$ & $\#$ & $\%$ & \# & $\%$ \\
\hline BOTANICA & 2 & 20,0 & 0 & 0,0 & 1 & 10,0 & 7 & 70,0 \\
\hline OCEANOGRAFIA & 0 & 0,0 & 0 & 0,0 & 0 & 0,0 & 4 & 100,0 \\
\hline ZOOLOGIA & 3 & 15,8 & 2 & 10,5 & 4 & 21,1 & 10 & 52,6 \\
\hline ECOLOGIA & 1 & 9,1 & 1 & 9,1 & 2 & 18,2 & 7 & 63,6 \\
\hline Total & 6 & 13,6 & 3 & 6,8 & 7 & 15,9 & 28 & 63,6 \\
\hline
\end{tabular}

\section{e) Revisão por pares e data de recebimento e aprovação}

O processo de revisão por pares (peer review) constitui-se em um dos aspectos que caracteriza um periódico científico e, para a análise do conjunto de periódicos do Grupo 2, verificou a existência de informação referente ao processo de revisão por pares (peer review) nas instruções aos 
autores. Dos 44 títulos considerados na análise, 41 periódicos $(93,2 \%)$ apresentam informação sobre o processo. Apenas 3 títulos $(6,8 \%)$ não apresenta informação sobre 0 processo publicada nas páginas dos respectivos periódicos.

Outro aspecto relacionado à revisão por pares que foi considerado na análise do Grupo 2, refere-se as principais datas do processo de arbitragem, em específica das datas de recebimento e aprovação dos manuscritos. $\mathrm{Na}$ Tabela 14, os resultados desta análise possibilitaram verificar que $63,6 \%$ do conjunto dos periódicos de botânica, oceanografia, zoologia e ecologia atendem a este quesito. Quando consideramos os periódicos de forma separada, encontramos os seguintes índices: botânica e oceanografia apresentam desempenho semelhante, com $80 \%$ e $75 \%$ respectivamente; enquanto que as áreas de zoologia e ecologia obtiveram os menores índices, com $57,9 \%$ e $54,5 \%$ respectivamente.

Tabela 14. Distribuição dos periódicos por data de recebimento e aprovação

\begin{tabular}{|l|c|c|c|c|c|c|}
\hline \multirow{2}{*}{\multicolumn{1}{|c|}{ ÁREAS }} & \multicolumn{5}{|c|}{ Datas de recebimento e aprovação } \\
\cline { 2 - 7 } & \multicolumn{3}{|c|}{ Apresenta } & \multicolumn{2}{|c|}{ Incompleta } & Não apresenta \\
\cline { 2 - 7 } & $\#$ & $\%$ & $\#$ & $\%$ & $\#$ & $\%$ \\
\hline BOTANICA & 8 & 80,0 & 0 & 0,0 & 2 & 20,0 \\
\hline OCEANOGRAFIA & 3 & 75,0 & 0 & 0,0 & 1 & 25,0 \\
\hline ZOOLOGIA & 11 & 57,9 & 1 & 5,3 & 7 & 36,8 \\
\hline ECOLOGIA & 6 & 54,5 & 2 & 18,2 & 3 & 27,3 \\
\hline \multicolumn{1}{|c|}{ TOTAL } & $\mathbf{2 8}$ & $\mathbf{6 3 , 6}$ & $\mathbf{3}$ & $\mathbf{6 , 8}$ & $\mathbf{1 3}$ & $\mathbf{2 9 , 5}$ \\
\hline
\end{tabular}

\section{f) Idiomas aceitos para publicação e idioma dos artigos publicados}

A definição dos idiomas de publicação de um periódico científico está diretamente relacionada à sua penetração nacional ou internacional, bem como às características específicas de sua comunidade, no que se refere ao idioma aceito para o consumo e a comunicação de informação científica. 
A adoção do idioma inglês para a publicação de periódicos constituise em tema de diversos eventos destinados a editores científicos, realizados em países periféricos, pois, se por um lado representa um desafio, por outro representa um em recurso eficiente para aumentar a visibilidade dos periódicos, dissolvendo barreiras globais e facilitando a comunicação entre pesquisadores em um âmbito internacional.

Os resultados da Tabela 15 mostram que apenas $11,8 \%$ dos periódicos não indicam, nas instruções aos autores, os idiomas aceitos para a publicação e que o idioma inglês é indicado pelos demais títulos considerados na análise. Do total de títulos analisados, 55,9\% dos periódicos publicam em outros idiomas, além do inglês, o que pode ser uma alternativa salutar para periódicos que buscam maior audiência internacional, porém querem manter sua circulação em âmbito nacional.

Tabela 15. Distribuição dos periódicos por idioma aceito para publicação

\begin{tabular}{|l|c|c|}
\hline Idioma aceito para publicação & \# periódicos & \% periódicos \\
\hline Inglês & 11 & 32,4 \\
\hline Português, Inglês, Espanhol & 11 & 32,4 \\
\hline Língua do país de publicação, Inglês & 5 & 14,7 \\
\hline Português, Inglês, Espanhol, Francês & 2 & 5,9 \\
\hline Português, Inglês, Espanhol, Francês, Italiano & 1 & 2,9 \\
\hline Não indica & 4 & 11,8 \\
\hline
\end{tabular}

Quando comparados estes dados com os dados do idioma dos artigos publicados, percebe-se sensível redução da porcentagem de periódicos com artigos publicados nos idiomas Português, Inglês e Espanhol, e, por outro lado, um aumento da porcentagem de periódicos com artigos publicados no idioma original do país e em inglês (Tabela 16). 
Tabela 16. Distribuição dos periódicos por idioma dos artigos

\begin{tabular}{|l|c|c|}
\hline Idioma dos artigos & \# periódicos & \% periódicos \\
\hline Inglês & 10 & 29,4 \\
\hline Língua do país de publicação, Inglês & 12 & 35,3 \\
\hline Português, Inglês, Espanhol & 5 & 14,7 \\
\hline Português & 3 & 8,8 \\
\hline Espanhol & 2 & 5,9 \\
\hline Português, Espanhol & 2 & 5,9 \\
\hline
\end{tabular}

Vale destacar que não constam nos dados apresentados nas Tabelas 15 e 16, 10 periódicos cujos países de publicação possuem como língua oficial o inglês, em específico: 5 periódicos do Reino Unido, 3 dos Estados Unidos, 1 da Nova Zelândia e 1 da Nigéria. 


\section{CONSIDERAÇÕES FINAIS}

O periódico científico constitui-se no veículo de maior impacto e prestígio utilizado pela comunidade científica das diferentes áreas temáticas, para registro e comunicação da ciência, tendo se consolidado como principal veículo para acesso, uso e produção de informação científica em determinadas áreas do conhecimento, como nas ciências da saúde, ciências biológicas, ciências exatas e da terra, ciências agrárias e engenharias. Em outras áreas - ciências sociais aplicadas, ciências humanas e as áreas de linguística, letras e artes - embora divida com o livro a importante missão de disseminar a informação científica, já galga por patamares mais elevados na estima das respectivas comunidades científicas.

Esta pesquisa analisou os periódicos que veiculam resultados de pesquisa na área de biodiversidade, incluindo a classificação no QUALIS, os indicadores bibliométricos e os aspectos formais.

A análise dos periódicos classificados pelo Programa Qualis da Área de Biodiversidade possibilitou verificar os seguintes aspectos:

a) Os periódicos classificados pelo Programa Qualis são, predominantemente, da grande área de ciências biológicas, porém com presença significativas de periódicos das ciências exatas e da terra e ciências agrárias.

b) Os artigos produzidos são veiculados em periódicos originários de 43 países e, majoritariamente, por cinco países: Estados Unidos, Inglaterra, Brasil, Países Baixos e Alemanha. Embora ocupe o terceiro lugar em quantidade de periódicos, o Brasil não apresenta periódicos classificados no estrato mais elevado, concentrando os títulos nos estratos B2, B3 e B4, o que pode ser um reflexo do baixo impacto ou da baixa qualidade dos periódicos nacionais.

c) Quanto considerada a distribuição dos periódicos de botânica, oceanografia, zoologia e ecologia pelos estratos Qualis, 
identificou-se significativa desproporção entre as áreas quanto às porcentagens de títulos classificados nos estratos superiores. Notou-se que, dentre as áreas BOZE, a área de zoologia distingue-se negativamente das demais e pode estar sendo prejudicada, considerando-se os critérios de avaliação do Qualis da Área de Biodiversidade.

Por sua vez, a análise dos indicadores bibliométricos - porcentagem na janela de citações em dois anos, variação do fator de impacto ao longo dos anos, distribuição da porcentagem da janela de citações dos periódicos por quartil e distribuição do fator de impacto dos periódicos por quartil revelou:

a) Os periódicos classificados pelo Qualis Biodiversidade apresentam uma baixa média, tanto da porcentagem da janela de citação, como do próprio Fator de Impacto, estando de acordo com as leis de dispersão que mostram alta concentração em baixos valores e pouca concentração em valores altos, fazendo com que a média se aproxime dos valores mais baixos.

b) Se por um lado os periódicos apresentam baixa média da porcentagem da janela de citação e do Fator de Impacto, a análise da variação do Fator de Impacto ao longo dos anos permitiu verificar que alguns poucos pesquisadores da área biodiversidade vêm publicando em periódicos de maior impacto, a cada ano.

c) A distribuição da porcentagem da janela de citação dos periódicos por quartil mostrou que três quartos dos periódicos BOZE possuem índices abaixo de $20 \%$ das citações dentro da janela de dois anos.

d) A análise comparativa das áreas BOZE, mostrou a adequação da utilização do Fator de Impacto para a análise da ecologia, pois a área apresenta uma cultura de citação a documentos publicados mais recentemente; por outro lado, a zoologia possui periódico 
cujas citações se dão a artigos mais antigos, sendo, portanto, prejudicada quando o Fator de Impacto é tomado como critério único de classificação.

e) O desempenho dos periódicos quanto ao Fator de Impacto versus a porcentagem da janela de citações, no ano mais recente (2011), revelou que os periódicos de ecologia possuem maior fator de impacto, enquanto que os periódicos de zoologia apresentam menor Fator de Impacto, em virtude da captação de um diminuto percentual do total de citações.

f) Os periódicos das áreas BOZE possuem diferenças significativas quanto à dinâmica de citações da produção científica, com destaque para as áreas de ecologia (maior obsolescência da literatura) e zoologia (menor obsolescência da literatura) que demonstraram desempenhos extremos.

g) Considerando-se os critérios de classificação atuais adotados pelo Qualis da Área de Biodiversidade, a área de zoologia vem sendo prejudicada, sendo imperativa a adoção de indicadores complementares ou mesmo a aplicação de critérios diferenciados para as áreas de botânica, oceanografia, zoologia e ecologia.

Por fim, a análise dos aspectos formais não revelou diferenças significativas entre os periódicos de botânica, oceanografia, zoologia e ecologia e, portanto, as considerações foram concentradas no conjunto dos periódicos do Grupo 2:

a) Os periódicos classificados nos estratos B3 e B4 são, predominantemente, veículos com criação recente e com tempo de existência de até 20 anos. São publicados seguindo a periodicidade semestral e com publicação de 35 artigos por ano em média, índices considerados baixos se comparados a outros periódicos da mesma área. Em sua maioria, os periódicos BOZE destinam, pelo menos, $50 \%$ dos fascículos para a publicação de 
artigos de pesquisa. Quando analisado o processo de revisão por pares, 93,2\% apresentaram a informação nas instruções aos autores e 63,6\% apresentam as datas de recebimento e aprovação de forma completa. $\mathrm{Na}$ análise do idioma aceito para publicação e idioma dos artigos publicados, verificou-se 0 predomínio do idioma inglês.

b) Se por um lado a análise dos aspectos formais não expressou diferenças entre as áreas BOZE, por outro lado chamou a atenção para a existência de títulos, dentre os classificados em B3 e B4, com distintos níveis de qualidade nos dois estratos. Identificou-se a necessidade de uma revisão da qualidade dos periódicos classificados nestes estratos, bem como da utilização de outros critérios, além do critério de uso utilizado pelo Qualis Biodiversidade.

Constituem-se em limitações da pesquisa a quantidade de periódicos submetidos à avaliação dos aspectos formais, bem como o baixo número de periódicos da área de oceanografia. Além disso, não foram considerados: a) os indicadores de uso dos periódicos classificados pelo Qualis da Área de Biodiversidade; e b) a quantidade de artigos publicados pelos programas de pós-graduação da área de biodiversidade. Tais limitações indicam os caminhos para a continuidade da pesquisa, a partir de estudos futuros.

O presente estudo esteve dedicado a conhecer as especificidades da comunicação científica em biodiversidade, por meio da avaliação dos periódicos que veiculam resultados de pesquisa na área e, embora possa trazer em seu conteúdo limitações e razões para questionamento, reformulações e aperfeiçoamentos, espera-se que possa oferecer subsídios para a adequação da avaliação realizada pelo Programa Qualis da CAPES, minimizando adversidades da avaliação da produção científica da área de biodiversidade. 


\section{REFERÊNCIAS}

AGUIAR, Afrânio Carvalho. Informação e atividades de desenvolvimento científico, tecnológico e industrial: tipologia proposta com base em análise funcional. Ciência da Informação, Brasília, v. 20, n. 1, p. 7-15, jan./jun. 1991.

ALBAGLI, Sarita. Divulgação científica: informação científica para a cidadania? Ciência da Informação, Brasília, v. 25, n. 3, p. 396-404, set./dez. 1996.

ANDRIOLO, A. et al. Classificação dos periódicos no sistema QUALIS da CAPES: a mudança dos critérios é urgente!. Psicologia e estudo, Maringá, v. 15, n. 1, mar. 2010. Disponível em: <http://www.scielo.br/scielo.php?script=sci_arttext\&pid=S1413$73722010000100001 \&$ lng=pt\&nrm=iso >. Acessos em: 01 set. 2013.

ARAÚJO, C. A. Bibliometria: evolução história e questões atuais. Em Questão, Porto Alegre, v. 12, n. 1, p. 11-32, 2006.

BALANCIERI, Renato et al. A análise de redes de colaboração científica sob as novas tecnologias de informação e comunicação: um estudo na Plataforma Lattes. Ciência da Informação, Brasília, v. 34, n. 1, jan. 2005. Disponível em: $<$ http://www.scielo.br/scielo.php?script=sci_arttext\&pid=S0100-

$19652005000100008 \&$ Ing=pt\&nrm=iso>. Acesso em: 01 set. 2013.

BAPTISTA, A. A.; COSTA, S. M. S., KURAMOTO, H.; RODRIGUES, E. Comunicação científica: o papel da Open Archives Initiative no contexto do acesso livre. Enc. Bibli: $R$. Eletr. Bibliotecon. Ciência da Informação, Florianópolis, n. esp., 1ํㅗ. sem. 2007.

BARRETO, Aldo de Albuquerque. Mudança estrutural no fluxo do conhecimento: a comunicação eletrônica. Ciência da Informação, Brasília, v. 27, n. 2, 1998. Disponível em: $<$ http://www.scielo.br/scielo.php?script=sci_arttext\&pid=S0100-

$19651998000200003 \&$ Ing=pt\&nrm=iso >. Acesso em: 23 jan. 2013.

BECERRA, H. C.; FLEITAS, M. E. M. Bibliometría, Informetría, Cienciometría: su etimología y alcance conceptual. Revista Cubana de la ciencia, 2002.

BETTONI, E. M. A contribuição da web no uso de indicadores da produção científica na área de ciências humanas e sociais aplicadas. 2011. Dissertação (Mestrado em Ciência da Informação) - Universidade Federal do Paraná.

BJÖRK, B. C. et al. Open Access to the Scientific Journal Literature: situation 2009. PLoS ONE, v. 5, n. 6, 2010.

BRAMBILLA, Sônia Domingues Santos; STUMPF, Ida Regina Chittó. Produção científica da UFRGS representada na Web of Science (2000-2009). Perspect. ciênc. inf., Belo Horizonte, $\begin{array}{lllll}\mathrm{v} & 17, \mathrm{n} . & 3 \text {, set. } & 2012 . & \text { Disponível }\end{array}$ <http://www.scielo.br/scielo.php?script=sci_arttext\&pid=S1413-

99362012000300004\&lng=pt\&nrm=iso>. Acesso em: 01 set. 2013.

BUCKLAND, M. K. Information as thing. Journal of the Americam Society for Information Science (JASIS), v. 45, n. 5, p. 351-360, 1991.

CABRAL FILHO, José Eulálio. Desafios do novo Qualis para a pós-graduação e o periodismo científico brasileiro. Rev. Bras. Saude Mater. Infant, Recife, v. 9, n. 1, mar. 2009. 
Disponível em: <http://www.scielo.br/scielo.php?script=sci_arttext\&pid=S1519$38292009000100001 \&$ lng=pt\&nrm=iso>. Acesso em: 01 set. 2013.

CAMARGO JR, Kenneth Rochel de. A indústria de publicação contra o acesso aberto. Rev. Saúde Pública, São Paulo, v. 46, n. 6, s.n., dez. 2012. Disponível em: $<$ http://www.scielo.br/scielo.php?script=sci_arttext\&pid=S0034-

$89102012000600020 \&$ Ing=pt\&nrm=iso >. Acesso em: 08 jul. 2013.

CAMPOS, J. N. B. Qualis periódicos: conceitos e práticas nas Engenharias I. Revista Brasileira de Pós-Graduação, Brasília, v. 7, n. 14, p. 477-503, 2010.

CAPES. Qualis Periódicos. [19-?]. Disponível em: <http://www.capes.gov.br/avaliacao/qualis>. Acesso em: 19 mar. 2013.

CAPES. A Nova Área de Biodiversidade da CAPES. 2011. Disponível em: <http://www.capes.gov.br/images/07_biod_comunicado_01-2011.pdf>. Acesso em: $17 \mathrm{de}$ junho de 2013.

CAPES. Atualização do WebQualis da área. 2013. Disponível em: http://www.capes.gov.br/images/Comunicado_01_2013_Qualis_Biodiversidade.pdf. Acesso em: 17 de junho de 2013

CARIBÉ, R. C. V. Comunicação científica para o público leigo no Brasil. 2011. Tese (Doutorado em Ciências da Informação) - Universidade de Brasília.

CASTRO, Regina C Figueiredo. Impacto da Internet no fluxo da comunicação científica em saúde. Rev. Saúde Pública, São Paulo, v. 40, n. spe, ago. 2006. Disponível em: $<$ http://www.scielo.br/scielo.php?script=sci_arttext\&pid=S0034-

89102006000400009\&lng=pt\&nrm=iso>. Acesso em: 23 jan. 2013.

CASTRO, Regina C. Figueiredo. Internacionalização das publicações científicas latinoamericanas em ciências da saúde: LILACS, SciELO e MEDLINE. Disponível em: http://www.pucrs.br/edipucrs/odonto/pdf/ReginaCastro.pdf. 2009. Acesso em: 20 de janeiro de 2013.

CHINCHILLA-RODRÍGUEZ, Zaida; MIGUEL, Sandra; DE-MOYA-ANEGÓN, Félix. Influencia del acceso abierto en las revistas de América Latina en el contexto internacional de la ciencia. Renata, 2012, vol. 2, n. 4, pp. 28-48.

CNPq. Conselho Nacional de Desenvolvimento Científico e Tecnológico. Programa de Apoio ao Desenvolvimento Científico e Tecnológico (PADCT). Brasília: MCT, [19-?]. Disponível em: <http://www.cnpq.br/web/guest/padct>. Acesso em: 21 de agosto de 2013.

CNPq. Conselho Nacional de Desenvolvimento Científico e Tecnológico. Tabela de Áreas do Conhecimento do CNPq. Disponível em: <http://200.17.161.80/prppg/projetos/tabelaareas-do-conhecimento-cnpq.pdf?PHPSESSID=80c785c0a871a440259e6d12fb6c47c9>. s.d. Acesso em: 10 de outubro de 2012.

CÔRTES, Pedro Luiz. Considerações Sobre a Evolução da Ciência e da Comunicação Científica. In: POBLACION, Dinah Aguiar; WITTER, Geraldina Porto; SILVA, José Fernando Modesto da (Org.). Comunicação \& Produção Científica. 1ed. São Paulo: Angellara Editora, 2006 , v. 1, p. 1-426.

COSTA, S. M. S. Abordagens, estratégias e ferramentas para o acesso aberto via periódicos e repositórios institucionais em instituições acadêmicas brasileiras. Liinc em revista, v. $4, \quad$ n. $2, \quad$ set. 2008.2 Disponível em: 
$<$ http://www.brapci.ufpr.br/documento.php?dd0=0000005080\&dd1=11726>. Acesso em: 15 jun. 2010.

DIAS, Fernando Skackauskas. Análise das relações interdisciplinares das pesquisas científicas em sistemas de informação. Perspect. ciênc. inf., Belo Horizonte, v. 13, n. 1, abr. 2008. Disponível em <http://www.scielo.br/scielo.php?script=sci_arttext\&pid=S141399362008000100013\&lng=pt\&nrm=iso >. Acesso em 01 set. 2013.

DOAJ. Directory of Open Acess Journal. Disponível em: http://www.doaj.org/doaj?func=byCountry\&uiLanguage=en. Acesso em: 10 de abril de 2013.

EZPONDA, J. E. Transferencia de conocimiento entre comunidades científicas. Arbor., v. 184, n. 731, p. 539-548, 2008.

FACHIN, Gleisy R. B.; HILLESHEIM, Araci Isaltina de Andrade. Periódico científico: padronização e organização. Florianópolis: Editora da UFSC, 2006. 186p.

FORESTI, Nóris. Estudo da contribuição das revistas brasileiras de biblioteconomia e ciência da informação enquanto fonte de referência para a pesquisa. 1989. Dissertação (Mestrado) - Departamento de Biblioteconomia da Universidade de Brasília, UnB, Brasília, 1989.

FREITAS, Maria Helena. Considerações acerca dos primeiros periódicos científicos brasileiros. Ciência da Informação, Brasília, v. 35, n. 3, dez. 2006. Disponível em: $<$ http://www.scielo.br/scielo.php?script=sci_arttext\&pid=S0100-

19652006000300006\&lng=pt\&nrm=iso>. Acesso em: 02 set. 2013. http://dx.doi.org/10.1590/S0100-19652006000300006.

GARFIELD, E. Journal impact fator: a brief review. CMAJ, v. 161, n. 8, 1999.

GOMES, Cristina Marques. Comunicação Científica: cartografia e desdobramentos. 2012. Tese (Doutorado em Ciência da Informação) - Universidade de São Paulo.

GOMEZ, Maria Nelida Gonzalez de; ORRICO, Evelyn Goyannes Dill. As políticas institucionais das configurações interdisciplinares dos conhecimentos: repercussões nas políticas de informação e nas práticas de avaliação. DataGramaZero: Revista de Ciência da Informação, v.5, n.6, s.n, dez., 2004.

GOULART, Sueli; CARVALHO, Cristina Amélia. O caráter da internacionalização da produção científica e sua acessibilidade restrita. Rev. adm. contemp., Curitiba, v. 12, n. 3, set. 2008. Disponível em: <http://www.scielo.br/scielo.php?script=sci_arttext\&pid=S141565552008000300011\&lng=pt\&nrm=iso>. Acesso em: 08 jul. 2013. http://dx.doi.org/10.1590/S1415-65552008000300011.

GUANAES, Paulo Cezar Vieira; GUIMARAES, Maria Cristina Soares. Modelos de gestão de revistas científicas: uma discussão necessária. Perspect. ciênc. inf., Belo Horizonte, v. 17, n. 1, mar. 2012. Disponível em: <http://www.scielo.br/scielo.php?script=sci_arttext\&pid=S141399362012000100004\&lng=pt\&nrm=iso>. Acesso em: 08 jul. 2013.

GUEDES, V.; BORSCHIVER, S. Bibliometria: uma ferramenta estatística para a gestão da informação e do conhecimento, em sistemas de informação, de comunicação e de avaliação científica e tecnológica. In: CINFORM - ENCONTRO NACIONAL DE CIÊNCIA DA INFORMAÇÃO, 6., 2005, Salvador. Anais... Salvador: ICI/UFBA, 2005.

GUMIEIRO, Katiucia Araujo; COSTA, Sely Maria de Souza. O uso de modelos de negócios por editoras de periódicos científicos eletrônicos de acesso aberto. Perspect. ciênc. inf., 
Belo Horizonte, v. 17, n. 4, dez. 2012. Disponível em: <http://www.scielo.br/scielo.php?script=sci_arttext\&pid=S1413-

99362012000400007\&lng=pt\&nrm=iso >. Acesso em: 08 jul. 2013.

HARLEY, A. M. G. Os critérios do Qualis CAPES. 2011. Disponível em: $<$ http://francaflavio.blogspot.com.br/2011/11/os-criterios-do-qualis-capes.html>. Acesso em: 10 junho de 2013.

HEYWOOD, V. H. Global biodiversity assessment. Cambridge: New York, NY, USA: Cambridge University Press, 1995.

HUANG, Mu-hsuan; CHANG, Yu-wei. Characteristics of Research Output in Social Sciences and Humanities: from a research evaluation perspective. Journal of the American Society for Information Science and Technology, v. 59, n. 11, p. 1819-1828, 2008.

IANNI, Aurea Maria Zöllner. Biodiversidade e Saúde Pública: questões para uma nova abordagem. Saude Soc., São Paulo, v. 14, n. 2, ago. 2005. Disponível em: $<$ http://www.scielo.br/scielo.php?script=sci_arttext\&pid=S0104-

12902005000200009\&lng=pt\&nrm=iso >. Acesso em: 4 ago. 2011.

IBICT. Acesso Livre [20-?]. Brasil. Disponível em: <http://acessolivrebrasil.wordpress.com/historico-2/>. Acesso em: 16 de março de 2013.

JACON, Maria do Carmo Moreira. Base Qualis e a indução do uso de periódicos da área de Psicologia. Transinformação, v. 19, n. 2, p. 189-197, 2007.

KUNZ, I. Dinâmica de produção de conhecimento na área de Direito no Brasil. 2011. Dissertação (Mestrado em Política Científica e Tecnologia) - Universidade Estadual de Campinas.

LÉVÊQUE, Christian. A biodiversidade. Bauru: EDUSC, 1999.

LIMA, Ricardo Arcanjo de; VELHO, Lea Maria Leme Strini. Indicadores ibero-americanos de atividade científica em bioprospecção. Revista Digital de Biblioteconomia e Ciência da Informação, Campinas, v. 6, n. 1, p. 01-14, 2008. Disponível em: <http://revista.ibict.br/ciinf/index.php/ciinf/article/viewFile/1148/794>. Acesso em: 15 mar. 2013.

LOPEZ ESPINOSA, J. A. La primera revista médica de América. ACIMED, Ciudad de La Habana, v. $\quad$ 8, n. $2,2000 . \quad$ Disponível em: <http://scielo.sld.cu/scielo.php?script=sci_arttext\&pid=S1024-

94352000000200005\&lng=es\&nrm=iso>. Acesso em: 22 jul. 2009.

MACHADO, Fábio A.; ZAHER, Hussam. Pitfalls of artificial grouping and stratification of scientific journals based on their Impact Factor: a case study in Brazilian Zoology. Zoologia, Curitiba, $\quad$ v. 27, n. 4, ago. $2010 . \quad$ Disponível em: $<$ http://www.scielo.br/scielo.php?script=sci_arttext\&pid=S1984$46702010000400002 \&$ Ing=pt\&nrm=iso>. Acesso em 02 set. 2013.

MACIAS-CHAPULA, C. A. O papel da informetria e da cienciometria e sua perspectiva nacional e internacional. Ciência da Informação, Brasília, v. 27, n. 2, p. 134-40, maio/ ago. 1998.

MARCONDES, Carlos Henrique et al. Ontologias como novas bases de conhecimento científico. Perspect. ciênc. inf., Belo Horizonte, v. 13, n. 3, dez. 2008. Disponível em 
$<$ http://www.scielo.br/scielo.php?script=sci_arttext\&pid=S1413-

99362008000300003\&lng=pt\&nrm=iso>. Acesso em: 23 jan. 2013.

MEADOWS, A. J. A comunicação científica. Brasília, DF: Briquet de Lemos, 1999.

MIRANDA, E. C. P. Periódicos científicos de turismo e hospitalidade no Brasil: padrões de normalização. 2012. Dissertação (Mestrado em Hospitalidade) - Universidade Anhambi Morumbi.

MIRANDA, D. B.; PEREIRA, M. N. F. O periódico científico como veículo de comunicação: uma revisão de literatura. Ciência da Informação, Brasília, v. 25, n. 3, p. 375-382, set./dez. 1996.

MOREIRA, Walter. Os colégios virtuais e a nova configuração da comunicação científica. Ciência da Informação, Brasília, v. 34, n. 1, jan. 2005. Disponível em $<$ http://www.scielo.br/scielo.php?script=sci_arttext\&pid=S0100$19652005000100007 \&$ Ing=pt\&nrm=iso>. Acesso em: 02 set. 2013.

MOREL, R. L. M. Ciência e Estado: a política científica no Brasil. São Paulo: TA Queiroz, 1979.

MUELLER, S. P. M. O estudo do tema comunicação científica e tecnológica no Brasil: tendências e perspectivas na área de Ciência da Informação. Tendências da Pesquisa Brasileira em Ciência da Informação, v. 1, n. 7, s.n., 2008.

MUELLER, S. P. M. O impacto das tecnologias de informação na geração do artigo científico. Ciência da Informação, Brasília, v. 23, n. 3, p. 309-317, 1994. Disponível em: $<$ http://revista.ibict.br/ciinf/index.php/ciinf/article/viewFile/1148/794>. Acesso em: 23 jan. 2013.

MUELLER, S. P. M. A ciência, o sistema de comunicação científica e a literatura científica. In: CAMPELLO, Beatriz Valadares; CENDÓN, Jeannette Marguerite Kremer (Org.). Fontes de informação para pesquisadores e profissionais. Belo Horizonte: Ed. UFMG, 2000. 319p

MUGNAINI, Rogerio. 40 anos de bibliometria no Brasil. In: HAYASHI, Maria Cristina Piumbato Innocentini; LETA, Jacqueline (Orgs.) Bibliometria e Cientometria: reflexões teóricas e interfaces. São Carlos: Pedro \& João Editores, 2013. 284p. ISBN 978-85-7993117-8. No prelo.

MUGNAINI, R. Indicadores bibliométricos da base de dados Pascal como fonte de informação científica e tecnológica do Brasil. 2003. 133 f. Dissertação (Mestrado em Biblioteconomia e Ciência da Informação) - Pontifícia Universidade Católica de Campinas, Campinas, 2003.

MUGNAINI, R.; PACKER, A.L.; MENEGHINI, R. Comparison of scientists of the Brazilian Academy of Sciences and of the National Academy of Sciences of the USA on the basis of the h-index. Braz J Med Biol Res, Ribeirão Preto, v. 41, n. 4, abr. 2008. Disponível em $<$ http://www.scielo.br/scielo.php?script=sci_arttext\&pid=S0100-

879X2008000400001\&lng=pt\&nrm=iso>. Acesso em: 02 set. 2013.

OLIVEIRA, Erica Beatriz Pinto Moreschi de; NORONHA, Daisy Pires. A comunicação científica e o meio digital. Informação \& Sociedade. Estudos, João Pessoa, v. 15, n. 1, p. 1 12, 2005.

OLIVEIRA, Érica Beatriz. Produção científica nacional na área de geociências: análise de critérios de editoração, difusão e indexação em bases de dados. Ciência da Informação, 
Brasília, v. $34, \quad$ n. 2, p. 34-42, ago. 2005 . Disponível em: <http://www.scielo.br/pdf/ci/v34n2/28553.pdf>. Acesso em: 23 jan. 2013.

Open Access Directory (OAD). Declarations in support of OA. Disponível em: $<$ http://oad.simmons.edu/oadwiki/Declarations_in_support_of_OA>. Acesso em: $21 \mathrm{de}$ março de 2013.

OpenDOAR. The Directory of Open Access Repositories (OpenDOAR). Disponível em: <http://www.opendoar.org>. Acesso em: 17 de março de 2013.

ORTEGA, Cristina Dotta; LARA, Marilda Lopes Ginez de. A noção de documento: de Otlet aos dias de hoje. DataGramaZero, v. 11, n. 2, abr. 2010. Disponível em: <http://www.dgz.org.br/abr10/Art_03.htm>. Acesso em: 12 maio 2011.

PACKER, A. L. Os periódicos brasileiros e a comunicação da pesquisa nacional. Revista USP, São Paulo, n. 89, p. 26-61, 2011.

PIRO, F. N.; AKSNES, D. W.; RØRSTAD, K. A macro analysis of productivity differences across fields: Challenges in the measurement of scientific publishing. J. Am. Soc. Inf. Sci., v. 64, p. 307-320, 2013.

RAVETZ, J. R. Scientific knowledge and its social problems. Oxford: Clarendon Press, 1971.

Registry of Open Access Repositories (ROAR). Disponível em: <http://roar.eprints.org/view/geoname/>. Acesso em: 19 de março de 2013.

RIOS, A. L. A.; SILVA, E. F. C.; SÁ, F. N. B. Biodiversidade: formação de recursos humanos. In: Workshop Biodiversidade: perspectivas e oportunidades tecnológicas, 1996, Campinas. Anais... Campinas: 1996.

RODRIGUES, Rosângela Schwarz; OLIVEIRA, Aline Borges de. Periódicos científicos na America Latina: títulos em Acesso Aberto indexados no ISI e SCOPUS. Perspect. ciênc. inf., Belo Horizonte, v. 17, n. 4, dez. 2012. Disponível em $<$ http://www.scielo.br/scielo.php?script=sci_arttext\&pid=S141399362012000400006\&lng=pt\&nrm=iso >. Acesso em: 08 jul. 2013.

SANTOS, Solange Maria dos. Perfil dos periódicos científicos de Ciências Sociais e de Humanidades: mapeamento das características extrínsecas. 2010. Dissertação (Mestrado em Ciência da Informação) - Universidade de São Paulo.

SCHWARTZMAN, S. Um espaço para a ciência: a formação da comunidade científica no Brasil. Reedição. Brasília: MCT/CNPq/CEE, 2001.

SCHWEITZER, Fernanda; RODRIGUES, Rosângela Schwarz; VARVAKIS, Gregório Jean. Comunicação científica e as tecnologias de informação e comunicação. Comunicação \& Sociedade, v. 32, n. 55, p. 83-104, jan./jun. 2011

SOUZA, Maria da Paixão Neres de. Efeitos das tecnologias da informação na comunicação de pesquisadores da Embrapa. Ciência da Informação, Brasília, v. 32, n. 1, abr. 2003. Disponível em <http://www.scielo.br/scielo.php?script=sci_arttext\&pid=S0100$19652003000100013 \&$ lng=pt\&nrm=iso $>$. Acesso em: 23 jan. 2013.

STUMPF, I. R. C. Avaliação das revistas de Comunicação pela comunidade acadêmica da área. Em Questão, Porto Alegre, v. 9, n. 1, p. 25-38, jan./jun. 2003. 
STUMPF, I. R. C. Passado e futuro das revistas científicas. Ciência da Informação, v. 25, n. 3, s.n., 1996.

STUMPF, I. R. C. Reflexões sobre as revistas brasileiras. Intexto, v. 1, n. 3, p. 1-10, 1998. Disponível em: <http://www.seer.ufrgs.br/index.php/intexto/article/view/3369/3953>.

TARGINO, M. G. Comunicação científica: uma revisão de seus elementos básicos. Revista Informação \& Sociedade: Estudos [online]. 2000, v. 10, n. 2 [citado 2013-01-23], p. 1-27. Disponível em: <http://www.ies.ufpb.br/ojs2/index.php/ies/article/view/326/248>.

UNESCO. What is Biodiversity. 2011. Disponível em: http://www.ecounesco.ie/ecobiodiversity-ireland. Acesso em: novembro de 2012.

VALENTIM, Marta Lígia Pomim. Inteligência Competitiva em Organizações: dado, informação e conhecimento. DataGramaZero: Revista de Ciência da Informação, v. 3 n. 4, ago. 2002.

VANTI, N. A. P. Da bibliometria à webometria: uma exploração conceitual dos mecanismos utilizados para medir o registro da informação e a difusão do conhecimento. Ciência da Informação, Brasília, v. 31, n. 2, p. 152-162, 2002.

WEITZEL, Simone R. Fluxo da informação científica. In: POBLACIÓN, Dinah Aguiar; WITTER, Geraldina Porto; SILVA, José Fernando Modesto da.. (Orgs.). Comunicação \& produção científica: contexto, indicadores e avaliação. São Paulo: Angellara, 2006, p. 1-426. 